Florida International University

FIU Digital Commons

6-26-2019

\title{
Generating Alternatives: The Possible Energy Transitions for France and Germany after the Paris Accord
}

Anna Fache

afach004@fiu.edu

Follow this and additional works at: https://digitalcommons.fiu.edu/etd

Part of the Environmental Studies Commons, Natural Resources and Conservation Commons, Natural Resources Management and Policy Commons, Oil, Gas, and Energy Commons, and the Sustainability Commons

\section{Recommended Citation}

Fache, Anna, "Generating Alternatives: The Possible Energy Transitions for France and Germany after the Paris Accord" (2019). FIU Electronic Theses and Dissertations. 4227.

https://digitalcommons.fiu.edu/etd/4227

This work is brought to you for free and open access by the University Graduate School at FIU Digital Commons. It has been accepted for inclusion in FIU Electronic Theses and Dissertations by an authorized administrator of FIU Digital Commons. For more information, please contact dcc@fiu.edu. 


\title{
FLORIDA INTERNATIONAL UNIVERSITY
}

Miami, Florida

GENERATING ALTERNATIVES: THE POSSIBLE ENERGY TRANSITIONS FOR FRANCE AND GERMANY AFTER THE PARIS ACCORD

\author{
A thesis submitted in partial fulfillment of \\ the requirements for the degree of \\ MASTER OF SCIENCE \\ in \\ ENVIRONMENTAL STUDIES \\ by \\ Anna Fache
}

2019 
To: Dean Michael R. Heithaus

College of Arts, Sciences and Education

This thesis, written by Anna Fache, and entitled Generating Alternatives: The Possible Energy Transitions for France and Germany after the Paris Accord, having been approved in respect to style and intellectual content, is referred to you for judgment.

We have read this thesis and recommend that it be approved.

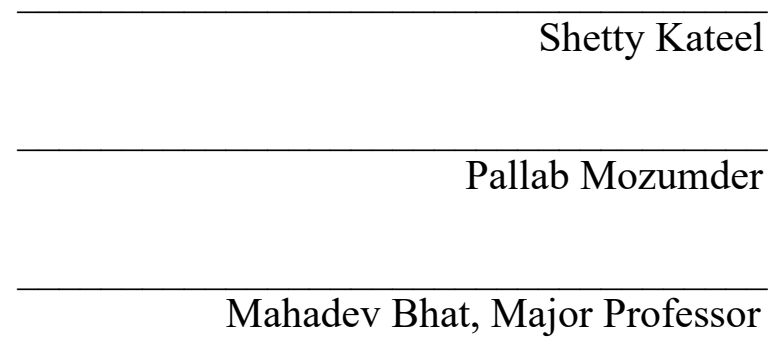

Date of Defense: June 26, 2019

The thesis of Anna Fache is approved

Dean Michael R. Heithaus College of Arts, Sciences and Education

Andrés G. Gil Vice President for Research and Economic Development and Dean of the University Graduate School

Florida International University, 2019 
ABSTRACT OF THE THESIS

GENERATING ALTERNATIVES: THE POSSIBLE ENERGY TRANSITIONS FOR FRANCE AND GERMANY AFTER THE PARIS ACCORD

by

Anna Fache

Florida International University, 2019

Miami, Florida

Professor Mahadev G. Bhat, Major Professor

Following the Paris Accord of 2015, multiple countries, including France and Germany, promised to reduce their greenhouse gas emissions in order to slow down climate change. Current energy production and consumption patterns do not allow for such targets. Meeting these emission reduction goals requires a transition in energy production. Energy transitions can be inefficient and costly if not planned properly, and multiple constraints need to be taken into account when putting such a process in place. The model proposed in the present study aims to find the most cost-effective energy portfolios for France and Germany, two highly industrialized nations in Europe. The model consists of national total energy production cost function and characterizes least cost pathway to supply energy while meeting the greenhouse gas emission targets until 2030. This model can be applied to other nations and regions of the world. The current research also conducts various scenario simulations to observe how different changes, such as GHG constraints or demand variation can affect the energy sector in the future. It is found that meeting GHG emission targets for both countries is financially feasible, and could be met through a reduction in overall energy demand as well as making a partial shift towards low- carbon renewable energy sources. 
(C) Copyright 2019 by Anna Fache

All rights reserved. 


\section{DEDICATION}

I dedicate this thesis to my parents, my brother and grandparents. Without their constant support, love and patience, I would not have been able to complete this work. 


\section{ACKNOWLEDGMENTS}

I wish to thank the members of my committee for their support, advising, and especially their patience.

I would like to thank Dr. Kateel Shetty, member of my committee, who was able to provide me with much insightful information that was highly relevant to this research.

I am very grateful to Dr. Pallab Mozumder, other member of my committee, that was able to challenge my thinking and my ideas in order to perform better.

I am deeply thankful to Dr. Mahadev Bhat, my major professor who has been of tremendous help towards the writing of this thesis, but also my overall experience in this master program. His guidance was very helpful to pick and develop a relevant and interesting research topic.

Lastly, I would like to once again thank my family and friends, who have been present through thick and thin, and have been supporting my work since day one. 


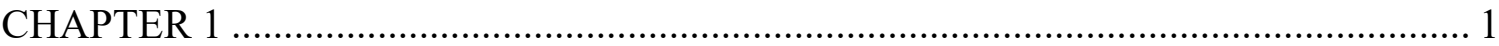

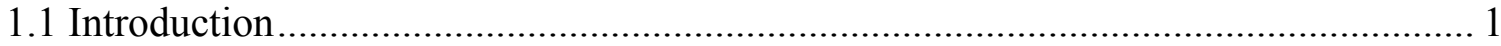

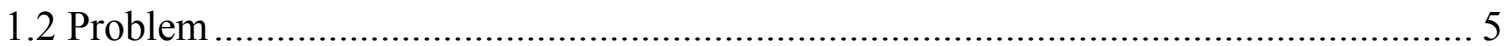

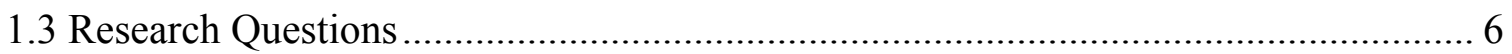

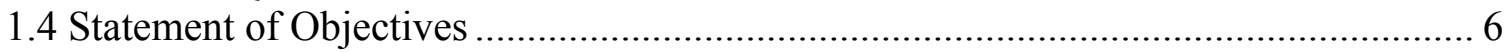

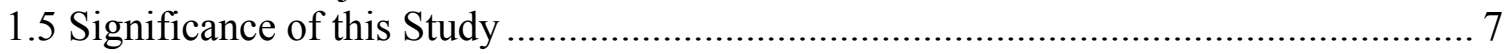

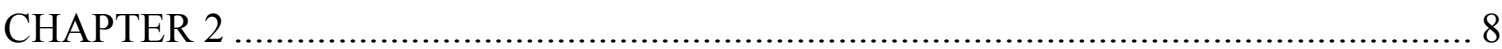

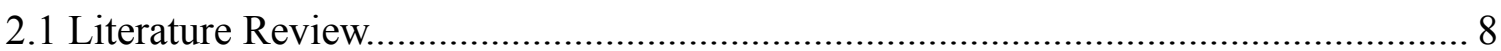

2.2 The Paris Accord.................................................................................................. 8

2.3 Energy Transition in Germany and France, and the Role of Europe as a Leader......... 9

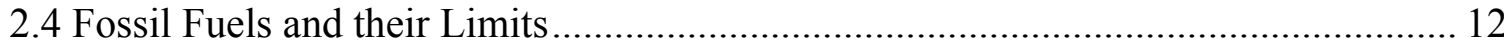

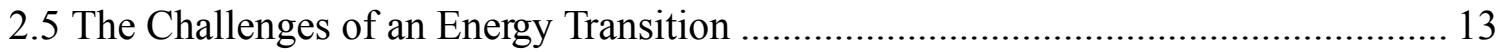

2.6 Previous Studies on Energy Transitions …………................................................ 15

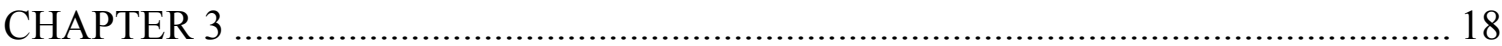

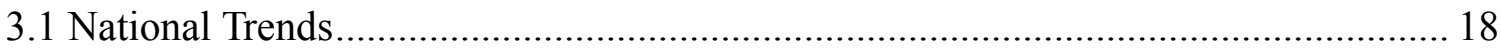

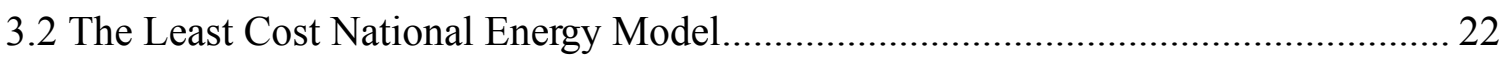

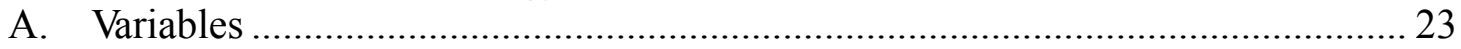

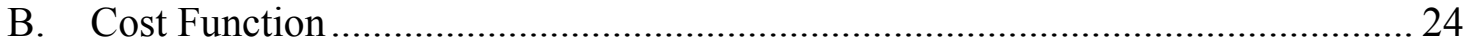

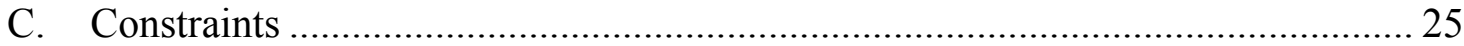

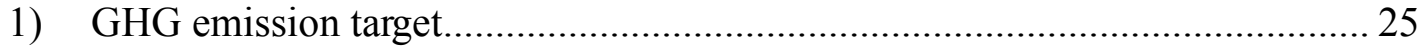

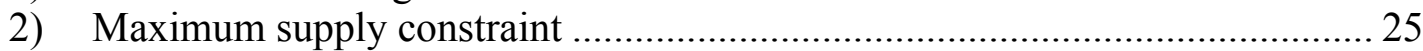

3) Maximum domestic supply constraint............................................................ 26

4) Minimum Demand Constraint .................................................................... 26

5) Minimum Domestic Demand Constraint ...........................................................2 27

6) Transportation Sector Constraint ................................................................. 27

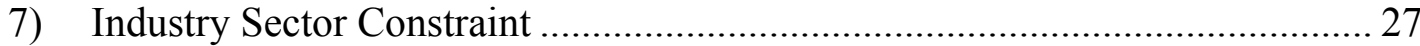

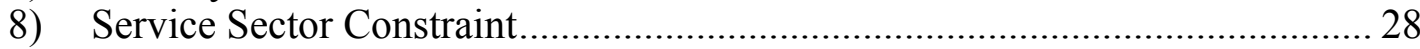

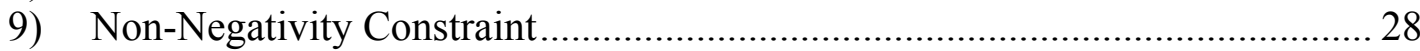




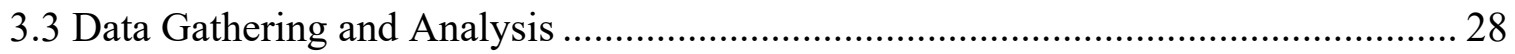

A. Electricity and Derived Heat Break Down .................................................... 30

B. Accounting for Trade ...................................................................................... 31

C. Levelized Cost of Electricity ……………………............................................. 33

D. Greenhouse Gas Coefficients and Targets ........................................................... 34

E. Forecasting for LCOE, Demand and Capacity ……........................................... 36

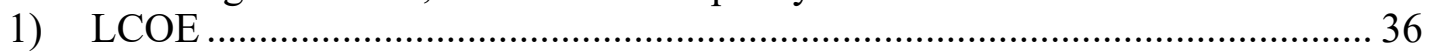

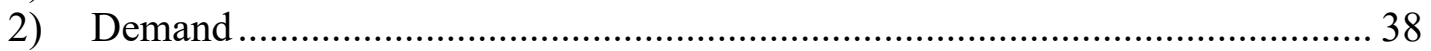

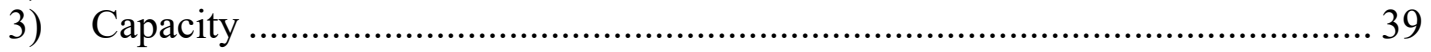

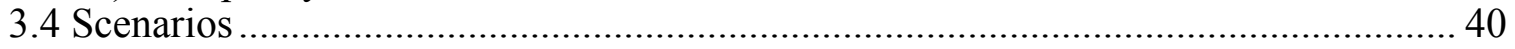

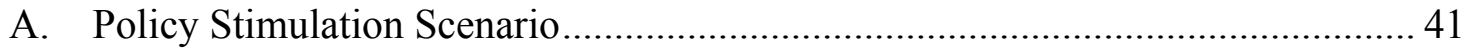

B. Business as Usual (BAU) Scenario.................................................................. 41

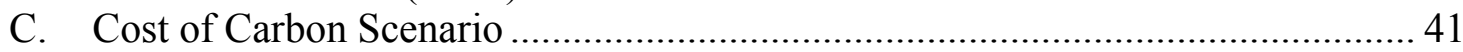

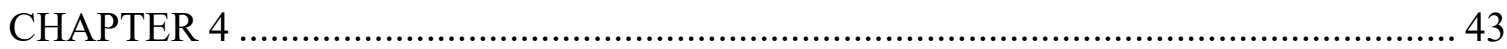

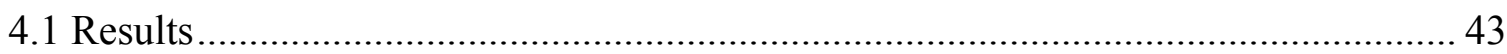

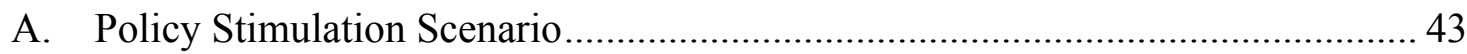

1) Results for France for the Policy Stimulation Scenario...................................... 43

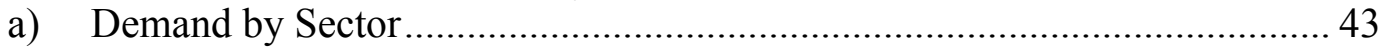

b) Domestic Production by Energy Type ............................................................ 45

c) Total Energy Consumption by Energy Type for France.................................4 47

d) Energy Consumption Mix for France .......................................................... 49

e) Total Cost and Total GHG emissions ……………..................................... 52

f) Total Demand and Total Cost .................................................................... 53

a. Results for Germany for the Policy Stimulation Scenario .................................. 54

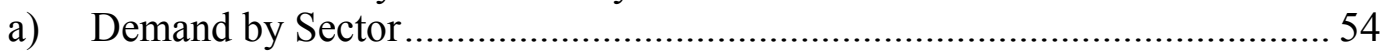

b) Domestic Production by Energy Type ……………....................................5 56

c) Total Energy Consumption by Energy Type for Germany ………………......58

d) Energy Consumption Mix for Germany ……………..................................59

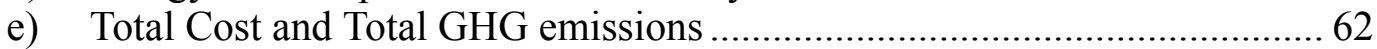

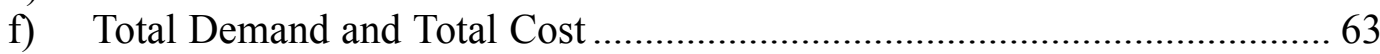

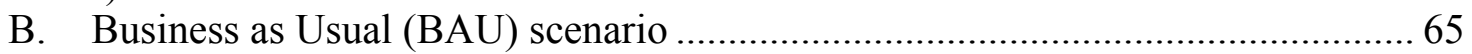

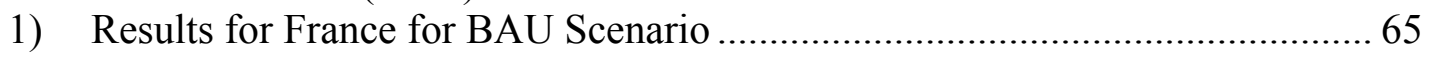

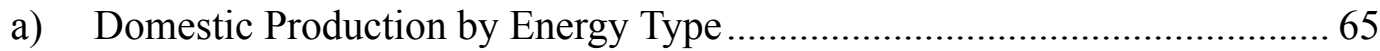

b) Comparison of Cost in Million Dollars under Scenario 1 and 2................... 67

c) Comparison of GHG emissions in Million Tonnes of $\mathrm{CO}_{2} \mathrm{e}$ under

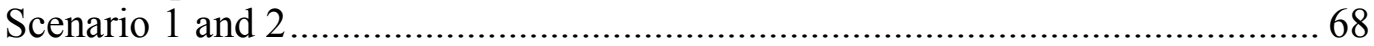

2) Results for Germany for Business as Usual Scenario........................................... 69

a) Domestic Production by Energy Type ........................................................... 69

b) Comparison of Cost in Million Dollars under Scenario 1 and 2................... 71

c) Comparison of GHG emissions in Million Tonnes of $\mathrm{CO}_{2}$ under

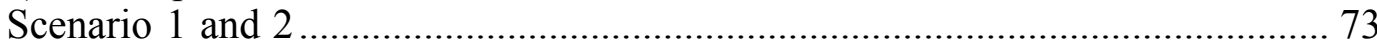

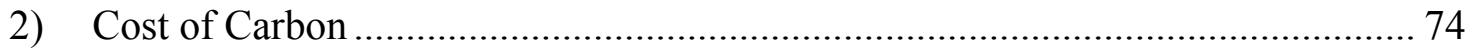

1) Results for Cost of Carbon for France ............................................................ 74

2) Results for Cost of Carbon for Germany ....................................................... 76 


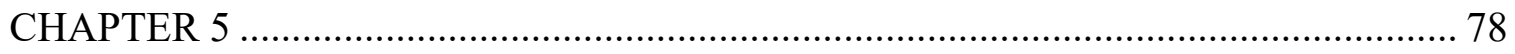

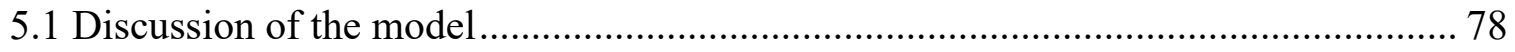

5.2 Implications for energy transition in France and Germany …............................... 79

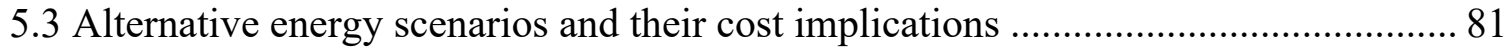

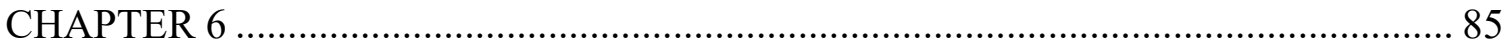

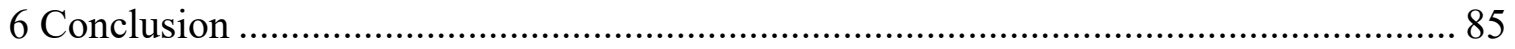

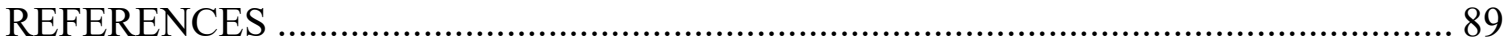




\section{$\underline{\text { LIST OF TABLES }}$}

TABLE

PAGE

Table 1: List of Variables Used in the Model and Constraints ...................................... 23

Table 2: Levelized Cost of Electricity (LCOE) in 2018 US\$/ MWh .............................. 34

Table 3: Greenhouse Gas Coefficients in Tonnes $\mathrm{CO}_{2}$ e / GWh ................................... 35

Table 4: Greenhouse Gas Targets for France and Germany in tonnes of $\mathrm{CO}_{2}$ e ............ 36

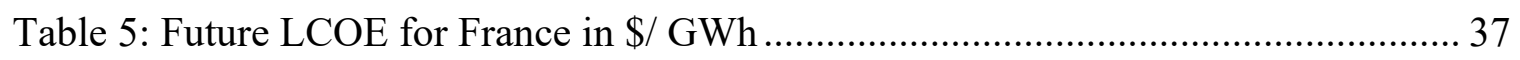

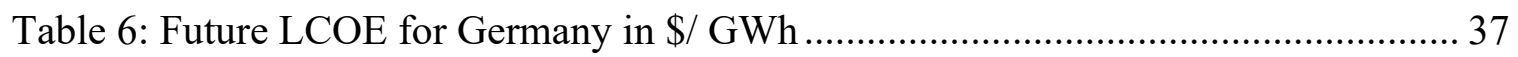

Table 7: Future Sector Demand for France in GWh .............................................. 38

Table 8: Future Sector Demand for Germany in GWh........................................... 38

Table 9: Future Domestic Production Capacity for France in GWh ............................. 39

Table 10: Future Domestic Production Capacity for Germany in GWh ........................ 40

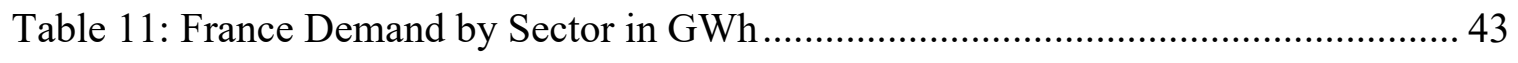

Table 12: France Domestic Production by Energy Type in GWh .............................. 45

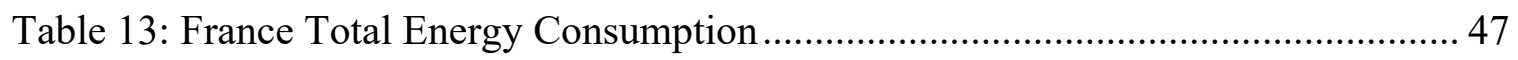

Table 14: France Total Cost and GHG Emissions in Millions Dollars and tonnes $\mathrm{CO}_{2} \mathrm{e} 52$

Table 15: France Total Demand and Total Cost in Millions GWh and Dollars.............. 53

Table 16: Germany Demand by Sector in GWh ................................................... 55

Table 17: Germany Domestic Production by Energy Type in GWh ............................. 56

Table 18: Germany Total Energy Consumption ..................................................... 58

Table 19: Germany Total Cost and GHG Emissions in Million Dollars and tonnes $\mathrm{CO}_{2} \mathrm{e}$ 62

Table 20: Germany Total Demand and Total Cost in Millions GWh and Dollars ........... 64

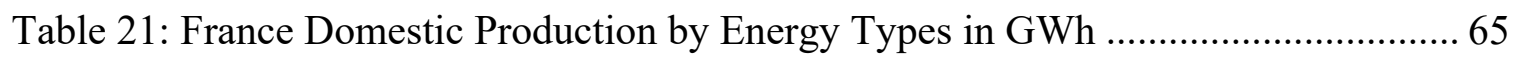




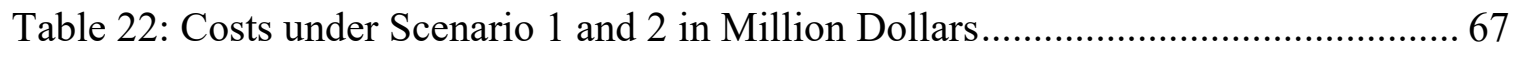

Table 23: GHG emissions under Scenario 1 and 2 in Million Tonnes CO2e................... 68

Table 24: Germany Domestic Production by Energy Types in GWh ........................... 70

Table 25: Costs under Scenario 1 and 2 in Million Dollars......................................... 72

Table 26: GHG Emissions under Scenario 1 and 2 in Millions...................................... 73

Table 27: 2015 Cost of Carbon Scenarios France ....................................................... 74

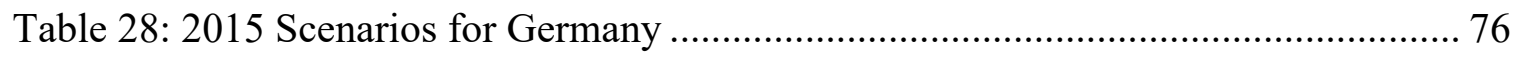




\section{LIST OF FIGURES}

FIGURE

PAGE

Figure 1: Original Domestic Production for France and Germany in 2015 ................... 19

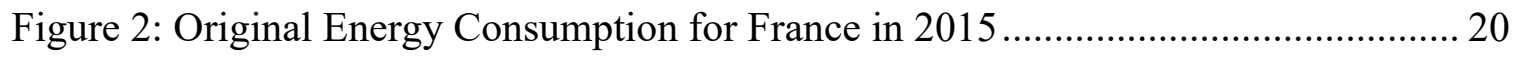

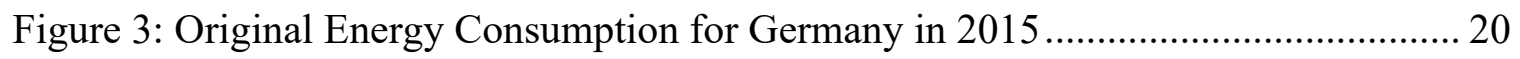

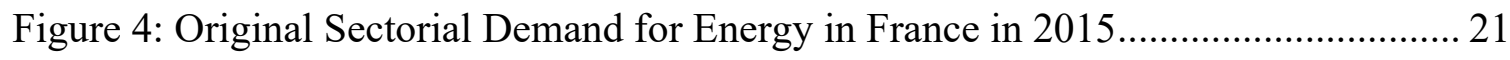

Figure 5: Original Sectorial Demand for Energy in Germany in 2015........................ 21

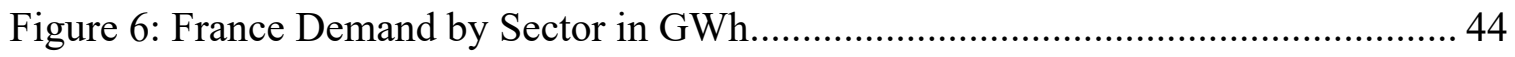

Figure 7: France Domestic Production in GWh .................................................... 46

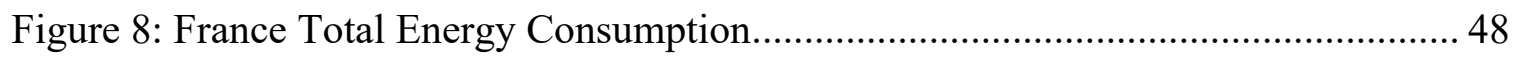

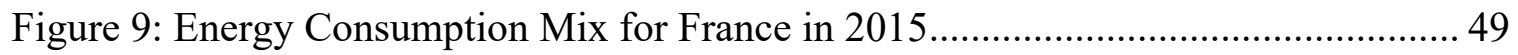

Figure 10: Energy Consumption Mix for France in 2020........................................... 50

Figure 11: Energy Consumption Mix for France in 2025........................................ 50

Figure 12: Energy Consumption Mix for France in 2030....................................... 51

Figure 13:France Total Cost and GHG Emissions in Millions Dollars and tonnes CO2e 52

Figure 14: France Total Demand and Total Cost in Millions GWh and Dollars.............. 54

Figure 15: Germany Total Demand by Sector in GWh .......................................... 55

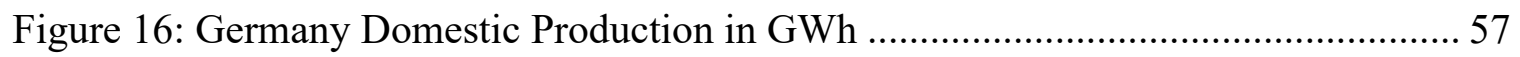

Figure 17: Germany Total Energy Consumption...................................................... 59

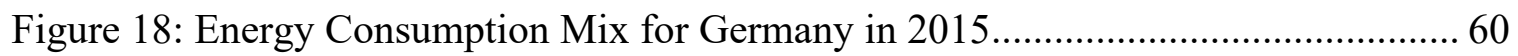

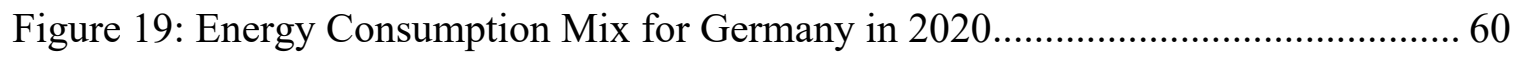

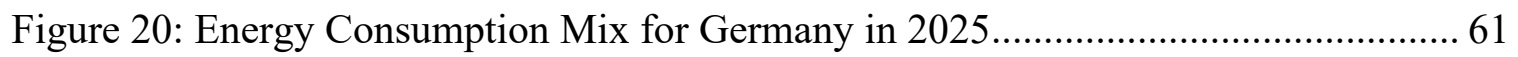

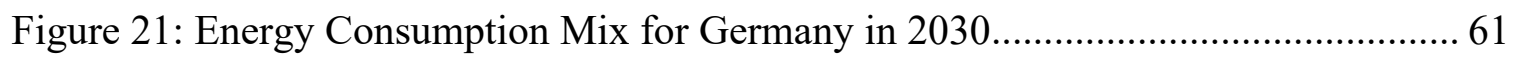


Figure 22: Germany Total Cost and GHG Emissions in Million Dollars and tonnes $\mathrm{CO}_{2} \mathrm{e}$ 63

Figure 23: Germany Total Demand and Total Cost in Millions GWh and Dollars ......... 64

Figure 24: France Domestic Production in GWh ....................................................6 66

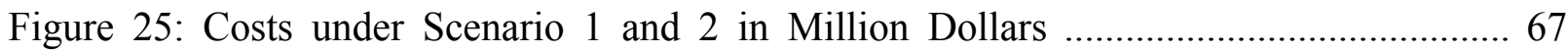

Figure 26: GHG Emissions under Scenario 1 and 2 in Million Tonnes CO2e ............... 69

Figure 27: Germany Domestic Production in GWh ............................................... 71

Figure 28: Costs under Scenario 1 and 2 in Million Dollars .................................... 72

Figure 29: GHG Emissions under Scenario 1 and 2 .............................................. 73

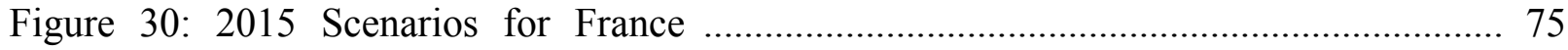

Figure 31: 2015 Scenarios for Germany ......................................... 77 


\section{CHAPTER 1}

\subsection{Introduction}

The Industrial Revolution promoted the emergence of mechanization and set the industrial sector as the new foundation the economic structure of society, instead of agriculture. The massive coal extraction coupled with the invention of the steam engine provided a new energy that gave the first push to the entire process through the development of rail networks and the acceleration of economic, human and material exchanges. Since the Industrial Revolution, we have been relying on non-renewable energy sources such as coal and oil. The use of such resources allowed for a quick economic development, as well as an increase in the standard of living in most countries. However, these resources are limited in time and place, and have negative impacts on the environment, such as the release of greenhouse gas emissions.

While a small amount of greenhouse gas (GHG) is produced naturally, the majority is emitted by human activities. As McMichael points out in his study, humans have been responsible for most of the global warming since 1950, with an increase in global temperatures of +0.7 degrees Celsius. It is expected that temperatures will continue to rise up to 1-2 degrees Celsius by 2050, and 3-4 degrees Celsius by 2100 (McMichael, 2013). The greenhouse effect is a phenomenon sensitive to changes in the composition of the atmosphere. The increase in GHG emissions modifies the atmospheric composition, causing an increase in the greenhouse effect. Such an imbalance causes a global warming that modifies the climates. Massive use of fossil fuels (coal, gas, oil), deforestation, intensive livestock and agriculture produce large amounts of GHGs that are 
concentrated in the atmosphere and trap heat (McMichael, 2013). Agriculture, by itself, produces 52 and $84 \%$ of global anthropogenic methane and nitrous oxide emissions (Smith, et al. 2007).

The extraction, transport and combustion of fossil fuels not only produce $\mathrm{CO}_{2}$, but also other greenhouse gases, as well as the emission of particles. As the IPCC report points out, the stabilization of GHG emission within the atmosphere, by limiting global warming to 1.5 degrees Celsius above pre-industrial levels, will require reducing emissions from energy, agricultural, transport and other sectors (Rogelj, et al. 2018), but even by completely stopping our greenhouse gas emissions, the equilibrium would not be restored rapidly since some greenhouse gases have a very long lifetime in the atmosphere. Obviously, such a mode of living is neither sustainable nor equitable since the less developed countries do not have access to the energy resources that wealthier countries do, but still have to suffer the consequences of GHG emissions (Stern, 2006).

Over the last decades, increasing attention has been given to renewable energy as a strategy for greenhouse gas reductions. However, the energy market is mainly dominated by oil and gas, and renewables have a hard time becoming competitive. Several international agreements were put in place through the years, such as the Kyoto Protocol of 1997, in order to reduce greenhouse gas emissions (Vasser, 2009). The initial objective of the Kyoto Protocol was to achieve during the 2008-2012 commitment period a reduction of anthropogenic greenhouse gas emissions by at least $5 \%$ (in committed countries) below the 1990 levels. Countries were separated into 2 groups: Annex 1 (developed countries) and Non-Annex 1 (developing countries). Annex 1 countries faced emissions limitations, representing a GHG reduction of $61.6 \%$ in total. Judging the success of the Kyoto protocol can bring mixed results: on one hand, countries did manage 
to reduce their GHG emissions, especially developed countries, but the way they did it was not sustainable: first hit by the financial crisis, these countries managed to move their high GHG emitting production to developing countries, therefore shifting these GHG emissions. However, international negotiations have failed to produce another binding agreement, but the Paris Conference on Climate change gave hope for the confection of such an agreement.

The Paris Agreement of 2015 brought together countries from all around the world, which recommitted to reducing emissions and therefore slowing down climate change. Following the Paris Agreement, European nations, among other countries, promised to reduce their greenhouse gas emissions. France and Germany, the two leading European nations, and have different energy portfolios. As Heinrichs and Markewitz (2017) note, the German government is working towards reducing greenhouse gases by $40 \%$ by 2020 and $80-95 \%$ by 2050 compared to 1990 levels. France, on its side, pledged to reduce its carbon emissions by $27 \%$ from 2013 levels by 2028, and by $75 \%$ in 2050 . With heavy uses of oil, coal and gas (i.e., constituting $63 \%$ and $68 \%$ of the country's total energy budget of France and Germany, respectively), these two countries have to explore alternative energy portfolios in order to meet their Paris Agreement targets.

An energy transition is an ecological goal that consists of a change from the current energy system to a new energy system focused on renewable resources. Such a transition mainly consists of reducing the consumption of fossil fuels in a large part of human activities: industry, transport, lighting, but also improving efficiency of technologies so that they emit less greenhouse gas emissions. Such an energy transition would require studying our energy mix, which should not be confused with the electricity mix. The energy mix corresponds to all the energy sources used to meet the energy needs 
of a country to move, heat, light, and operate our electrical equipment, etc, and an energy mix only supplied by renewables is so far, not realistic (Kim and Park, 2018) The electricity mix only concerns the energies used to produce electricity, and could on the other hand be switched to renewables.

Although a transition to renewable energy may help these countries make progress towards meeting the Paris Agreement targets, several economic, technological and energy capacity questions confront such transition. These challenges are relevant for both countries considered in the present study. Indeed, the price of energy resources, as well as the cost to produce them will determine the share of this resource within the portfolio. Additionally, its substitution by other energies will be important: for example, oil does not have any viable large-scale competitor for the transportation sector, meaning that countries like France have to import all their demand since they do not produce any. Technology is another challenge all countries will have to face: not only they have to make sure they have all infrastructure needed to produce energy, they also have to invest in research towards energy efficiency, as well as energy storage. Lastly, the issue of capacity is one that can also be linked to energy storage: not only countries have to make sure they meet their demand, they also have to guarantee a constant and stable supply of energy which can be challenging with the intermittence of some renewables. The main goal of the research is to determine what kind of energy portfolios the above European countries will possibly attain in the near- and medium-term future and whether such transition will be within reasonable costs. 


\subsection{Problem}

Energy transitions are crucial for our future societies but can be difficult to put in place and costly if not planned properly. Many factors need to be taken in account when planning such a step, and realistic goals need to be put in place. Germany and France are two of the largest economic players of Europe and have very different energy mixes. Germany started investing in renewables prior to other countries, and France followed a similar transition. However, both countries still rely heavily on non-renewables in order to meet their energy demand: Germany on fossil fuels and France on nuclear heat. Both countries are still heavily reliant on fossil fuels, especially oil, in order to meet their transportation demands. Both countries have been focusing on reducing their GHG emission levels, and so far, have been decreasing these numbers, but still have a long way to go, especially Germany who has very ambitious targets. In order to meet their Paris Accord targets, both countries will have to make major energy shifts from the current scenario, which could have large cost and technological implications. Countries can supply their demand thanks to domestic production but also imports if their territory does not have the resources or infrastructures to produce a certain type of energy. Models are a useful tool for scientists to project future scenarios, and in the case future of the present research, costs and emissions as well. Indeed, previous studies such as Price and Keppo (2017) have used models in order to explore the different possibilities and costs implications of these possibilities. Models can also be used in order to estimate the cost of carbon and the efficiency of the GHG targets proposed by the countries of choice for this study. 


\subsection{Research Questions}

This research will address the following questions:

1. What is the actual share of energy today of France and Germany and what are their patterns of use and production?

2. How would the energy portfolios (both in terms of renewable vs nonrenewable and domestic vs imported) of the two countries change as a result of meeting their respective GHG reduction targets?

3. What are cost implications of meeting the emission targets?

4. How would costs and GHG emissions behave in a scenario without demand and GHG constraints?

5. Are countries already at their cost optimal GHG targets?

\section{$1.4 \underline{\text { Statement of Objectives }}$}

The main objectives of this research are to review the past and current energy trends for both countries, including consumption, production, as well as imports. Additionally, the present research will create a least-cost optimization model that takes into consideration multiple constraints including greenhouse gas (GHG) emission reduction targets, energy production capacity and energy demands, including specific sectorial demand such as transportation. This project will also evaluate the effects of committing to different greenhouse gas emission reduction scenarios at different slacks or limits on total cost as well as on future energy supplies of France and Germany. Lastly, the research will draw broad policy conclusion for making the energy transition smooth and sustainable. 


\subsection{Significance of this Study}

The study will propose energy shares for both countries derived from forecasted demand and GHG targets. Such a study is significant because it could help countries plan future shares bases on estimations, and also forecast future expenses in renewable energy infrastructures. Additionally, the present study can be used for any nations that have the data required to run the model and the need to characterize pathways of complex energy mix that comply with global environmental standards. 


\section{CHAPTER 2}

\subsection{Literature Review}

Chapter 2 presents a literature review of the main concepts of the study as well as previous work related to the topic. The chapter starts with a short review of the Paris Accord. The next section will provide the role of France, Germany and Europe as whole leaders of sustainable development. Following, a discussion about fossil fuels and their limitations will be given. The next section will mention the challenges of an energy transition, and the last section will discuss previous studies revolving around the subject of modelling for energy transitions.

\subsection{The Paris Accord}

In 2015, 195 countries attended a Conference in Paris on climate change and created the Paris Agreement. It took into account that putting extreme emission limits on countries would not be successful and required countries to pledge to self-determined (or nationally-determined) emission targets (Falkner, 2016). The goal of the agreement is to avoid a rise in global temperature higher than 2 degrees Celsius above pre-industrial levels. In order to do so, four main points were highlighted:

1. The negotiation of a universal agreement, in accordance with Durban's mandate, putting in place rules and mechanisms in order to gradually raise the motivation of all signing nations to respect the limit of $2^{\circ} \mathrm{C}$.

2. The presentation by all countries of their nationally determined contributions, prior to COP21, in order to have scheduled goals and to demonstrate that all States are advancing, according to their national opportunities, in the same direction. 
3. The financial component will support developing countries and finance the transition to low-carbon and resilient economies, before and after 2020 .

4. Strengthening the commitments of civil society and non-state actors and multi stakeholder initiatives of the Agenda of Solutions or Lima-Paris Action Plan, in order to involve all actors and to initiate concrete actions without waiting the entry into force of the future agreement in 2020.

Unlike the Kyoto Protocol, the Paris Agreement includes both industrialized and developing countries, and highlights the idea of "support for and international cooperation on adaptation efforts" (Falkner, 2016). Another very important difference is the fact the Paris agreement recognizes that no countries would be able to put in place drastic measures to cut down greenhouse gas emissions, therefore adopting a more realistic approach to the issue. As we all know, climate change is usually associated with the combustion of fossil fuels such as oil, coal and gas, which has become the backbone of the industrial economy. Therefore, Falkner believes that the idea of a decarbonization of the economy would need to be supported by reengineering of the entire industrial system, which can lead to political opposition and encounter practical challenges. Even though some technology is already existing, replacing fossil fuels will be more difficult than expected in some of the consumption sectors.

\subsection{Energy Transition in Germany and France, and the Role of Europe as a Leader}

Germany is not only one of the strongest economies in the world, but is also one of the highest $\mathrm{CO}_{2}$ emitters, raising the question of sustainability and energy transition. Renowned for being ahead in the field of renewable energy development, Germany is often given as an example. In September 2010, the government published an ambitious 
energy roadmap called the "Energiekonzept" which supports the Energiewende project. Among the main objectives was to reduce primary energy consumption and promote the use of renewable resources (Steinbacher and Röhrkasten, 2019). The Fukushima accident of 2011 acted as a trigger for Chancellor Angela Merkel, who decided to reconsider Germany's position on nuclear power and initiate a phase out by 2022 (Drmota, 2017). Between 2000 and 2016, the country invested heavily in renewable energies in order to launch an ambitious energy transition and manages to change its electricity production portfolio. Germany also insisted on an international aspect of its transition by encouraging energy partnerships between different countries. Even though the nation puts forward these steps towards a cleaner energy mix, the reality is that its electricity production is still heavily reliant on coal, and the transport sector on oil (Steinbacher, Röhrkasten, 2019).

France sharply reduced its dependence on hydrocarbon imports after the 1973 oil shock, by launching a vast nuclear power plant construction program. With the Kyoto and Paris Accords, the country decided, as Germany, to take a leadership role when it came to clean energy and put in place the $17^{\text {th }}$ of August 2015, a law that would promote an energy transition and sustainable development. The 2015 law sets strict targets for energy consumption reduction, renovation of buildings, reduction of greenhouse gas emissions, and even a reduction of nuclear energy. There is also a clear research and set of action plans put in place in France and all over Europe in order to improve energy use efficiency (Berghmans, 2017). Even though France has been increasing its share of renewable energy, it is still unknown how the country will manage an important reduction in nuclear energy knowing that it represents a large portion of the electricity production mix. Some point out that such a phase out is not beneficial in the time period 
for the energy transition: what would actually replace nuclear power and guarantee that all energy demand is met?

Welsch (2017) points out that the European Union is given the chance to be a leader in terms of greenhouse gas emissions litigation, since it is the third largest the emitter of greenhouse gas in the world, after the US and China. He also highlights the fact that there should be a radical energy transformation of the energy sector since it is such an important source of greenhouse gases. Even though each country will still use fossil fuel he urges the fact that the electricity generation sector should be almost completely decarbonized which will depend on the development of renewable energy's. A think tank called Insight $\mathrm{E}$ was set up in order to join forces for a multidisciplinary energy advice, not only to propose potential public policy actions but also to assess the impact of political decisions. The group delivers a multitude of tools such as Rapid Response Energy Briefs, which answer sharply current energy policy questions, Policy Reports, which deeply analyze policy options and impacts, Hot Energy Topics, which are topics brought up in anticipation of policy agendas and lastly an Observatory of the Energy Transition in order to provide relevant and unbiased advice on energy transitions. The European Union is fairly dependent on fossil fuels imports, which urges the development of the renewable sector. Since the European Union decided to follow the trend towards sustainable development, countries such as Germany or Denmark took the lead. Even though fossil fuel powered generation represents most of the electricity of the European Union, other modes of generation have been increasing in particular nuclear power and Hydro power. Since the European Union is made up of the various countries it can be challenging to harmonize market reforms which is why the Energy Union was created in order to supply and support climate goals. 


\subsection{Fossil Fuels and their Limits}

Fossil energies are still very much used today in the world and two main issues can arise with their consumption. The first is that their scarcity will create geopolitical tensions in the world, on top of the fact that a small number of suppliers is in charge of those resources (Rojey, 2009). The availability of reserves is an important source of concern. At the current rate of consumption, oil is expected to be the first fossil fuel that the world will run out off, followed by gas and coal. Regarding nuclear energy, the price of uranium for operation of current reactors sets the consumption rate, and according to the Global Nuclear Energy Report (2014) the current uranium reserves give 80 to 90 years of operation at the current rate of consumption. It may be that we still have these energies a little longer because we rely on the proven reserves, that is to say the reserves that we are sure to exploit. However, estimates are made to know the ultimate reserves that could be discovered, thus increasing the operating life of the energy.

The second problem is that the $\mathrm{CO}_{2}$ emissions generated by fossil fuels are high and contribute significantly to global warming. Indeed, GHG coefficients of oil, coal and gas are the highest compared to other resources such as wind power, solar power or even nuclear power (World Nuclear Association). Even though the climate change topic is full of debate, we can still say that a global movement is emerging to face the new climate. The energy "transition" is above all energy: it aims to free the world economy from its dependence on fossil fuels, since by burning coal, oil and natural gas for their activities, men release billions of tonnes of greenhouse gases every year, that accumulate in the atmosphere and disrupt the climate. 


\subsection{The Challenges of an Energy Transition}

The concept of an energy transition is very appealing, however can be quite difficult to put in place. Our civilization is heavily dependent on fossil fuels, resulting in changes in land cover that emit high amounts of greenhouse gases, leading to increases in average tropospheric temperature. By 2030, the world is expected to consume two additional thirds of what is already consuming today and developing countries will represent the highest proportion in this demand (Dorian, Franssen and Simbeck, 2006). The previous authors identify four main challenges that arise with energy transitions: increasing oil scarcity, promoting energy security, fighting environmental degradation and finally meeting the demand from developing countries. However, they point out that even though science is useful in order to plan an energy transition, it is also fundamental to take in account both economic and political factors, which will govern the transition. Technology is a key component of energy transitions, however as Smil (2016) mentions, progress in electronics and technology created a perverse effect: the world expects new discoveries to fix the issue of climate change, phenomenon he refers to as the Moore's curse. Throughout his article, Smil (2016) reflects on a set of points that need to be kept in mind when dealing with energy transitions. First of all, he points out that the pace of energy transitions will be very different depending on the type country that you are studying. However he does insist that overall, all global energy transition are gradual processes based on the alternative resources available, and even programs such as the Energiewende in Germany prove that such actions are not only costly, but can sometimes hide negative outcomes, such as the use of environmentally degrading materials, like lignite, which not only produces more $\mathrm{CO}_{2}$ than hard coal, but also can affect groundwater reserves in mines dump discharges (Lenk and Wisotzky, 2009). 
Since we are such a heavy fossil fuel civilization Smil (2016) insists that the goal of the energy transition should not be switching from an energy to another but instead reducing the greenhouse gas emissions. Not only, he points out the global growth of new renewables has been quite slow, especially with the problem of intermittence that makes countries still rely on fossil fuels as a backup energy, but he also makes the point that the energy transitions that we focus on relate to electricity generation rather than total energy consumption. Removing fossil fuels will be more difficult than what we expect it to be since the transportation sector is so dependent on these resources, on top of other sectors that use these fuels to create other products, such as plastic. Dorian, Franssen and Simbeck (2006) also highlight the role of oil in energy transitions, specifically its known limit: the finite aspect of its abundance. The demand of oil is expected to rise by more than $50 \%$ by 2030 , but the amount of oil available will not face such an increase, creating a future lack of supply.

As Smil (2016) points out, we are still a fossil fueled civilization, and renewable energies only grow at a $3 \%$ rate annually. The approach to a transition in energy consumption is a gradual process, and even programs such as the Energiewende in Germany prove that such actions are not only costly, but can sometimes hide negative outcomes, such as the use of environmentally degrading materials, like lignite, which not only produces more $\mathrm{CO}_{2}$ than hard coal, but also can affect groundwater reserves in mines dump discharges (Lenk, Wisotzky, 2009). Additionally, not all consumption sectors will react equally to the introduction of renewables. For instance, in the case of the transport sector in America, although ethanol production diverts a large portion of corn reserves, it cannot fully meet the fuel demand (Smil, 2016). Similarly, Welsh (2017) points out that the transport sector represents a quarter of EU's greenhouse gas emissions, 
and that the European Commission's Transport White paper sets a goal to reduce these emissions by $60 \%$ below the 1990 levels by 2050 . We have to keep in mind that fossil fuels have been used for generations, and therefore investments have been made in order to put in place very costly infrastructure. Under an energy transition, these infrastructures would have to be listed as stranded assets.

\subsection{Previous Studies on Energy Transitions}

Proposing an energy transition requires careful evaluation of its economic cost. Price and Keppo (2017) explore the diversity of near cost optimal energy pathways possibilities and their uncertainties using the TIAM UCL model, which separates the world into 16 regions. They focus on an international level, and on a multitude of sectors to come up with significantly different scenarios concerning the energy portfolios. They use an approach called: Modeling to Generate Alternatives (MGA) which was also used by DeCarolis in his study that we will mention later. Their approach "forces an optimization model to search the feasible, near- optimal region of the solution space for alternative solutions that are maximally different in decision space" (DeCarolis, 2010). Price and Keppo (2017) implement MGA to make sure that supply meets demand, while guaranteeing the lowest cost in order to show future plausible scenarios. Their results show that variability occurs for certain energy sources such as coal and gas while oil is not as affected as much, which could mean that its replacement will be more difficult than the replacement of other energies. Additionally, the authors find that coal and gas have the tendency to substitute for each other, even though coal is mostly used for power generation and natural gas is used in different parts of the energy system. Interestingly, with an increase in energy demand, the model ends up choosing less efficient 
technologies and resulted in an increase in the cost. Lastly, as mentioned earlier, not all sectors react to energy portfolios changes in the same way: in this case it is shown that the transport sector relied heavily on oil, therefore there would be a slower transition with this energy source.

DeCarolis (2010) performs another modeling to generate alternatives study, using $\mathrm{CO}_{2}$ emissions constraints until 2050. He executes two scenarios, one without any constraints, and the second with $\mathrm{CO}_{2}$ emissions limitations of $15 \%$ of 2005 . The author uses a simple least-cost linear optimization model in order to observe the replacement of existing fossil fuel infrastructures by renewables to meet the energy demand, and then also applies MGA model to the same scenarios in order to compare the results. The base model shows a combination of cycle gas turbines and pulverized coal, while the MGA model suggests replacing the conventional coal with IGCC and geothermal. In general, while running the MGA, one can observe that maximum cost flexibility to find alternative solutions is present, which means that the cost of electricity is higher when running MGA than the base model. However, unlike the base model, using MGA provides a "set of feasible, near-optimal alternatives without the need to further constrain the model" (DeCarolis, 2010).

The types of resources used during the energy transitions will impact the amount of emissions released. Nuclear power, which is a popular energy source in France, could be a major leader on the energy transition scene. Liquefied natural gas emits 490 $\mathrm{tCO}_{2} / \mathrm{GWh}$ while nuclear power only produces $12 \mathrm{tCO}_{2} / \mathrm{GWh}$, making it an interesting alternative to reduce emissions (Lee et al., 2017). Indeed, countries could use nuclear power in order to compensate for their demand from fossil fuels. Lee et al. examined the existence of a link between nuclear power proportion and $\mathrm{CO}_{2}$ emissions. They found 
that by expanding the nuclear power proportion by $1 \%$, a $0.26-0.32 \%$ decline in $\mathrm{CO}_{2}$ emissions per capita would follow. The environmental potential of this energy source is favorable for an energy transition; however, the possible risks of a nuclear catastrophe need to be kept in mind. Multiple countries already started phasing out this type of energy source because of the fear of an accident. The authors highlight the idea that even though some countries are starting to close down their power plants, using nuclear power more intensively would help reaching GHG targets.

Similarly, Raimundo et al. (2018) performed a study in Brazil in order to observe the possible reduction in greenhouse gas emissions in Brazil thanks to wind generation. Wind power is a renewable energy that is becoming more and more popular, especially in countries within the European Union. Depending on the location of the wind farm, the life cycle emissions vary between 7.1 to $34.1 \mathrm{~g} \mathrm{CO}_{2} \mathrm{eq} / \mathrm{kWh}$, which is significantly lower than other sources such as coal, gas or even solar PV. Therefore, wind power is a strong competitor to help Brazil reach its Paris Agreement target of GHG reduction by 43\% (Raimundo et al., 2018). The study estimated the avoided $\mathrm{CO}_{2}$ emissions between 2001 and 2016 to be $0.485 \mathrm{tCO}_{2}$ per MWh generated. They analyzed three scenarios for 2030 . It was found that the amount of avoided greenhouse gas emissions could reach $5.77 \%$ of the total Brazilian Energy Matrix emissions in 2030, which the authors considered to be very significant since it only represented one energy source. Once again, using wind coupled with other renewable energies would be beneficial to transition to a more sustainable society, however because of the issue of intermittence, nuclear power could be a tool for backup. 


\section{CHAPTER 3}

\subsection{National Trends}

France and Germany are two very different nations with regard to their energy mix. France has been heavily reliant on nuclear heat to fulfill its electricity needs, and barely produces any fossil fuels, which are needed by different consumption sectors. The fossil fuel shortage has to be met by imports. France has also been investing into renewables lately but has still some catching up to do in order to meet its neighbor's level: Germany, as can be observed from Figure 1. Germany has an advantage over France in that its energy portfolio is much more diversified, and the country produces fossil fuels and can therefore cover at least a portion of its demand, as Figure 1 shows. Germany has been investing in fossil fuels, especially after launching its energy transition project in 2012. However, as shown in Figure 1, France has a very high production of nuclear heat, which is useful for an energy transition as it produces low levels of GHG emissions. The Eurostat data sets were analyzed in order to understand energy resources not only used by both countries, but also their domestic production levels and breakdown by consumption sectors.

The energy sources considered for this research are: solid fuels, oil, gas, hydropower, wind power, solar thermal and PV, solid biomass, biogas, biogasoline and biodiesel, and finally nuclear heat. These energies represent the largest part in the energy portfolio of both countries. Following are graphics that display patterns of consumption energy mixes in 2015 , as well as share of sectors for total demand for both countries. As observed on the following Figures 2 and 3, France and Germany energy portfolios are very different. Indeed, France uses a majority of nuclear heat, for electricity generation 
purposes, and also uses large amounts of oil and gas. In terms of renewables, the country does use solid biomass, but its share in renewables compared to other energies is very minimal. For Germany, the country uses a very large amount of fossil fuels, as can be observed on Figure 3. The next largest energy share is from nuclear, followed by renewables, which are in small portions compared to fossil fuels, but still higher than for France. For energy consumption sectors, as can be observed on Figures 4 and 5, both countries have similar trends, with the non-energy sector being the smallest, and the service sector representing a similar share. However, for France, the largest sector of consumption is the residential sector, while for Germany it is the industrial sector.

Figure 1: Original Domestic Production for France and Germany in 2015

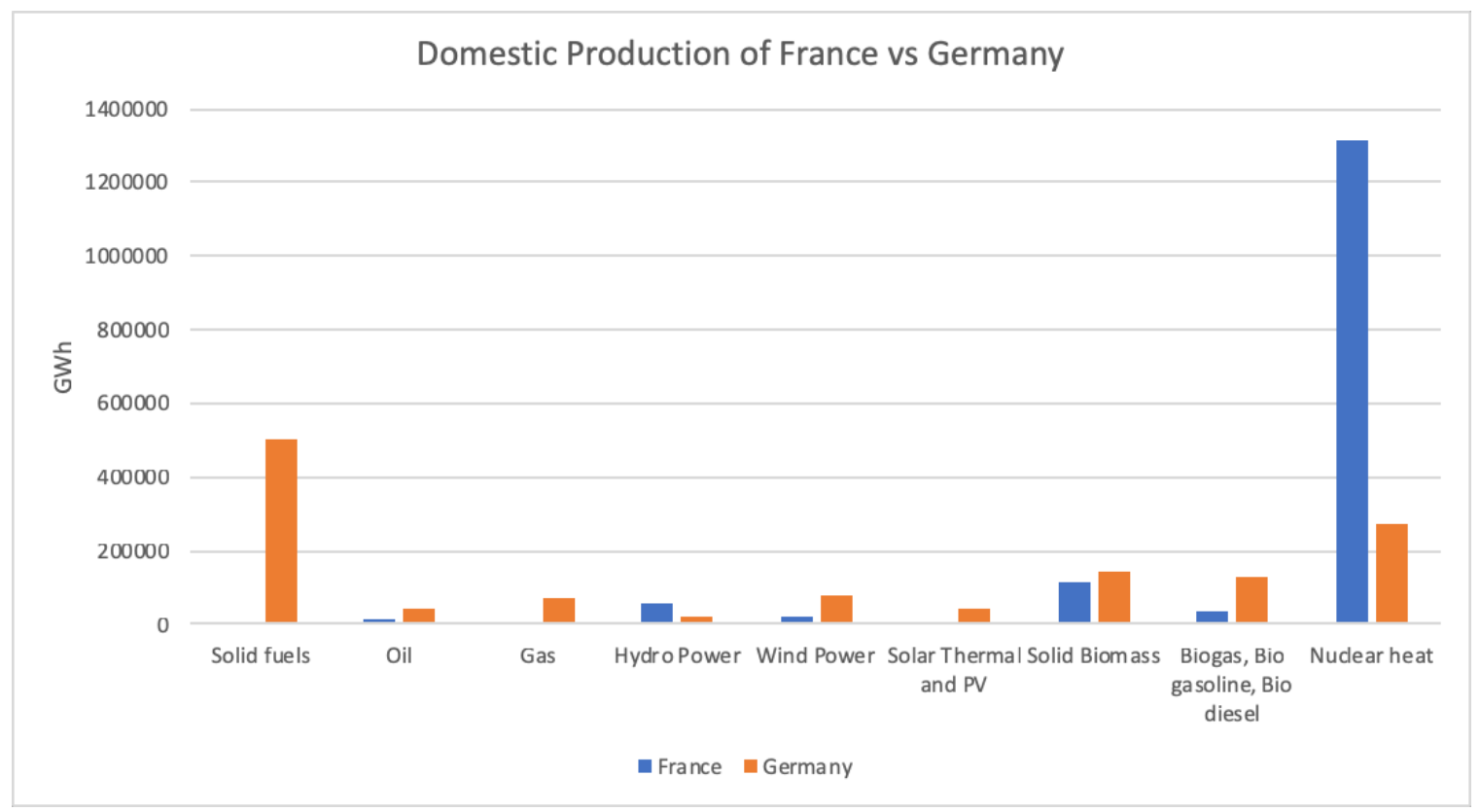


Figure 2: Original Energy Consumption for France in 2015

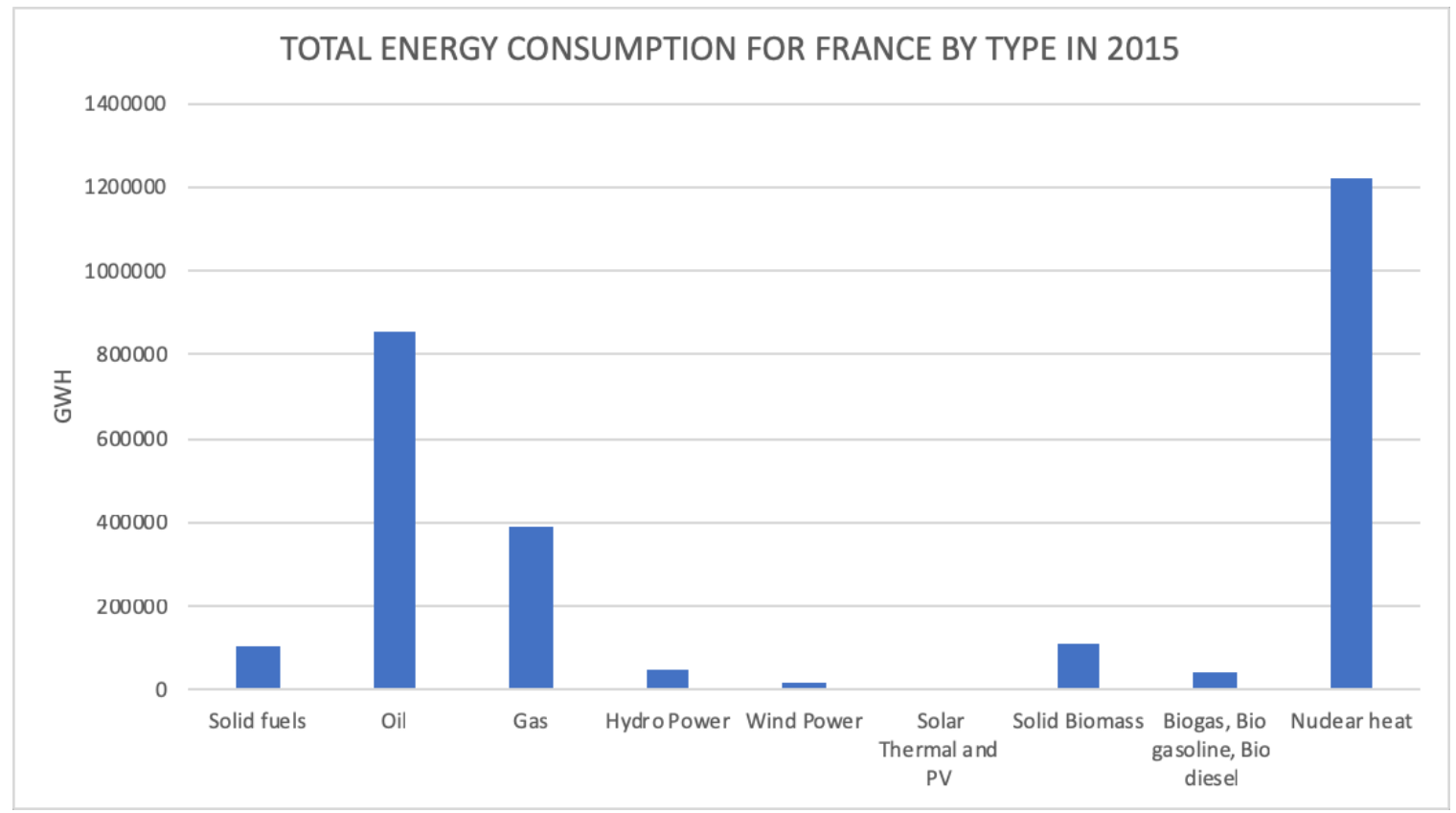

Figure 3: Original Energy Consumption for Germany in 2015

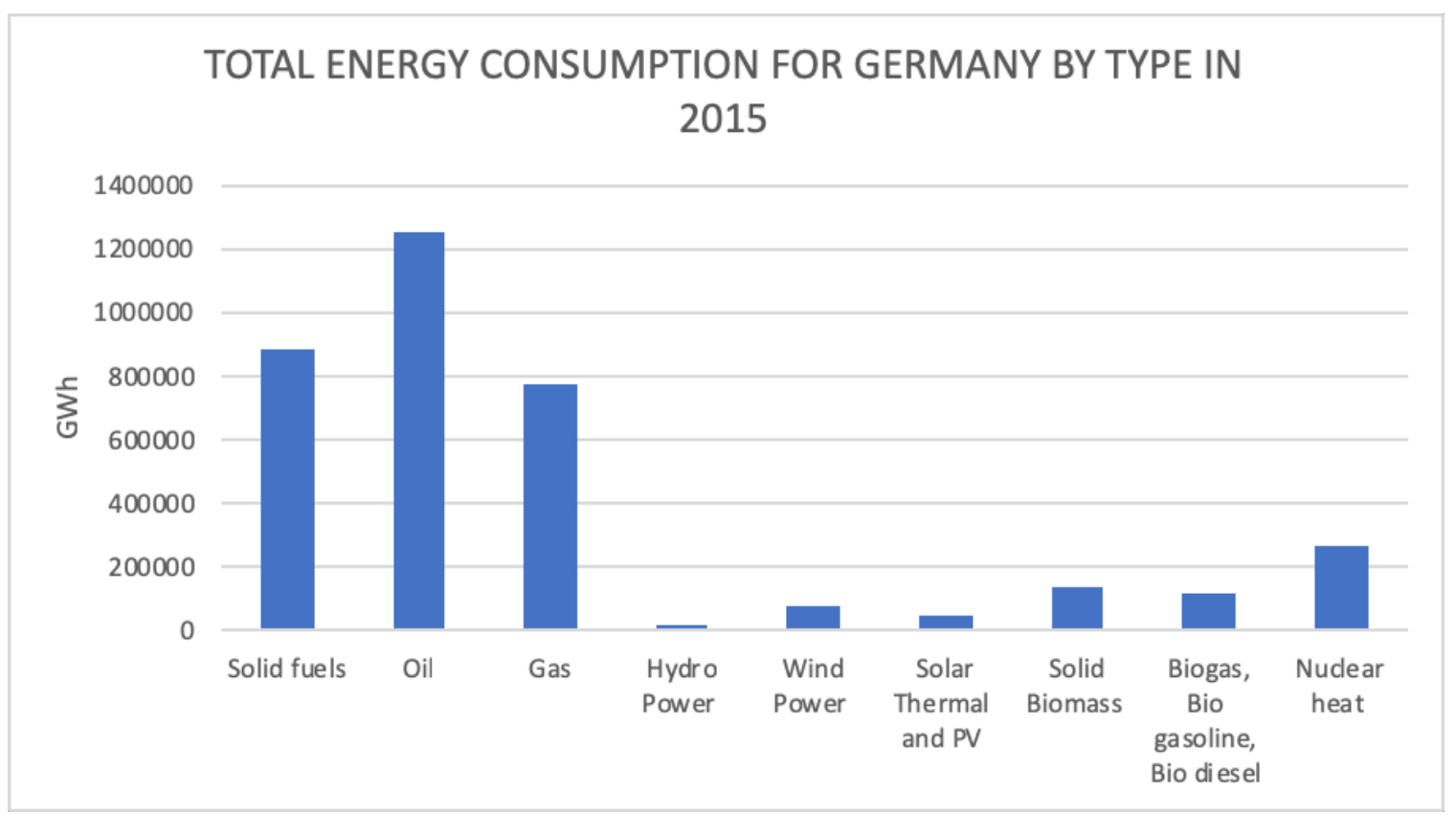


Figure 4: Original Sectorial Demand for Energy in France in 2015

Demand for Energy by Sector for France in 2015

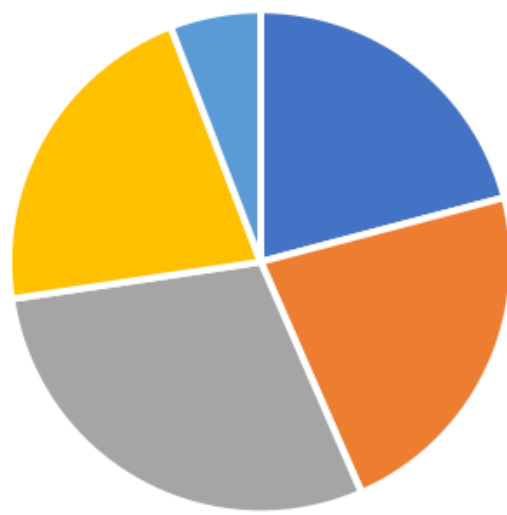

- Industry - Transport " Residential " Services " Non Energy

Figure 5: Original Sectorial Demand for Energy in Germany in 2015

Demand for Energy by Sector in 2015 for Germany

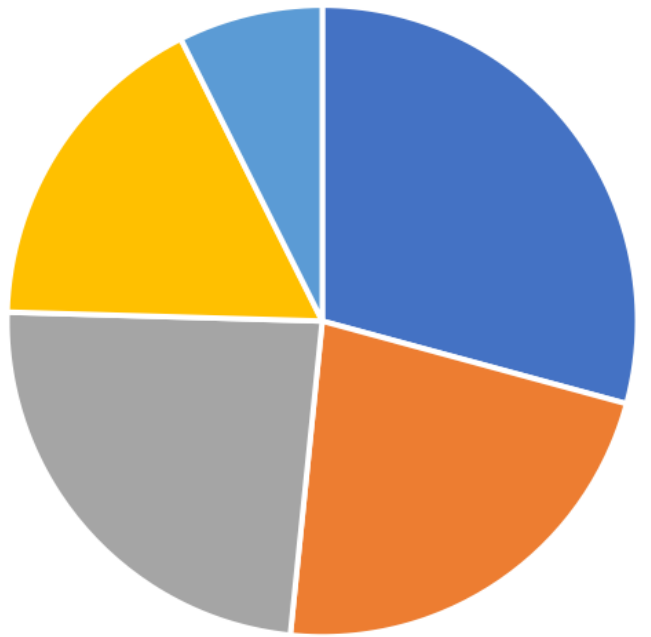

- Industry | Transport " Residential

Services

- Non Energy 


\subsection{The Least Cost National Energy Model}

A linear programming model was set up in order to find the most cost optimal solutions for both countries to fulfill greenhouse gas targets while meeting energy demand. Each country's scenario was run separately and has its own energy portfolio represented by energy sources (e.g.: solid fuels, oil, gas, hydro power, wind power, solar thermal and PV, solid biomass, biogas, biogasoline and biodiesel, and finally nuclear power), as well as end-use energy demand sectors (industrial, transportation, residential, services and non-energy).

On the supply side of this model, energy resources can either come from domestic production or from imports. To prevent the least-cost model from substituting import sources for domestic sources, we kept the costs of import energy sources higher than the domestic sources. For lack of better information, the costs of all imports were kept $10 \%$ higher than those of domestic energy sources. Additionally, renewable energies were allowed to expand with some reasonable capacity restrictions, while fossil fuels and nuclear energy productions are set at current capacities. We also put minimum domestic supplies on all sources to ensure that the model do not replace any energy sector drastically within a short time, allowing for a smooth inter-source transition. On the demand side, growth projections for sectorial demands for both France and Germany are applied, and overall demand is expected to decrease throughout the study years. The model runs from its base year of 2015 to 2030 in 5-year intervals.

The goal of the model is to ensure that the GHG targets for both countries are met while guaranteeing that the supply of energy meets the sectorial demands, while keeping cost at the lowest level possible and respecting inputted constraints (such as growth 
constraints, minimum demand constraints or sectorial constraints). This linear program is solved using the Simplex method on Microsoft Excel.

\section{A. Variables}

Table 1 delineates the model's variables.

Table 1: List of Variables Used in the Model and Constraints

\begin{tabular}{|c|c|}
\hline Notation & Definition \\
\hline$i$ & $\begin{array}{l}\text { Energy source } i=1 \text { (solid fuels), } 2 \text { (oil), } 3 \text { (gas), 4, (hydro power), } 5 \text { (wind } \\
\text { power), } 6 \text { (solar thermal and PV), } 7 \text { (solid biomass), } 8 \text { (biogas, bio gasoline } \\
\text { and biodiesel), } 9 \text { (nuclear) }\end{array}$ \\
\hline$j$ & $\begin{array}{l}\text { Energy consumption sector } j=1 \text { (industry ), } 2 \text { (transportation), } 3 \\
\text { (residential), } 4 \text { (services), } 5 \text { (non energy) }\end{array}$ \\
\hline$F, G$ & Model countries, France and Germany, respectively \\
\hline$t$ & $t=2015,2020,2025$, and 2030 \\
\hline$D S_{i j t}^{F}, D S_{i j t}^{G}$ & $\begin{array}{l}\text { Amount of domestic energy supplied by source } i \text { to consumption sector } j \text { in } \\
\text { year } t \text { for France and Germany, respectively }\end{array}$ \\
\hline$I_{i j t}^{F}, I_{i j t}^{G}$ & $\begin{array}{l}\text { Amount of energy source } i \text { imported for consumption sector } j \text { in France } \\
\text { and Germany, respectively }\end{array}$ \\
\hline$c_{i t}^{F}, c_{i t}^{G}$ & $\begin{array}{l}\text { Cost of producing energy for each sector i in each country } F \text { and } G \text {, } \\
\text { respectively, for year } \mathrm{t}\end{array}$ \\
\hline$p_{i t}^{F}, p_{i t}^{G}$ & $\begin{array}{l}\text { Price of energy source i imported by country } F \text { and } G \text {, respectively, in year } \\
\mathrm{t}\end{array}$ \\
\hline$\overline{S_{i t}^{F}}, \bar{S}_{i t}^{G}$ & $\begin{array}{l}\text { Maximum amount of energy supplied by sector i in country } F \text { and } G \text {, } \\
\text { respectively, in year } \mathrm{t}\end{array}$ \\
\hline
\end{tabular}




\begin{tabular}{|c|l|}
\hline$\overline{D S}_{i t}^{F}, \overline{D S}_{i t}^{G}$ & $\begin{array}{l}\text { Maximum amount of domestic energy supplied by sector i in country } F \\
\text { and } G, \text { respectively, in year t }\end{array}$ \\
\hline $\bar{D}_{i j t}^{F}, \bar{D}_{i j t}^{G}$ & $\begin{array}{l}\text { Minimum amount of energy demanded by sector } \mathrm{j} \text { in country } F \text { and } G, \\
\text { respectively, in year t }\end{array}$ \\
\hline$\overline{D D}_{i j t}^{F}, \overline{D D}_{i j t}^{G}$ & $\begin{array}{l}\text { Minimum amount of domestic energy demanded by sector i in country } F \\
\text { and } G, \text { respectively, in year t }\end{array}$ \\
\hline$g_{i t}^{F}, g_{i t}^{G}$ & $\begin{array}{l}\text { Greenhouse gas emission in } \mathrm{CO}_{2}{ }^{\mathrm{e}} / \mathrm{MWh} \text { for each sector i in each country } \\
F \text { and } G, \text { respectively, in year t }\end{array}$ \\
\hline $\bar{G}_{t}^{F}, \bar{G}_{t}^{G}$ & $\begin{array}{l}\text { Maximum amount of greenhouse gas emissions allowed for each sector i } \\
\text { in each country } F \text { and } G, \text { respectively, in year t }\end{array}$ \\
\hline
\end{tabular}

\section{B. Cost Function}

It is assumed that the national energy planning agency of each country attempts to minimize the following objective function of national energy costs:

Total Energy Cost of France in year $t$

$$
=\sum_{i=1}^{M} \sum_{j=1}^{N}\left\{c_{i t}^{F} D S_{i j t}^{F}+p_{i t}^{F} I_{i j t}^{F}\right\} \quad \text { for all } t
$$

Total Energy Cost of Germany in year $t$

$$
=\sum_{i=1}^{M} \sum_{j=1}^{N}\left\{c_{i t}^{G} D S_{i j t}^{G}+p_{i t}^{G} I_{i j t}^{G}\right\} \quad \text { for all } t
$$

Each objective function is the sum of total the national costs of producing energy from all model domestic sources and foreign source in a given period of time. Previous studies have set up multi-year, least-cost optimization model in terms of present values of 
future costs. In our study, for simplicity, we simulate comparative static models for several years independently, by treating model parameters exogenous (for instance, costs, demands, capacity constraints, etc.). Our premise is that the future energy demand and supply are more driven mostly by exogenous factors such as population, national income, technology, and environmental regulations. Therefore, a series of static models with appropriate adjustments for exogenous changes in model parameters would suffice for evaluating our study objectives.

C. Constraints

1) GHG emission target

$$
\begin{gathered}
\sum_{i=1}^{M} \sum_{j=1}^{N}\left\{D S_{i j t}^{F}+I_{i j t}^{F}\right\} g_{i t}^{F} \leq \bar{G}_{t}^{F} \quad \text { for all } t \text { and France } \\
\sum_{i=1}^{M} \sum_{j=1}^{N}\left\{D S_{i j t}^{G}+I_{i j t}^{G}\right\} g_{i t}^{G} \leq \bar{G}_{t}^{G} \quad \text { for all } t \text { and Germany }
\end{gathered}
$$

Each country has a specific GHG emission target that it needs to respect in order to promote the Paris Accord. This constraint ensures that this target is met by forcing the model to keep the total GHG emissions lower than the target. For each year, the constraint will change based on the GHG emission target for each country, which strives to decrease.

2) Maximum supply constraint

$$
\begin{array}{lc}
\sum_{i=1}^{M} \sum_{j=1}^{N}\left\{D S_{i j t}^{F}+I_{i j t}^{F}\right\} \leq \bar{S}_{i t}^{F} & \text { for all } i, t \text { and France } \\
\sum_{i=1}^{M} \sum_{j=1}^{N}\left\{D S_{i j t}^{G}+I_{i j t}^{G}\right\} g_{i t}^{G} \leq \bar{S}_{i t}^{G} & \text { for all } i, t \text { and Germany }
\end{array}
$$


The maximum constraint guarantees that the total amount of energy $i$ supplied to all consumption sectors combined through domestic production and imports be lower than the total supply capacity for year $t$ in both countries. The constraint also ensures that the model does not call for unlimited shift to imports of certain high-carbon and low-cost energy sources instead of shift to renewable sources. The supply of fossil fuels and nuclear power is kept constant, while the supply of renewables (except hydropower) is set to increase based on the targets of share of renewable energy for each country.

3) Maximum domestic supply constraint

$$
\begin{array}{ll}
\sum_{i=1}^{M} \sum_{j=1}^{N} D S_{i j t}^{F} \leq \overline{D S}_{i t}^{F} & \text { for all } i, \mathrm{j} t \text { and France } \\
\sum_{i=1}^{M} \sum_{j=1}^{N} D S_{i j t}^{G} \leq \overline{D S}_{i t}^{G} & \text { for all } i, \mathrm{j} t \text { and Germany }
\end{array}
$$

Similarly, to the previous constraint, the maximum domestic supply constraint sets a maximum domestic supply capacity that the model should not surpass.

4) Minimum Demand Constraint

$$
\begin{aligned}
& \sum_{i=1}^{M}\left\{D S_{i j t}^{F}+I_{i j t}^{F}\right\} \geq \bar{D}_{j t}^{F} \quad \text { for all } j, t \text { and France } \\
& \sum_{i=1}^{M}\left\{D S_{i j t}^{G}+I_{i j t}^{G}\right\} \geq \bar{D}_{j t}^{G} \quad \text { for all } j, t \text { and Germany }
\end{aligned}
$$

The minimum demand constraint makes sure that the actual supply of energy to consumption sectors through domestic production and imports is higher than the minimum demand of these consumption sectors. 
5) Minimum Domestic Demand Constraint

$$
\begin{aligned}
& D S_{i j t}^{F} \geq \overline{D D}_{i j t}^{F} \quad \text { for all } i, j, t \text { and France } \\
& D S_{i j t}^{G} \geq \overline{D D}_{i j t}^{G} \quad \text { for all } i, j, t \text { and Germany }
\end{aligned}
$$

Similarly, to the previous constraint, the minimum domestic constraint ensures that domestic supply of energy to the consumption sectors is higher than the minimum demand in different types of energies $i$ to sectors $j$. This constraint ensures that there is no abrupt reduction in any energy supplied from each production sector to each consumption sector in a short amount of time.

6) Transportation Sector Constraint

$$
\begin{gathered}
\sum_{i=2,8}^{M}\left\{D S_{i, j=2, t}^{F}+I_{i, j=2, t}^{F}\right\} \geq \bar{D}_{j=2, t}^{F} \quad \text { for all } t \text { and France } \\
\sum_{i=2,8}^{M}\left\{D S_{i, j=2, t}^{G}+I_{i, j=2, t}^{G \leftarrow}\right\} \geq \bar{D}_{, j=2 t}^{G} \quad \text { for all } t \text { and Germany }
\end{gathered}
$$

The transportation sector is unique in that it will have difficulties transitioning to greener energies and that it is heavily reliant on oil, and some biofuel. To guarantee a minimum transportation fuel demand met, the model forces the transportation sector to draw a minimum amount of energy from these two resources.

7) Industry Sector Constraint

$$
\begin{gathered}
\sum_{i=7}^{M}\left\{D S_{i=7, j=1, t}^{F}+I_{i=7, j=1, t}^{F \leftarrow}\right\} \leq \bar{D}_{i=7, j=1, t}^{F} \quad \text { for all } j=2, t \text { and France } \\
\sum_{i=7}^{M}\left\{D S_{i=7, j=1, t}^{G}+I_{i=7, j=1, t}^{G \leftarrow}\right\} \leq \bar{D}_{i=7, j=1, t}^{G} \quad \text { for all } j=2, t \text { and Germany }
\end{gathered}
$$


Biomass is an energy that is usually used by households for heating and cooking purposes. In order to prioritize residential use, the industry sector constraint forces the model to supply a certain amount of biomass and not more to the industrial sector.

8) Service Sector Constraint

$$
\begin{array}{cc}
\sum_{i=2}^{M} D S_{i=7, j=4, t}^{F}+I_{i=7, j=4, t}^{F \leftarrow} \leq \bar{D}_{i=7, j=4, t}^{F} & \text { for all } j=2, t \text { and France } \\
\sum_{i=2}^{M} D S_{i=7, j=4, t}^{G}+I_{i=7, j=4, t}^{G \leftarrow} \leq \bar{D}_{i=7, j=4, t}^{G} & \text { for all } j=2, t \text { and Germany }
\end{array}
$$

The service sector constraint is similar to the previous constraint. The domestic biomass supplied to the service sector has no other substitute and hence the model ensures a minimum demand to be met for the said sector.

9) Non-Negativity Constraint

$$
D S_{i j t}^{F}, D S_{i j t}^{G}, Y_{j t}^{F \leftarrow}, Y_{j t}^{G \leftarrow}, \geq 0
$$

The non-negativity constraint simply states that none of the values obtained in this model are to be negative.

\subsection{Data Gathering and Analysis}

Energy balance sheets for the countries of France and Germany were obtained through the Eurostat database (Eurostat, 2017). The database provides information for different energy resources including the amounts of domestic production, imports, exports, gross inland consumption inputs and outputs to create derived heat and electricity, as well as available energy for final consumption. Furthermore, the 
information on the breakdown of their consumption between different sectors is also available. These data were obtained from years 1990 to 2015 for France, Germany, as well as the European Union. The energy sources chosen for this research were: solid fuels, oil, gas, hydro power, wind power, solar thermal and PV, solid biomass, biogas, biogasoline and biodiesel and nuclear heat. The portfolio of energies chosen gives a diversified choice of resources and focuses on the most used ones for these two nations. As mentioned before, these energy sources together represent 99 percent of total energy consumed in France and 98 percent in Germany in 2015. Fossil fuels are still an important portion of consumption and had to be represented. Similarly, nuclear heat makes up a large share of the energy portfolio for both countries. In terms of renewables, hydro power was accounted for, even though dams have usually a long process for construction and new infrastructure is less likely to appear. In contrast, wind power and solar power will take less time to put in place. Biomass is an energy that is used by many households, and biofuels are an important alternative to oil, especially in the transportation sector. In terms of demand sectors, industrial, residential, transportation, services and non-energy sectors were chosen. These consumption sectors represent 97 percent and almost 100 percent of France and Germany's consumptions, respectively. The first step after the data was extracted was to convert the existing data in kilotonne of oil equivalent to gigawatt per hour. The conversion rate used for this step was:

$$
1 \mathrm{ktoe}=11.63 \mathrm{GWh}
$$




\section{A. Electricity and Derived Heat Break Down}

Since the breakdown of electricity and indirect heat was not available in the worksheet, the computation had to be done in order to make sure to account for all energy types used at the end. Gross inland consumption was calculated by adding primary production with imports and subtracting exports from the total. The research performed in this paper does not account for possible exports for both countries. From the gross inland consumption of each energy type, a certain portion goes towards input to create derived heat, electricity and other products, while another portion goes directly to the final consumption. To calculate the electricity and derived heat by source type, the first step was to subtract transformation output from transformation input in order to get rid of any byproducts that were created and only focus on derived heat and electricity. Some fuels such as hydro power, wind power and a portion of solar were accounted in the Exchange, Transfers and Returns row, and directly produced electricity. The Total Transformation Input was calculated by adding each energy's inputs, as well as the Exchange, Transfers and Returns. After that, similarly, the total derived heat and electricity from transformation output as well as the one from Exchange, Transfers and Returns were summed to give a Total Transformation Output. This Total Transformation Output gives the total electricity and derived heat produced but does not yet account for losses.

The next step is to find the share of each type of energy within the total inputs.

Share of Input of Energy $i=\frac{\text { Input of energy } i}{\text { TOTAL TRANSFORMATION INPUT }} \times 100$ 
It is important to remember that when producing electricity, losses occur, therefore Total Transformation Output does not equal Total Available for Consumption. Since we were given the Total Available for Consumption of electricity and derived heat, and the Total Transformation Output is available as well, we can find the efficiency of electricity and derived heat production for both countries

$$
\text { Efficiency }=\frac{\text { TOTAL AVAILABLE FOR CONSUMPTION }}{\text { TOTAL TRANSFORMATION OUTPUT }} \times 100
$$

For France, the efficiency was found to be $75.31 \%$ while for Germany it was found to be $81.54 \%$. These percentage can be applied to each input of fuel in order to obtain the amount of energy used for electricity and derived heat for each source type. To spread these numbers to the different sectors of demand, the share of electricity and derived heat from the total available was calculated for each of the five sectors. The final step to obtain the final available for consumption numbers for each fuel type was to sum up the original total available with the numbers from electricity production by fuel type.

\section{B. Accounting for Trade}

In order to keep the model simple, exports were not taken into account in the presented research since they were a small portion of the total energy production in most cases. However, imports were explicitly considered since they can supply additional fuels for each energy type and significantly contribute to GHG targets. For exports, the same percentages of electricity and derived heat production were used, and the results were subtracted from the total gross inland consumption. For imports, the same steps for 
finding shares of energy types towards electricity and derived heat production were used, however Total European numbers were used, as we would expect electricity and derived heat imports to come from different countries within the European Union. Additionally, we noted that gas and oil sources had a unique situation and needed to be treated different. Even though their domestic productions were fairly low, we noticed that a high amount of gas and oil was still exported. Since pipelines go through the countries and therefore distribution of gas and oil were reported as both an import and an export even if the country in question did not use it. Therefore, the exports of both countries were subtracted from their imports, meaning that we assumed that all domestic production went towards the country's own consumption and that their exports of oil and gas were zero.

We have now a new Gross Inland Consumption which accounts for the imports and the domestic production for each country by fuel type, as well as the electricity and derived heat production by fuel type. The next step was to break down this Gross inland consumption into the different consumption sectors. The same ratio from consumption by sector compared to total available for consumption was used in order to do so

$$
\text { Final GIC for sector } j=\frac{\text { Final Energy Consumption Sector } j}{\text { Total Available for Consumption }} \times \text { Updated Gross Inland Consumption }
$$

The share of domestic production for each energy type was also calculated using the following formula:

$$
\text { Domestic production share }=\frac{\text { Primary production-exports }}{\text { Gross inland consumption }} \times 100
$$


From this calculation, the GWh from primary production for each fuel were obtained for each demand sector.

\section{Levelized Cost of Electricity}

The levelized cost of electricity (LCOE) coefficients were obtained thanks to multiple reports, such as the International Energy Agency Electricity Information report, which listed LCOE for multiple countries. Levelized cost refers to the unit cost of an asset over the lifetime electricity generating capacity of that asset. When data for one or the other country were unavailable, a conversion factor was used. In order to do so, a comparison of electricity plants existing in both countries was used, and a ratio was obtained by comparing average price difference for these plants. It was found that average LCOE of French power plants was on average 106.5\% more expensive than the same power plants in Germany. Additionally, since most of the costs were not for 2015, a GDP deflator was used to calculate the net present value. Here listed are the final levelized cost of electricity that were used for France and Germany:

Table 2 lists the final LCOE of energy that were used for France and Germany. The production costs indicated below correspond to the average production costs incurred by an investor throughout the economic life of his installation. They depend in particular on the following parameters:

- investment costs (excluding connection): equipment, civil engineering, contingencies, dismantling; 
- operating and maintenance costs including fuel costs when purchased (which is not the case, for example, with the wind or the sun);

- the discount rate, which is the expected rate of return that could be obtained by investing the same capital elsewhere;

- the level of production: the following data will be given "reasonably favorable" conditions;

- the economic life of the plant.

Table 2: Levelized Cost of Electricity (LCOE) in 2018 US\$/ MWh

\begin{tabular}{cccccccccc}
\hline & $\begin{array}{c}\text { Anthracite } \\
\text { and } \\
\text { Lignite }\end{array}$ & Oil & Gas & $\begin{array}{c}\text { Hydro } \\
\text { Power }\end{array}$ & $\begin{array}{c}\text { Wind } \\
\text { Power }\end{array}$ & $\begin{array}{c}\text { Solar } \\
\text { Thermal } \\
\text { and PV }\end{array}$ & $\begin{array}{c}\text { Solid } \\
\text { Biomass }\end{array}$ & $\begin{array}{c}\text { Biogas, } \\
\text { Biogasoline } \\
\text { and } \\
\text { Biodiesel }\end{array}$ & Nuclear \\
\hline Germany & 79 & 512 & 107 & 112 & 112 & 117 & 86 & 90 & 82 \\
France & 83 & 478 & 100 & 112 & 112 & 117 & 86 & 90 & 85 \\
\hline
\end{tabular}

D. Greenhouse Gas Coefficients and Targets

The greenhouse gas emissions were available from the World Nuclear Association's report (WNA, 2011), with lowest, highest and mean values. These numbers were expressed in tonnes $\mathrm{CO} 2$ equivalent per gigawatt hour. Table 3 shows all the greenhouse gas emissions per source. 
Table 3: Greenhouse Gas Coefficients in Tonnes $\mathrm{CO}_{2}$ e / GWh

\begin{tabular}{|c|c|c|c|c|c|c|c|c|c|}
\hline Resource & $\begin{array}{l}\text { Anthracite } \\
\text { and } \\
\text { lignite }\end{array}$ & Oil & Gas & $\begin{array}{l}\text { Hydro } \\
\text { power }\end{array}$ & $\begin{array}{l}\text { Wind } \\
\text { power }\end{array}$ & $\begin{array}{l}\text { Solar } \\
\text { thermal } \\
\text { and PV }\end{array}$ & $\begin{array}{l}\text { Solid } \\
\text { Biomass }\end{array}$ & $\begin{array}{l}\text { Biogas, } \\
\text { biogasoline } \\
\text { and bio } \\
\text { diesel }\end{array}$ & Nuclear \\
\hline Germany & 971 & 733 & 499 & 26 & 26 & 88 & 45 & 90 & 29 \\
\hline France & 971 & 733 & 499 & 26 & 26 & 88 & 45 & 90 & 29 \\
\hline
\end{tabular}

In order to gather these data, the mean values for greenhouse gas emissions were used. For anthracite and lignite, we used an average of both sources. For biogas, the greenhouse gas coefficient was computed by dividing the total amount of greenhouse gas in Germany coming from biogas (O’Connor, 2011) by the total GWh used.

Since each country has specific greenhouse gas target, and that these targets are based on 1990 consumption levels, the same computations as above were performed on the 1990 data for both countries to calculate the greenhouse gas emissions level in that basis year. Following, the table 4 lists the greenhouse gas emission targets in tonnes $\mathrm{CO}_{2} \mathrm{e}$ for both nations between 2015 to 2050 , which were derived from their reduction goals. 
Table 4: Greenhouse Gas Targets for France and Germany in tonnes of $\mathrm{CO}_{2} \mathrm{e}$

\begin{tabular}{lllll}
\hline Country & 2015 & 2020 & 2025 & 2030 \\
\hline France & $964,950,675$ & $877,253,166$ & $767,596,520$ & $657,939,874$ \\
& & & & \\
Germany & $2,196,117,315$ & $1,699,350,479$ & $1,486,931,669$ & $1,274,512,859$
\end{tabular}

E. Forecasting for LCOE, Demand and Capacity

1) $\mathrm{LCOE}$

Estimation for France future's demand was based on the ADEME Energy

Transition Scenario Report (Vidalenc, Meunier and Topper, 2013), which gave

projections for the future demand of Transportation, Industry, Service, Residential. Nonenergy was not included in the report therefore we applied the same growth rate as the industrial sector.

Levelized Cost Of Electricity future estimation was based on the CE Delft report “Cost-effective share bioenergy 2030", which listed the percent reduction of LCOE between 2015 and 2030 (Warringa, Schep, Afman and Bruyn, 2016). For wind, offshore and onshore values were averaged. Similarly, for solar, thermal and PV values were also averaged. For biogas, bio gasoline and biodiesel, the value for biofuels was used. For non-renewable energies, a $2 \%$ price increase per year was applied, using an average cost inflation (Eurostat, 2018). For hydropower, since it is less likely for countries to build 
dams because of the cost and time needed, a 1\% price increase was applied. Following are the estimated future LCOEs.

Table 5: Future LCOE for France in $\$ /$ GWh

\begin{tabular}{|c|c|c|c|c|c|c|c|c|c|}
\hline & Anthracite & & & & & Solar & & Biogas, bio & \\
\hline & and & Oil & Gas & & & thermal & & gasoline and & \\
\hline & lignite & & & power & power & and PV & B1 & biodiesel & Nuclear \\
\hline 2015 & 83,000 & 478,049 & 100,000 & 112,000 & 112,000 & 117,000 & 86,000 & 143,840 & 85,000 \\
\hline 2020 & 91,639 & 527,804 & 110,408 & 117,713 & 100,800 & 100,035 & 81,127 & 135,210 & 93,847 \\
\hline 2025 & 101,177 & 582,739 & 121,899 & 123,718 & 89,600 & 83,070 & 76,253 & 126,579 & 103,615 \\
\hline 2030 & 111,707 & 643,391 & 134,587 & 130,029 & 78,400 & 66,105 & 71,380 & 117,949 & 114,399 \\
\hline
\end{tabular}

Table 6: Future LCOE for Germany in $\$$ / GWh

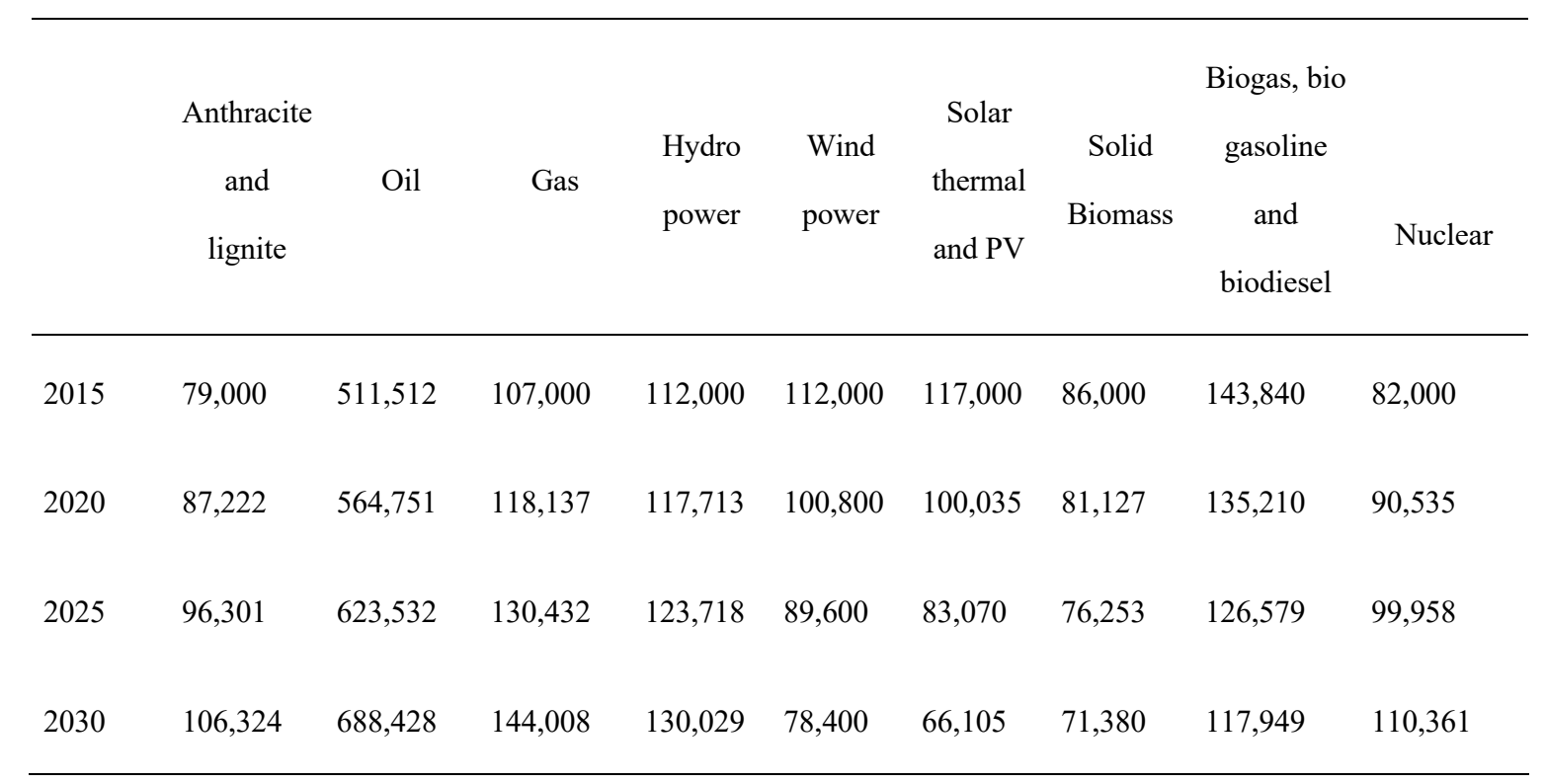




\section{2) Demand}

We estimated future energy demands using two sources: the ADEME study

(Vidalenc, Meunier and Topper, 2013) for France and the Enerdata study (Hafner, 2017) for Germany. These studies gave the evolution for demand of different sectors. For the non-energy sector which there was no available information for, the same percent change in future demand as for the industry was assumed for lack of better information.

Table 7: Future Sector Demand for France in GWh

\begin{tabular}{ccccc}
\hline & 2015 & 2020 & 2025 & 2030 \\
\hline Industry & 630,672 & 616,482 & 602,611 & 589,053 \\
Transport & 816,466 & 777,684 & 740,744 & 705,559 \\
Residential & 601,895 & 561,267 & 523,382 & 488,054 \\
Services & 162,930 & 156,413 & 150,156 & 144,150 \\
Non-Energy & 584,191 & 571,047 & 558,199 & 545,639 \\
Total Demand & $2,796,155$ & $2,670,328$ & $2,550,164$ & $2,435,406$ \\
\hline
\end{tabular}

Table 8: Future Sector Demand for Germany in GWh

\begin{tabular}{ccccc}
\hline & 2015 & 2020 & 2025 & 2030 \\
\hline Industry & $1,047,678$ & $1,020,409$ & 993,850 & 967,982 \\
Transport & 803,294 & 753,848 & 707,446 & 663,900 \\
Residential & 854,457 & 797,792 & 744,886 & 695,487 \\
Services & 614,555 & 610,159 & 605,795 & 601,461 \\
Non-Energy & 265,707 & 258,791 & 252,056 & 245,495 \\
Total Demand & $3,585,692$ & $3,461,937$ & $3,342,454$ & $3,227,095$ \\
\hline
\end{tabular}




\section{3) Capacity}

It was important to also account for future changes in capacity, especially for renewables. In order to do so, we used the renewable share target for France ( $23 \%$ by $2020,32 \%$ by 2030$)$ and Germany ( $60 \%$ by 2050$)$ (European Commission) and increased the domestic production capacity accordingly. The fossil fuels and nuclear heat capacities were kept constant for the model as the productions from these sources were expected to be reduced and keeping them constant would not affect the model results. For hydro power, the supply was also kept constant since the chances of new dams being built in the model's time frame is small.

Table 9: Future Domestic Production Capacity for France in GWh

\begin{tabular}{ccccc}
\hline & 2015 & 2020 & 2025 & 2030 \\
\hline Solid fuels & 103,417 & 103,417 & 103,417 & 103,417 \\
Oil & 852,053 & 852,053 & 852,053 & 852,053 \\
Gas & 387,443 & 387,443 & 387,443 & 387,443 \\
Hydro Power & 51,049 & 51,049 & 51,049 & 51,049 \\
Wind power & 20,144 & 53,785 & 61,414 & 68,248 \\
Solar Thermal and & 8,016 & 21,402 & 24,438 & 27,157 \\
PV & & & 335,709 & 373,064 \\
Solid Biomass & 110,111 & 294,005 & 124,096 & 137,905 \\
$\quad \begin{array}{c}\text { Biogas, } \\
\text { Biodiesel }\end{array}$ & 40,703 & 108,680 & & \\
$\begin{array}{c}\text { Nuclear heat } \\
\text { Biogaline and }\end{array}$ & $1,223,220$ & $1,223,220$ & $1,223,220$ & $1,223,220$ \\
\hline
\end{tabular}


Table 10: Future Domestic Production Capacity for Germany in GWh

\begin{tabular}{ccccc}
\hline & 2015 & 2020 & 2025 & 2030 \\
\hline Solid fuels & 882,860 & 882,860 & 882,860 & 882,860 \\
Oil & $1,254,666$ & $1,254,666$ & $1,254,666$ & $1,254,666$ \\
Gas & 777,372 & 777,372 & 777,372 & 777,372 \\
Hydro Power & 19,537 & 19,537 & 19,537 & 19,537 \\
Wind power & 76,023 & 118,730 & 157,956 & 193,981 \\
Solar Thermal and & 44,753 & 69,893 & 92,984 & 114,192 \\
PV & & & 290,094 & 356,257 \\
Solid Biomass & 139,621 & 218,053 & 247,394 & 303,819 \\
$\quad \begin{array}{c}\text { Biogas, } \\
\text { Biogasoline and }\end{array}$ & 119,070 & 185,957 & & \\
Biodiesel & & & 271,790 & 2,790 \\
\hline \begin{tabular}{l} 
Nuclear heat \\
\hline
\end{tabular}
\end{tabular}

\section{4_ Scenarios}

Three main scenarios were performed thanks to this model in order to generate alternative results. The first scenario performed was a policy stimulation one, with the goal of promoting a decrease in GHG emissions in order to meet the Paris Accord targets, as well as a decrease in sectorial demand. The second scenario was a business as usual (BAU) scenario, where demand and GHG total emissions were kept at the 2015 level. The last scenario performed was the cost of carbon scenario, where we aimed to find the cost to remove a tonne of carbon with different GHG levels. 


\section{A. Policy Stimulation Scenario}

The current research starts with the policy stimulation scenario, model that runs in the years 2015,2020, 2025 and 2030. For these years, demands were estimated thanks to two studies: for Germany, the Enerdata study written by Hafner (2017) was used, while for France the ADEME study of 2013 was applied. Both of these studies provided 2030 sectorial demands by share of total consumption. For the non-energy sector, which was not listed in these research papers, the same rate as the industrial sector was applied. This scenario is the main one for this research as it promotes the idea that an energy transition is doable, and that conservation and efficiency will not only reduce GHG emissions but will also cut costs.

\section{B. Business as Usual (BAU) Scenario}

The second set of scenarios that were performed did not include any changes in demand nor any GHG emission constraints over time, in order to compare how the total energy cost and GHG emissions would evolve. We kept the demand and the GHG emissions at the 2015 level, while increasing the capacity in the same way as we did in the policy stimulation scenario. The scenario presented is fundamental as it shows how costs and GHG emissions will evolve if no action plan is put in place in order to mitigate climate change.

\section{Cost of Carbon Scenario}

For the baseline year of 2015, the model was run by applying different slacks to the greenhouse gas emissions constraints until the model could not find a solution. For France, the model was run at $100 \%, 95 \%, 90 \%$, and finally $86 \%$. For Germany, the 
model was run at $100 \%, 97.5 \%, 95 \%$ and $94.5 \%$. These last scenarios are crucial to evaluate the impact and efficiency of the current GHG emissions for the 2015 level: if the marginal cost of removing an additional tonne of carbon is low, it means the country can still reduce its target without facing major costs and without making major technological changes. If the cost is high, it means that the country is already closest to the least-cost optimal energy mix for the given emission target. 


\section{CHAPTER 4}

\subsection{Results}

\section{A. Policy Stimulation Scenario}

\section{1) Results for France for the Policy Stimulation Scenario}

Below are the tables that show the results for the country of France when running the policy stimulation scenario.
a) Demand by Sector

Table 11 shows the sectorial demand for energy for France for different years.

Table 11: France Demand by Sector in GWh

\begin{tabular}{ccccc}
\hline & 2015 & 2020 & 2025 & 2030 \\
\hline Industry & 584,191 & 571,047 & 558,199 & 545,639 \\
Transport & 630,672 & 616,482 & 602,611 & 589,053 \\
Residential & 816,466 & 777,684 & 740,744 & 705,559 \\
Services & 601,895 & 561,267 & 523,382 & 488,054 \\
Non-Energy & 162,930 & 156,413 & 150,156 & 144,150 \\
Total Demand & $2,796,155$ & $2,682,894$ & $2,575,092$ & $2,472,454$ \\
\hline
\end{tabular}


Figure 6: France Demand by Sector in GWh

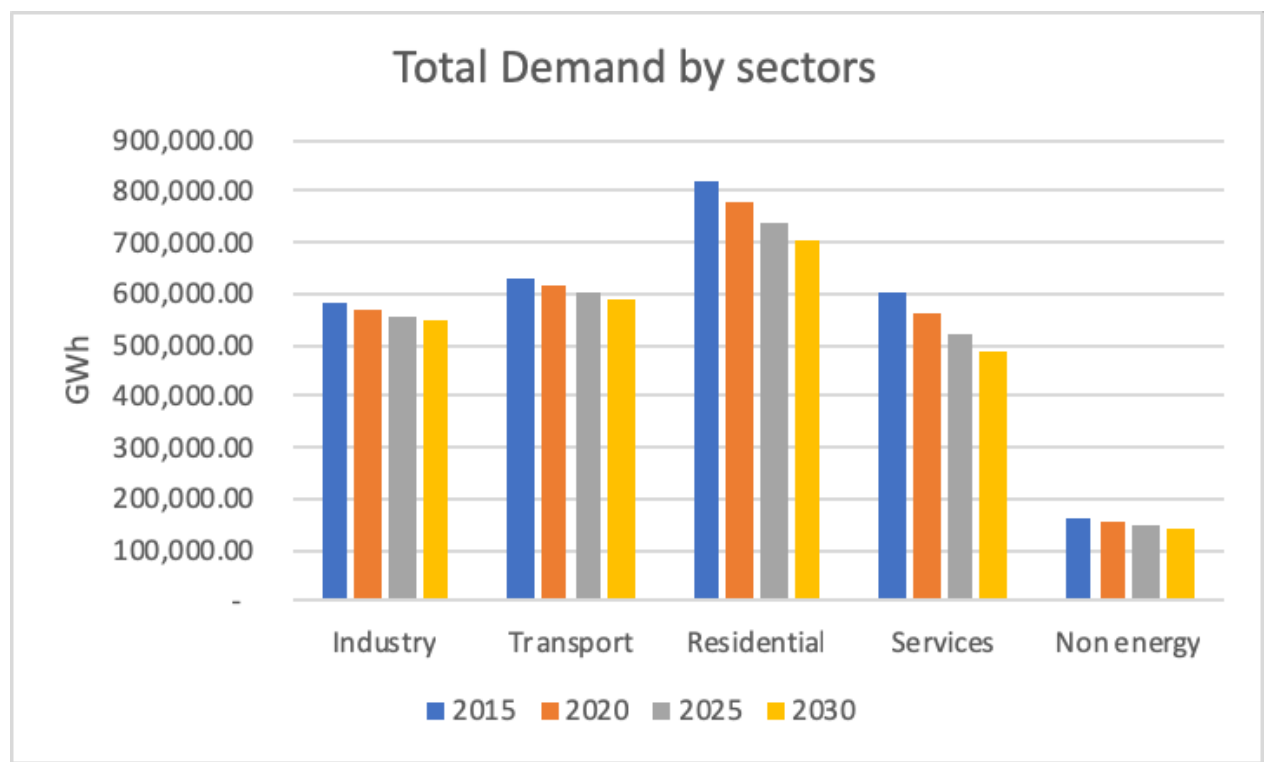

Table 11 and figure 6 present optimal combination of energy demand for France. As we can observe, some sectors are set to decrease in demand faster than others, such as the residential sector, but overall, we have a decreasing trend. The optimal total energy consumption will decrease from 2,796,155 GWh in 2015 to 2,472,454 GWh in 2030 (Table 11), which is an almost $12 \%$ reduction. It is important to note that by design sectors such as transportation or non-energy will have more difficulties transitioning to renewables and are still dependent heavily on fossil fuels. Overall, the decreasing trend can be explained by conservation efforts, but also by improvements in technologies that will increase efficiency. 
b) Domestic Production by Energy Type

Table 12 shows France's domestic production until 2030 for different energy types.

Table 12: France Domestic Production by Energy Type in GWh

\begin{tabular}{|c|c|c|c|c|}
\hline & 2015 & 2020 & 2025 & 2030 \\
\hline \multicolumn{5}{|l|}{ Solid fuels } \\
\hline Oil & 12,576 & 12,576 & 12,576 & 12,576 \\
\hline Gas & 222 & 185 & 177 & 170 \\
\hline Hydro Power & 56,154 & 43,367 & 41,305 & 39,355 \\
\hline Wind power & 22,158 & 59,163 & 67,556 & 75,073 \\
\hline Solar Thermal and & 8,817 & 23,542 & 26,882 & 29,873 \\
\hline \multicolumn{5}{|l|}{ PV } \\
\hline Solid Biomass & 121,123 & 323,405 & 366,670 & 349,727 \\
\hline Biogas, & 39,115 & 104,439 & 119,254 & 132,523 \\
\hline \multicolumn{5}{|l|}{ Biogasoline, } \\
\hline \multicolumn{5}{|l|}{ Biodiesel } \\
\hline Nuclear Heat & $1,312,284$ & $1,312,284$ & $1,312,284$ & $1,211,341$ \\
\hline Total Domestic & $1,572,448$ & $1,878,961$ & $1,946,703$ & $1,850,638$ \\
\hline Production & & & & \\
\hline
\end{tabular}


Figure 7: France Domestic Production in GWh

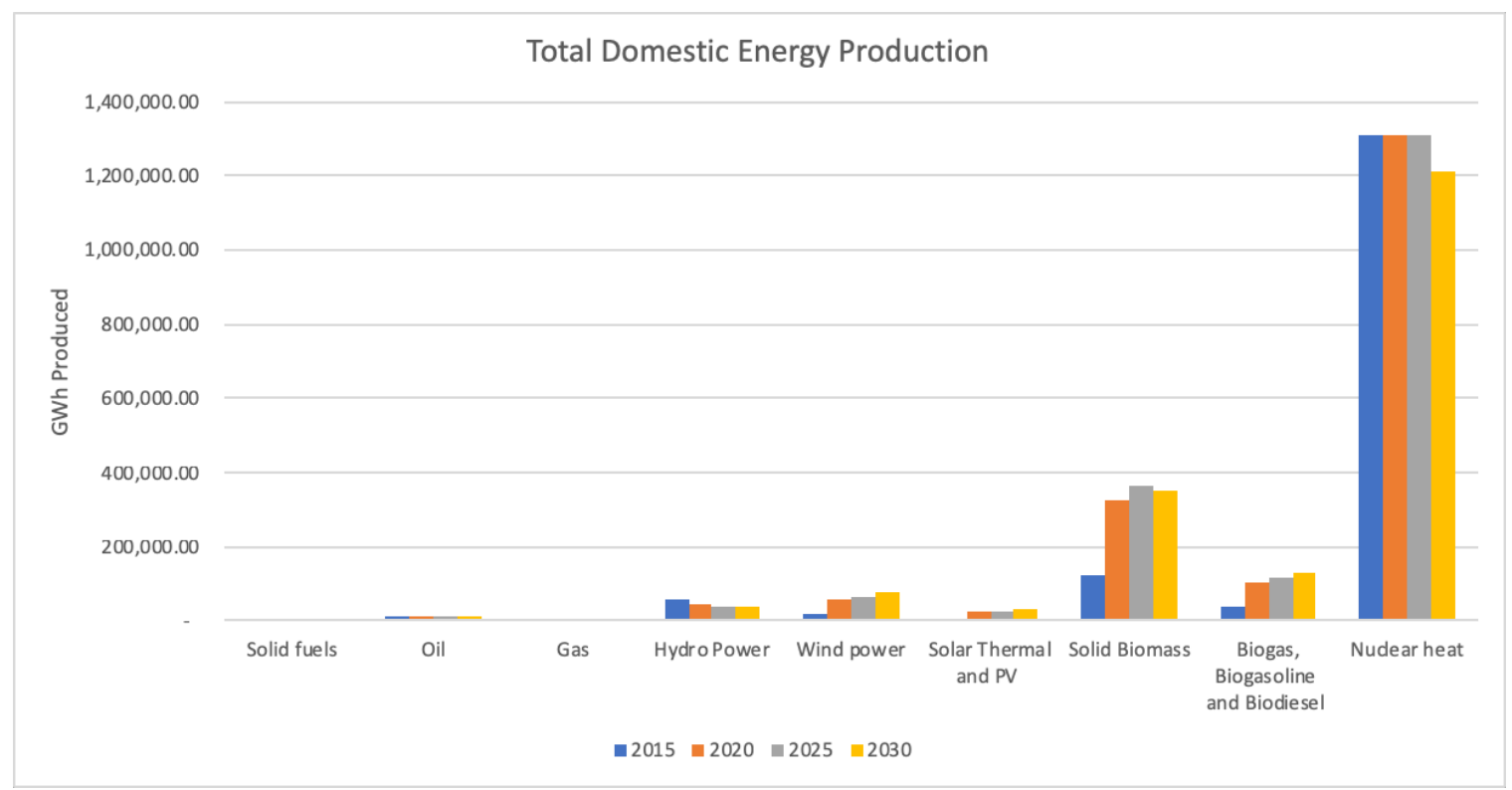

As we can observe from table 12 and figure 7, the total domestic energy supply will increase from 1,572,448 GWh in 2015 to $1,850,6378$ in 2018. In total, the domestic supply will observe an increase of $18 \%$ percent during the model period. Wind power, solar power and biofuels are the sectors that are expected to increase the most (over $300 \%$ ). Hydro power on the other hand is the sector that is expected to decrease the most (a reduction in almost 30\%) due to its increase in price, and the fact that it is not as needed as fossil fuels. France energy portfolio in terms of production was, and will continue to be, restricted to certain energy types, especially nuclear power. The country barely produces any fossil fuels, meaning that they will need to import these resources in order to meet the demand. The country produces some renewables at an increasing proportion, and even though they are not comparable to nuclear power. It is important that even though the country produces high amounts of nuclear energy, this type of 
energy goes towards electricity production, and therefore, cannot supply demand of the non-energy sector.

c) Total Energy Consumption by Energy Type for France

Following is table 13 listing total energy consumed by energy types for France in thousands GWh until 2030.

Table 13: France Total Energy Consumption

\begin{tabular}{|c|c|c|c|c|}
\hline & 2015 & 2020 & 2025 & 2030 \\
\hline Solid fuels & 318 & 187 & 43 & 10 \\
\hline Oil & 709 & 615 & 578 & 545 \\
\hline Gas & 170 & 0 & 0 & 0 \\
\hline Hydro Power & 56 & 43 & 41 & 39 \\
\hline Wind power & 22 & 59 & 68 & 75 \\
\hline Solar Thermal and & 9 & 24 & 27 & 30 \\
\hline \multicolumn{5}{|l|}{ PV } \\
\hline Solid Biomass & 121 & 323 & 369 & 410 \\
\hline Biogas, & 45 & 120 & 137 & 152 \\
\hline \multicolumn{5}{|l|}{ Biogasoline, } \\
\hline \multicolumn{5}{|l|}{ Biodiesel } \\
\hline Nuclear Heat & 1,346 & 1,312 & 1,312 & 1,211 \\
\hline
\end{tabular}


Total Domestic

2,796

2,683

2,575

2,472

Production

Figure 8: France Total Energy Consumption

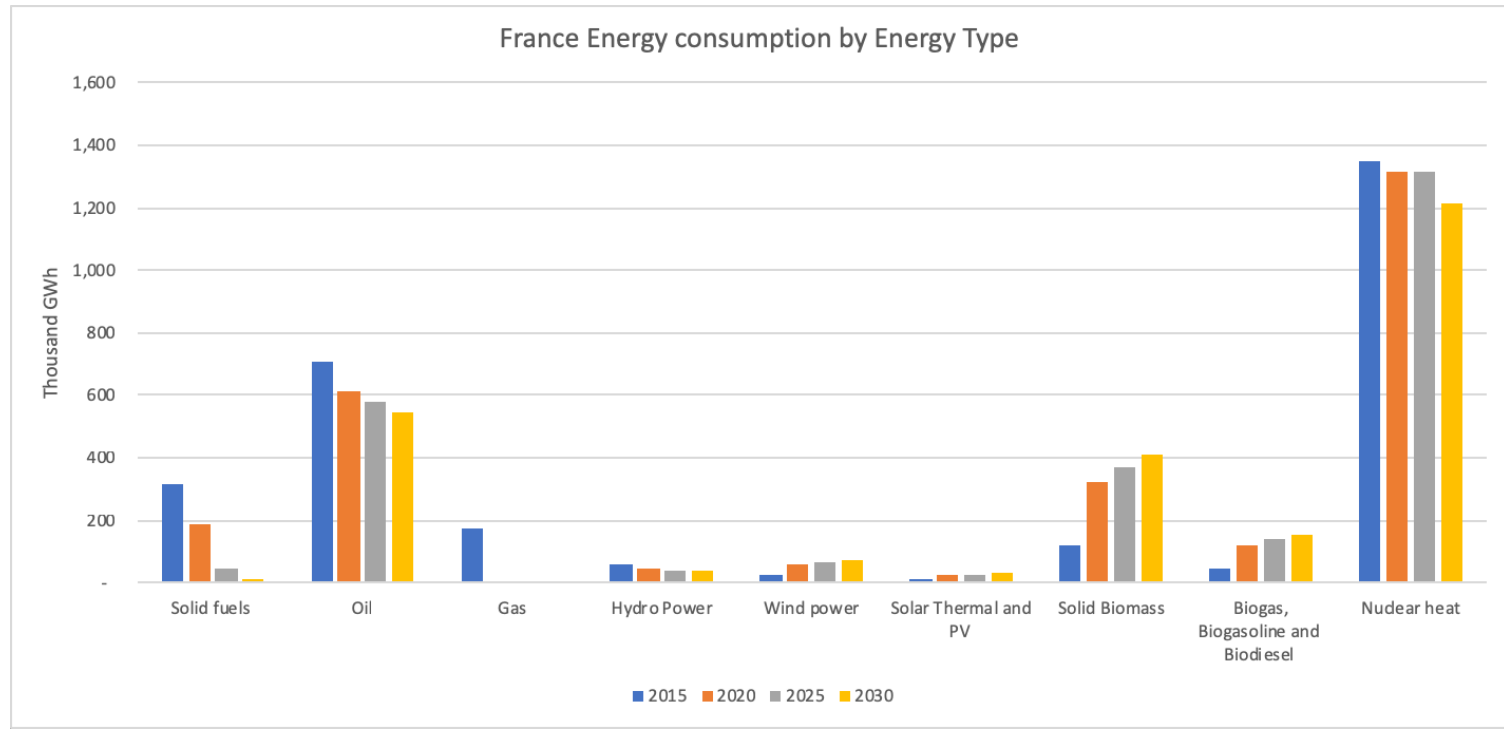

As it can be noticed, France's energy consumption varies to some extent by 2030 . Indeed, it can be observed that fossil fuels decrease significantly, especially solid fuels and gas. This can be explained not only by the fact that these resources are very high in $\mathrm{CO}_{2}$ emissions, but also because France does produces very low amount of fossil fuels, meaning that they need to import the needed resources, which add up to be costly. Oil does decrease in amount; however, it is still very high which can be explained by the reliance on this resource of the transport sector. It is notable that the biofuel sector increases, giving the opportunity to substitute some of the oil demand. Nuclear still represents a high portion of the consumption, mainly due to its low GHG coefficient. However, you can see a decrease throughout the years which can be explained by a lower demand but also a higher price. In terms of renewables, there is a slight increase for all 
sectors except the hydropower one (due to its increase in price). This increase is slow because of all the minimum demand constraints inputted, in order to guarantee a smooth and stable transition.

d) Energy Consumption Mix for France

Following are graphical representations of the energy mixes for France for the future years that the model was run.

Figure 9: Energy Consumption Mix for France in 2015

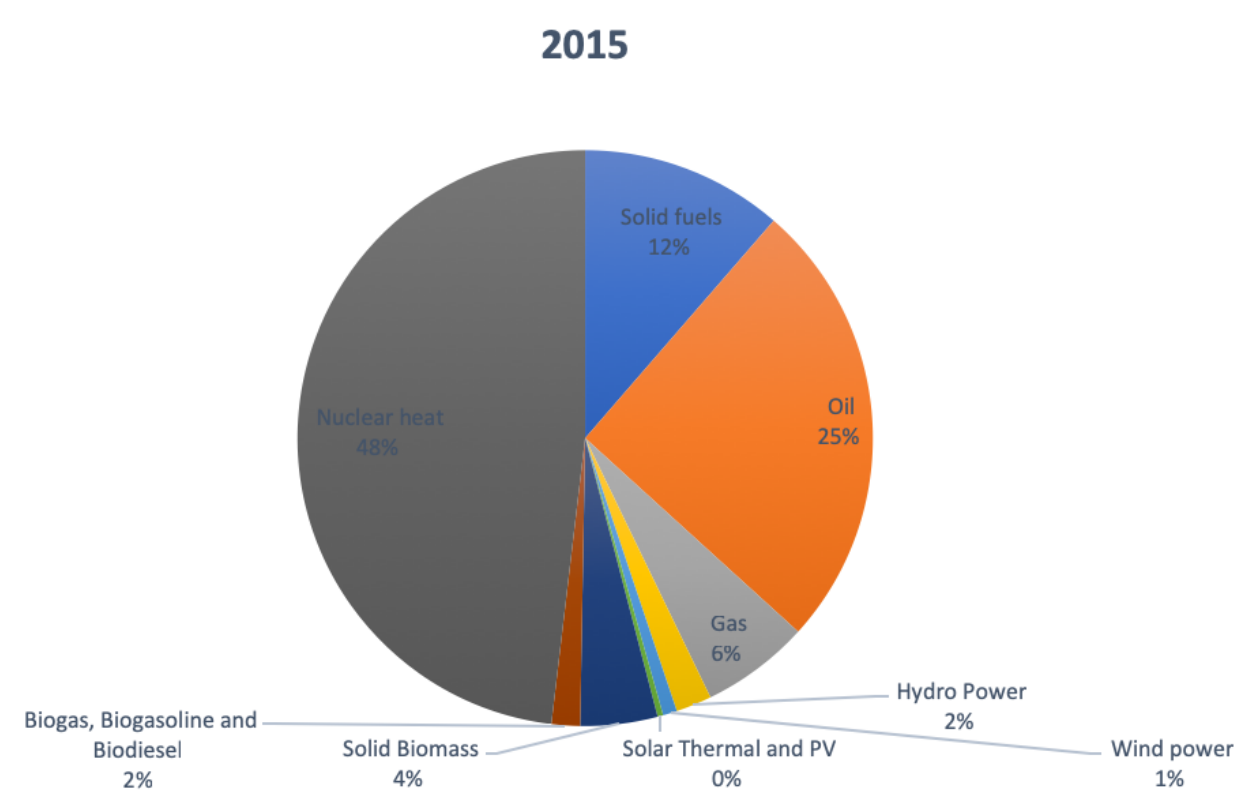


Figure 10: Energy Consumption Mix for France in 2020

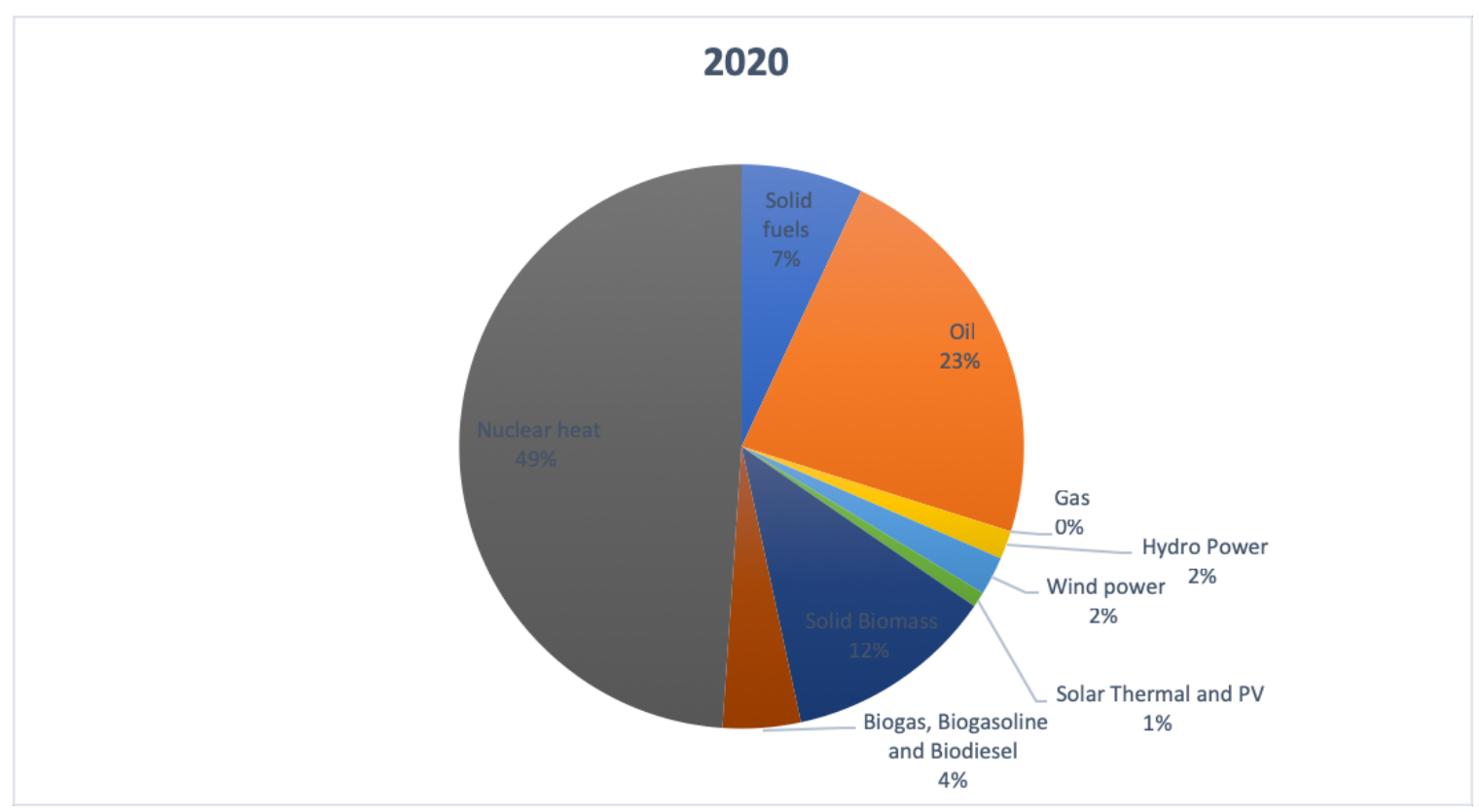

Figure 11: Energy Consumption Mix for France in 2025

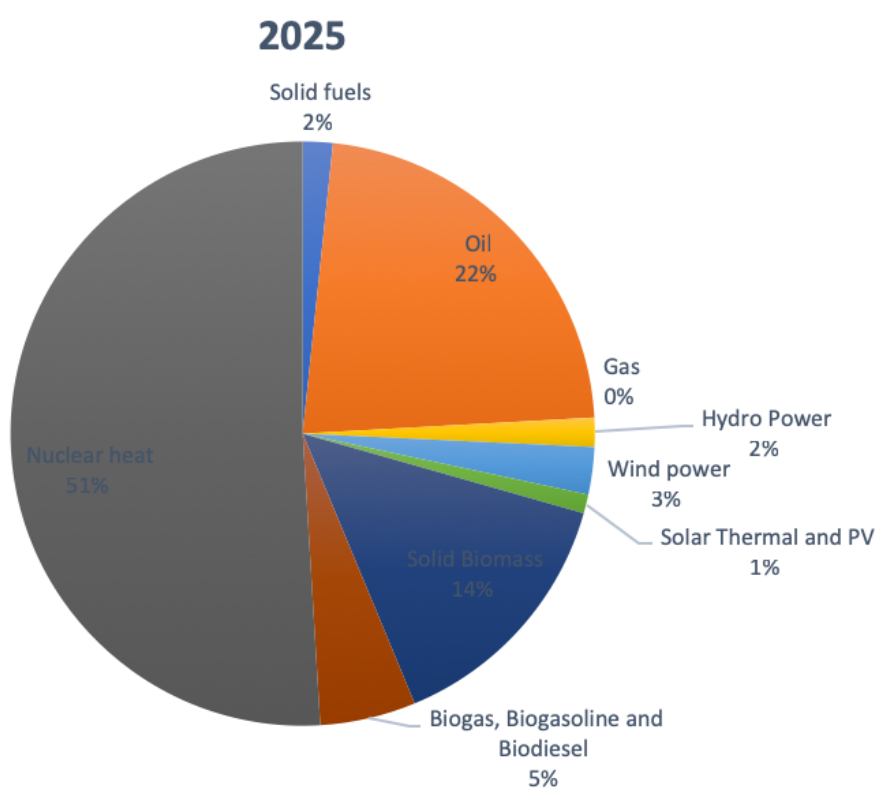


Figure 12: Energy Consumption Mix for France in 2030

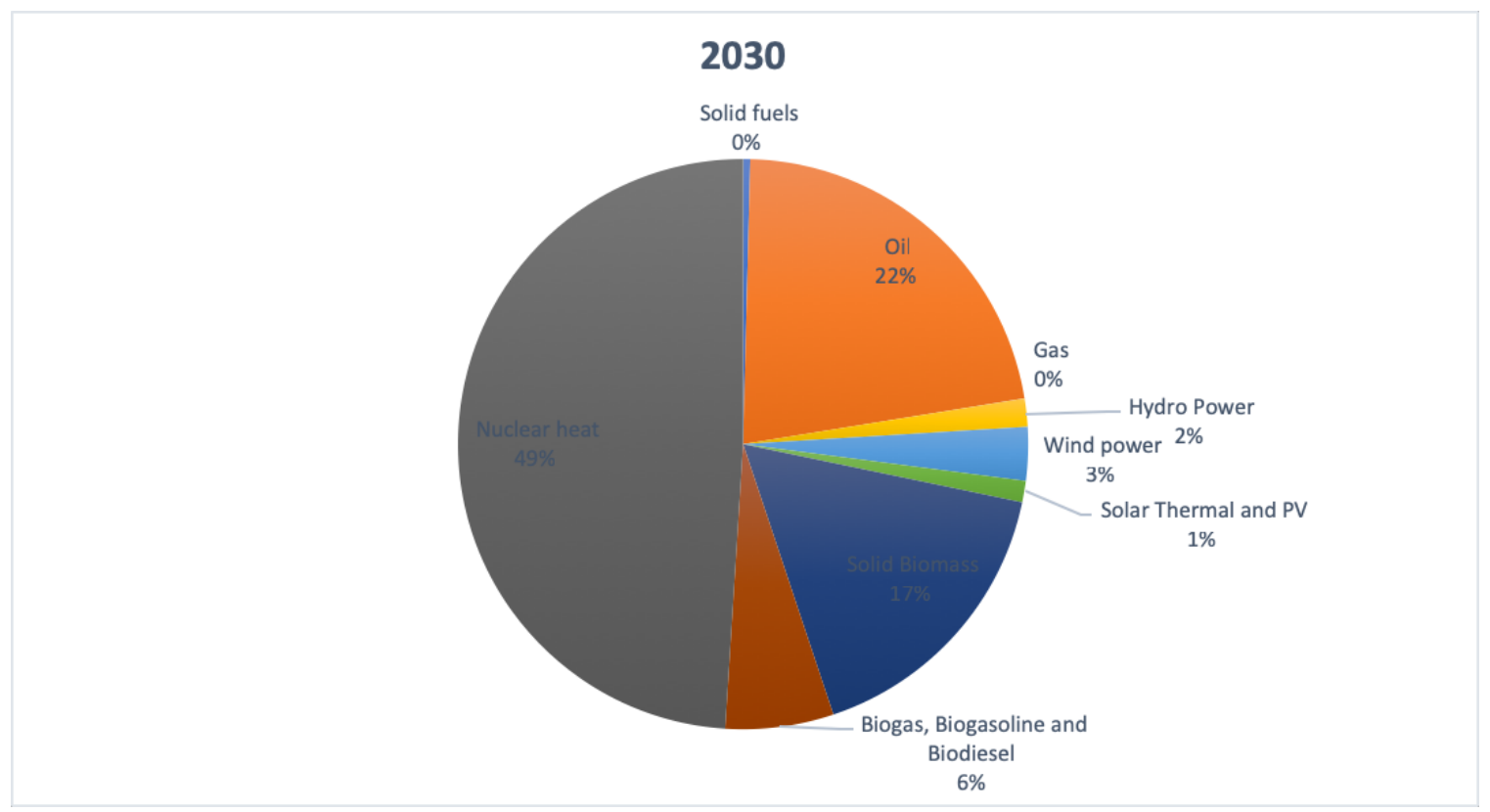

As it can be observed, in 2015 fossil fuels and nuclear represent over $80 \%$ of

France's energy consumption, while for 2030, they represent less than $75 \%$. Even though this is not an immense change, we are focused on a smooth and durable transition. From the Figures 9 to 12, both solid fuels and gas are taken out of the energy mix, which is great since they produce high GHG emissions. However, oil still represents about a quarter of the energy mix, even by 2030 . This is due to the fact that the transport sector is so reliant on this type of energy. In terms of renewables, their overall consumption and production increases, except for hydropower (because of its cost increase). Wind power increases by $2 \%$, solar continues to represent about $1 \%$ of the consumption mix, biogas increase from 2 to $6 \%$, while solid biomass manages to increase from 4 to $17 \%$, mainly because of its low emissions, rather low cost and high use in residential. 
e) Total Cost and Total GHG emissions

Following is Table 14 showing total cost and total GHG emissions for France until 2030.

Table 14: France Total Cost and GHG Emissions in Millions Dollars and tonnes $\mathrm{CO}_{2} \mathrm{e}$

\begin{tabular}{ccccc}
\hline & 2015 & 2020 & 2025 & 2030 \\
\hline $\begin{array}{c}\text { Total Cost in } \\
\text { Millions }\end{array}$ & 561,451 & 554,175 & 569,851 & 585,249 \\
Total GHG in & & & & \\
Millions & 965 & 700 & 538 & 482 \\
\hline
\end{tabular}

Figure 13:France Total Cost and GHG Emissions in Millions Dollars and tonnes CO2e

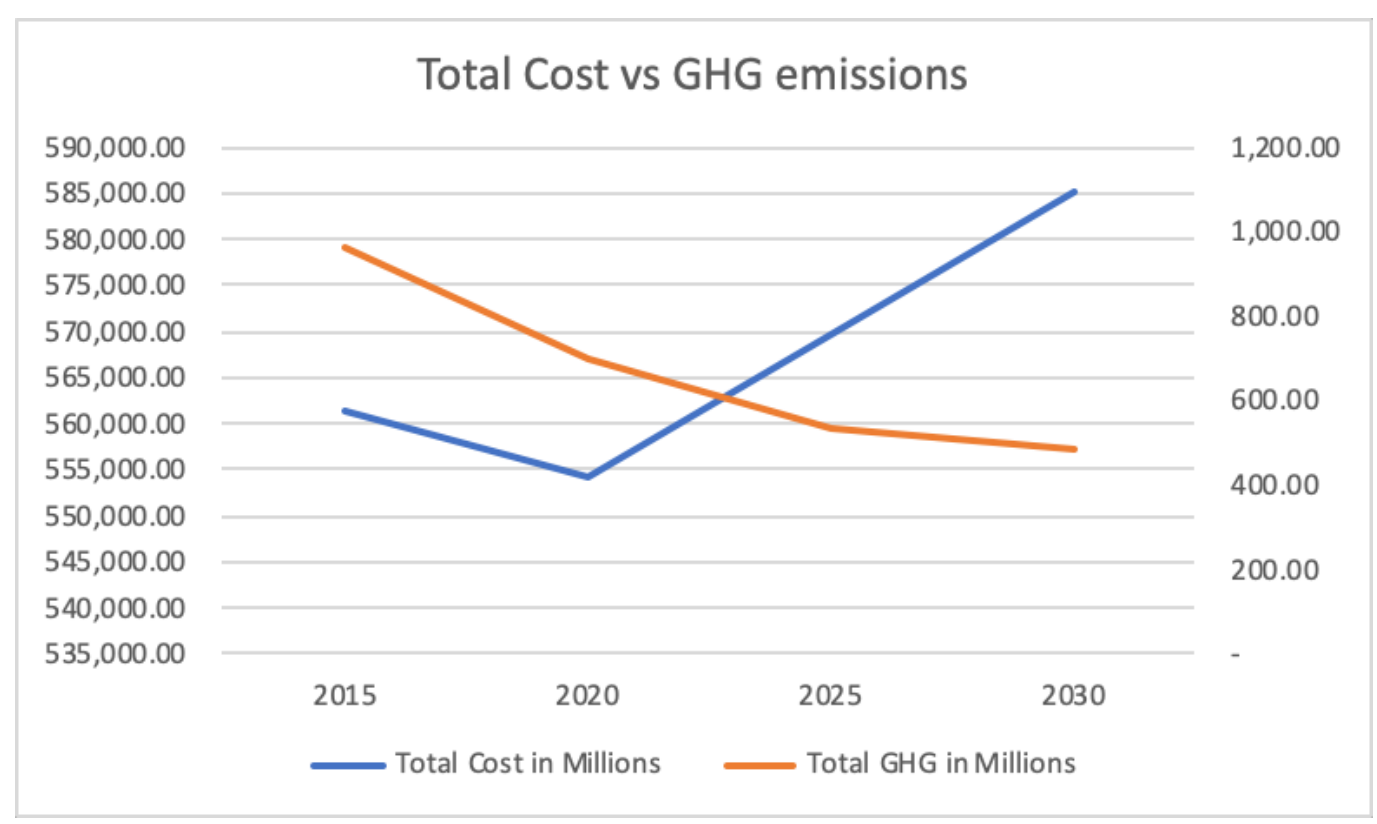


Table 14 and figure 13- show the total cost of energy consumed and the total GHG emitted. As expected, GHG emissions go down since we imposed constraints to meet the GHG targets throughout the years and as required by the Paris Climate Accord. In terms of costs, we do see a decrease at first in 2020, which can be explained by the fact that demand has decreased while costs have increased slightly for fossil fuels and nuclear. However, after that costs will increase due to the fact that prices of the fossil fuels and nuclear energy increase, and France still has to meet a minimum demand of these energies for some sectors such as transport. Since France does not produce any fossil fuels, it has to import them which costs additional money for the nation.

\section{f) Total Demand and Total Cost}

Following is Table 15 showing total demand and total cost for France until 2030.

Table 15: France Total Demand and Total Cost in Millions GWh and Dollars

\begin{tabular}{lcccc}
\hline & 2015 & 2020 & 2025 & 2030 \\
\hline $\begin{array}{c}\text { Total Cost in } \\
\text { Millions }\end{array}$ & 561,451 & 554,175 & 569,851 & 585,249 \\
$\begin{array}{c}\text { Total Demand in } \\
\text { Millions }\end{array}$ & 2.80 & 2.68 & 2.58 & 2.47 \\
\hline
\end{tabular}


Figure 14: France Total Demand and Total Cost in Millions GWh and Dollars

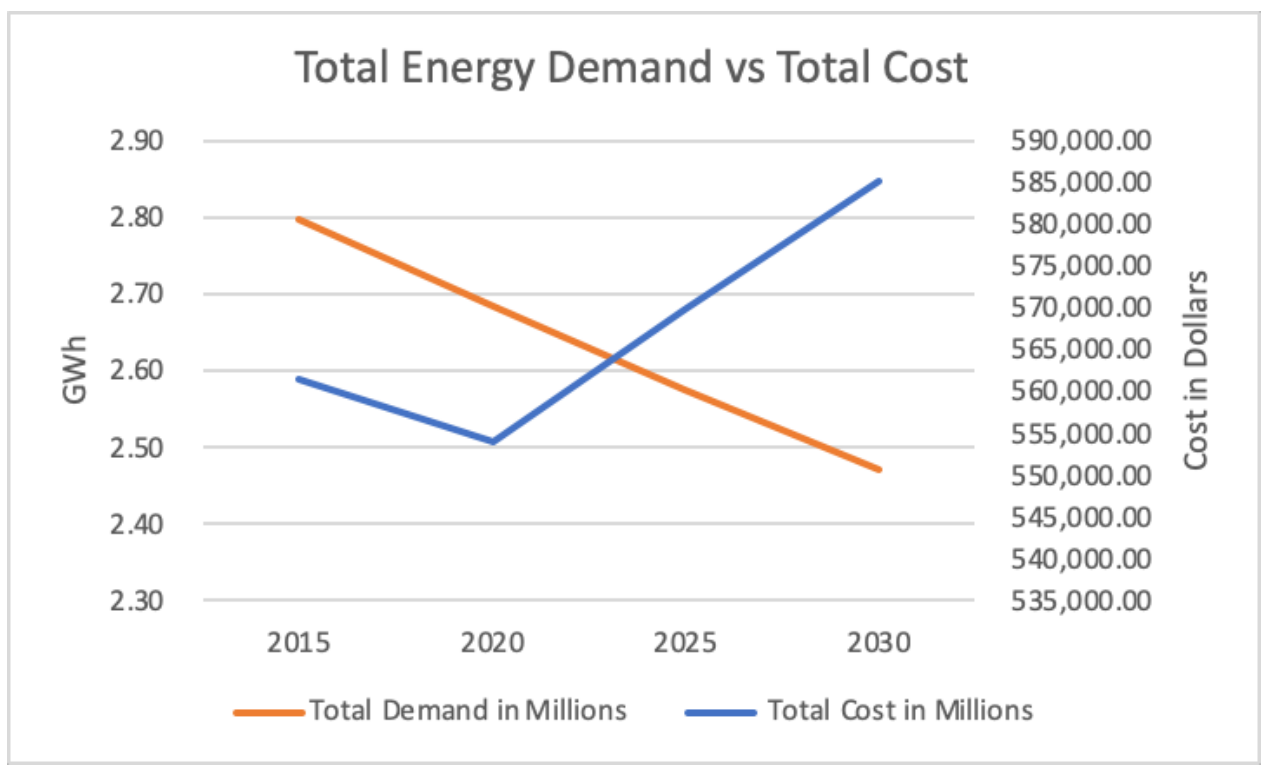

As mentioned earlier, demand is set to decrease throughout the years, which can be explained by not only conservation actions put in place, but also by increased efficiency that allows technologies to use less energy for the same output level. As demand starts decreasing for 2020, the total costs decrease as well simply because of a smaller need of energy resources. However, with increased costs of fossil fuels and nuclear source, which still make up a larger portion of France's consumption portfolio, the overall costs will increase for the future years. We would expect a transition that switches automatically to renewables, however such a plan is not realistic. Indeed, an adaptation time, where fossil fuels are still present while renewables increase is needed.

\section{a. Results for Germany for the Policy Stimulation Scenario}
a) Demand by Sector

Table 16 lists the demand by sectors for Germany until 2030 . 
Table 16: Germany Demand by Sector in GWh

\begin{tabular}{ccccc}
\hline & \multicolumn{2}{c}{2015} & 2025 & 2030 \\
Industry & $1,047,678$ & $1,020,409$ & 993,850 & 967,982 \\
Transport & 803,294 & 753,848 & 707,446 & 663,900 \\
Residential & 854,457 & 797,792 & 744,886 & 695,487 \\
Services & 614,555 & 610,159 & 605,795 & 601,461 \\
Non-Energy & 265,707 & 258,791 & 252,056 & 245,495 \\
Total Demand & $3,585,692$ & $3,441,001$ & $3,304,032$ & $3,174,327$ \\
\hline
\end{tabular}

Figure 15: Germany Total Demand by Sector in GWh

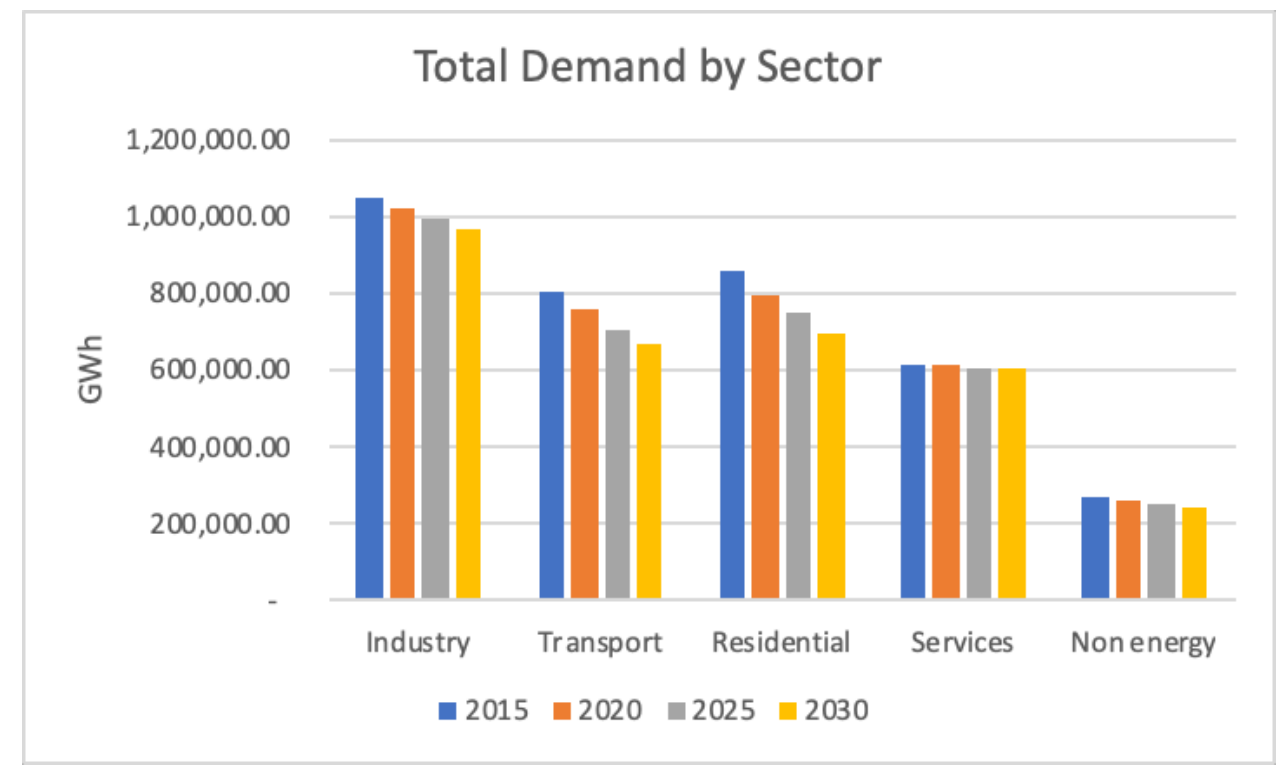

Similarly to France, Germany will have an overall decreasing trend when it comes to sectoral demand, but the decreases are in different sectors compared to France's case. Unlike France, Germany sees a large decrease in its transport sector, meaning that they 
will have to find alternatives for petroleum to power vehicles. Unlike France, the services sector does not decrease a lot, and so doesn't the non-energy sector.

b) Domestic Production by Energy Type

Table 17 depicts Germany's domestic energy production under the policy stimulation scenario.

Table 17: Germany Domestic Production by Energy Type in GWh

\begin{tabular}{|c|c|c|c|c|}
\hline & 2015 & 2020 & 2025 & 2030 \\
\hline Solid fuels & 500,135 & 500,135 & 311,893 & 377,912 \\
\hline Oil & 42,055 & 42,055 & 42,055 & 42,055 \\
\hline Gas & 73,677 & 73,677 & 73,677 & 73,677 \\
\hline Hydro Power & 20,875 & 18,977 & 18,976 & 18,977 \\
\hline Wind power & 83,626 & 123,700 & 164,569 & 202,103 \\
\hline Solar Thermal and & 49,228 & 72,671 & 96,681 & 118,731 \\
\hline \multicolumn{5}{|l|}{ PV } \\
\hline Solid Biomass & 153,583 & 219,076 & 291,455 & 357,929 \\
\hline Biogas, & 130,977 & 200,807 & 267,150 & 328,080 \\
\hline \multicolumn{5}{|l|}{ Biogasoline and } \\
\hline \multicolumn{5}{|l|}{ Biodiesel } \\
\hline Nuclear heat & 275,358 & 275,358 & 275,358 & 275,358 \\
\hline
\end{tabular}


Figure 16: Germany Domestic Production in GWh

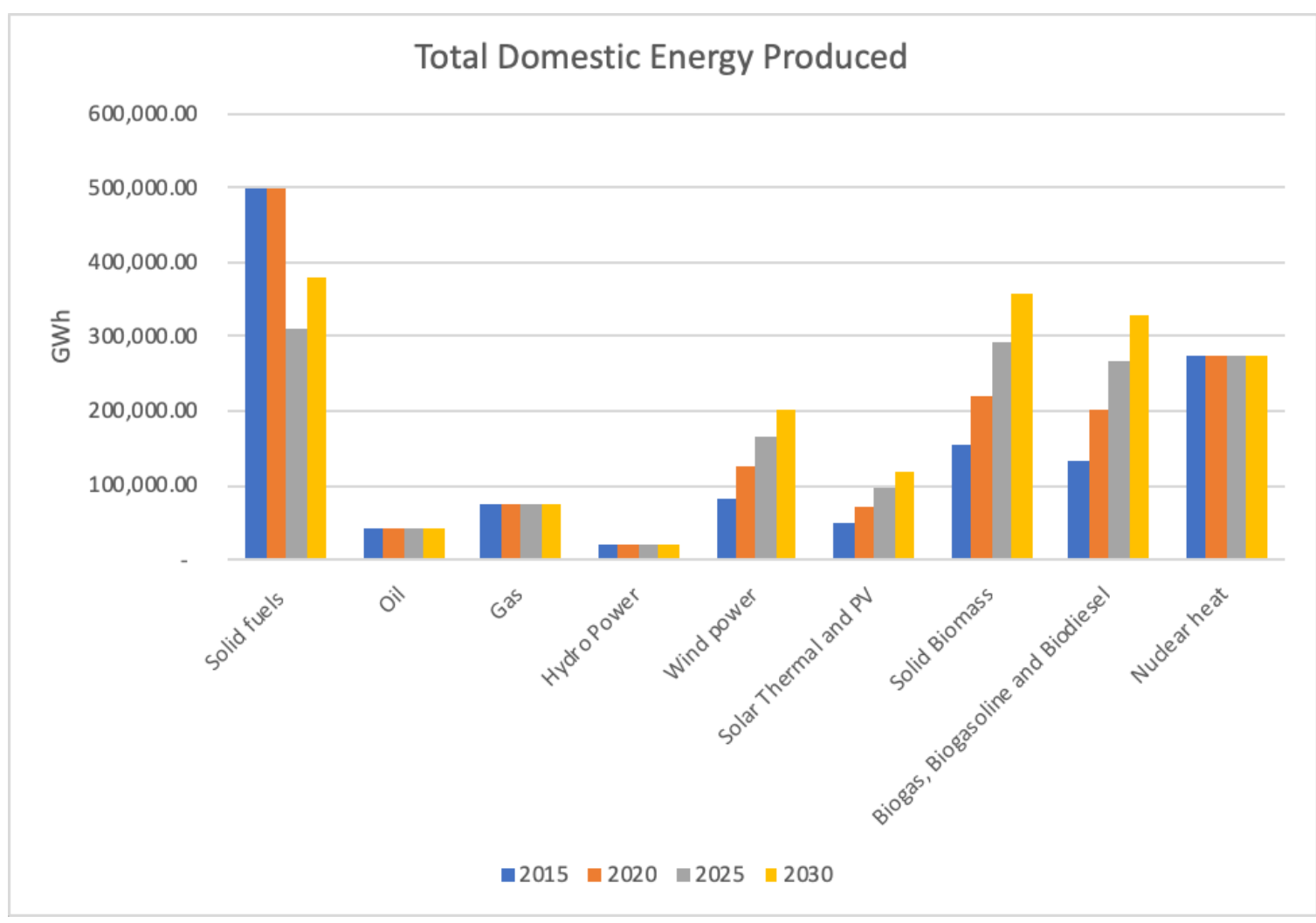

As we can observe from this graphic, Germany has a much more diversified portfolio than France does since it does produce quite some fossil fuels. On top of that, Germany is known to be a pioneer country when it comes to renewables and has been heavily investing in them (Beveridge and Kern, 2013), especially after the Energiewende program they put in place a few years ago. Even though there are many political initiatives to close nuclear plants by 2022 in Germany (Drmota, 2017), we decided to keep the supply constant (for both countries) in order to guarantee a smooth transition, since nuclear power is known to have very low GHG emissions. The domestic production 
portfolio of Germany is more optimal than France's because it produces a minimum level of each type of energy, meaning that they do not have to import as much as France does.

c) Total Energy Consumption by Energy Type for Germany

Table 18: Germany Total Energy Consumption

\begin{tabular}{|c|c|c|c|c|}
\hline & 2015 & 2020 & 2025 & 2030 \\
\hline Solid fuels & 1,085 & 877 & 312 & 378 \\
\hline Oil & 993 & 738 & 951 & 557 \\
\hline Gas & 787 & 855 & 855 & 855 \\
\hline Hydro Power & 21 & 21 & 21 & 21 \\
\hline Wind power & 84 & 131 & 174 & 213 \\
\hline Solar Thermal and & 49 & 77 & 102 & 126 \\
\hline \multicolumn{5}{|l|}{ PV } \\
\hline Solid Biomass & 154 & 240 & 319 & 392 \\
\hline Biogas, & 131 & 205 & 272 & 334 \\
\hline \multicolumn{5}{|l|}{ Biogasoline, } \\
\hline \multicolumn{5}{|l|}{ Biodiesel } \\
\hline Nuclear Heat & 299 & 601 & 879 & 848 \\
\hline Total Domestic & 3,603 & 3,744 & 3,877 & 3,725 \\
\hline Consumption & & & & \\
\hline
\end{tabular}


Figure 17: Germany Total Energy Consumption

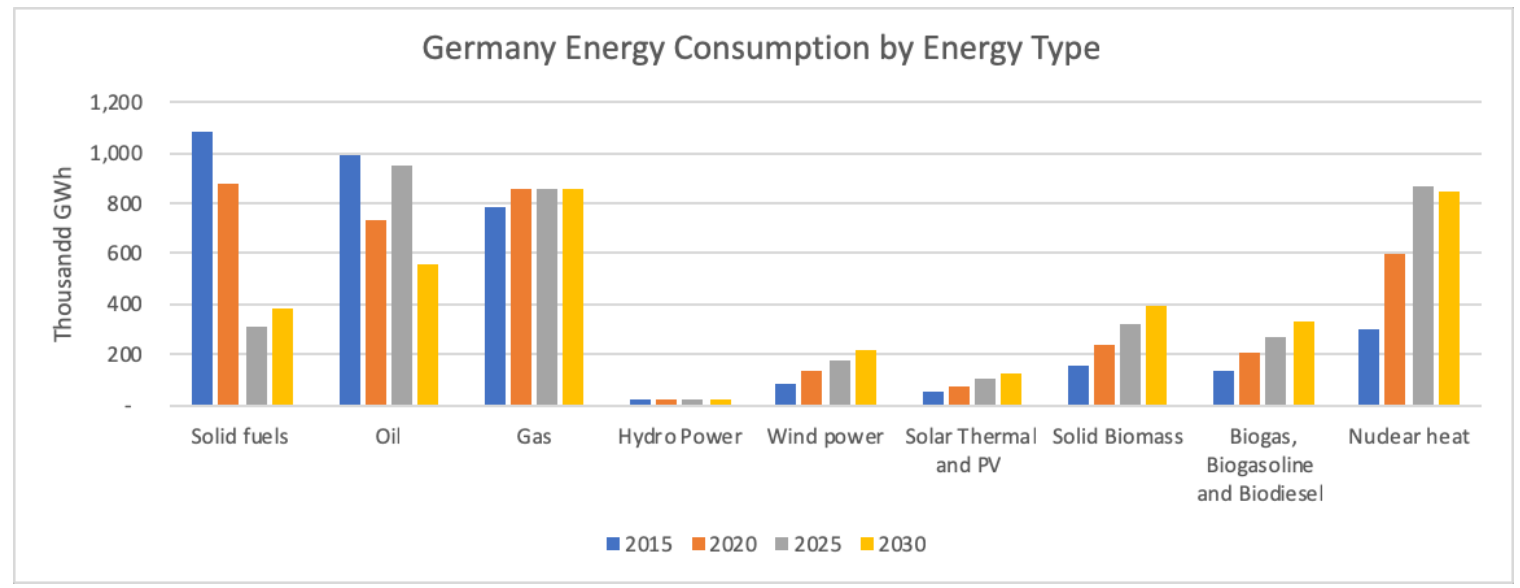

As it can be noticed on this graph, there is an overall decline for Germany when it comes to fossil fuels. Indeed, solid fuels are reduced dramatically, and so is oil consumption. For some reason, the model supplies large amounts of gas in order to meet demand. It is also important to point out that nuclear power increases throughout the years, which can be explained by its low GHG coefficient. In terms of renewables, all of them increase except hydro power, Solid biomass and biogas increase the most, which is good since biomass has a low GHG emissions, and biofuels can be used to replace oil.

d) Energy Consumption Mix for Germany 
Figure 18: Energy Consumption Mix for Germany in 2015

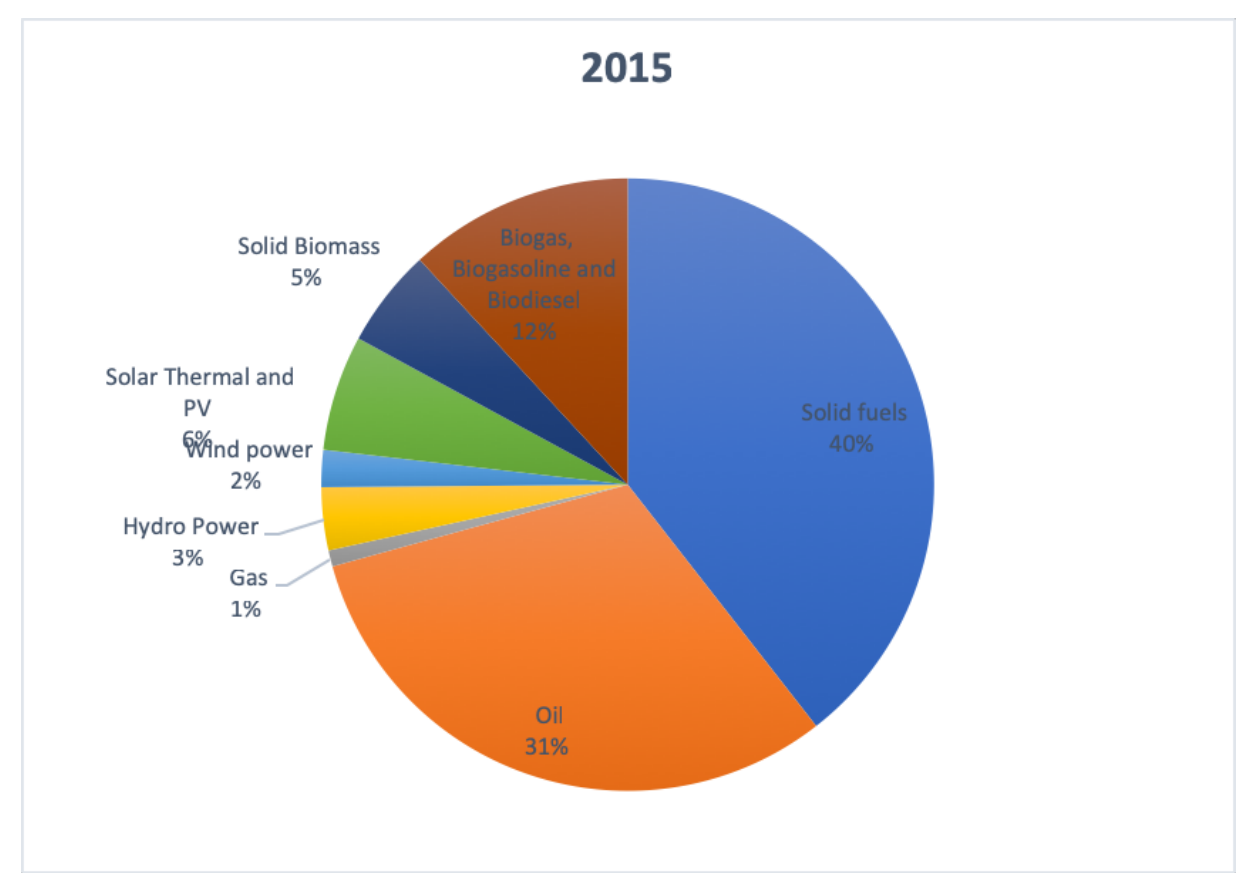

Figure 19: Energy Consumption Mix for Germany in 2020

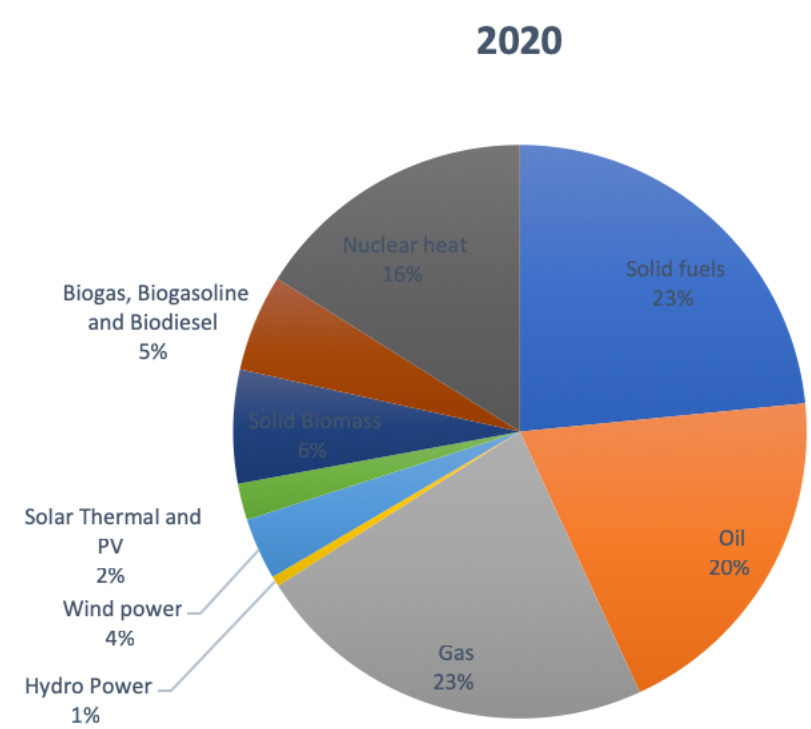


Figure 20: Energy Consumption Mix for Germany in 2025

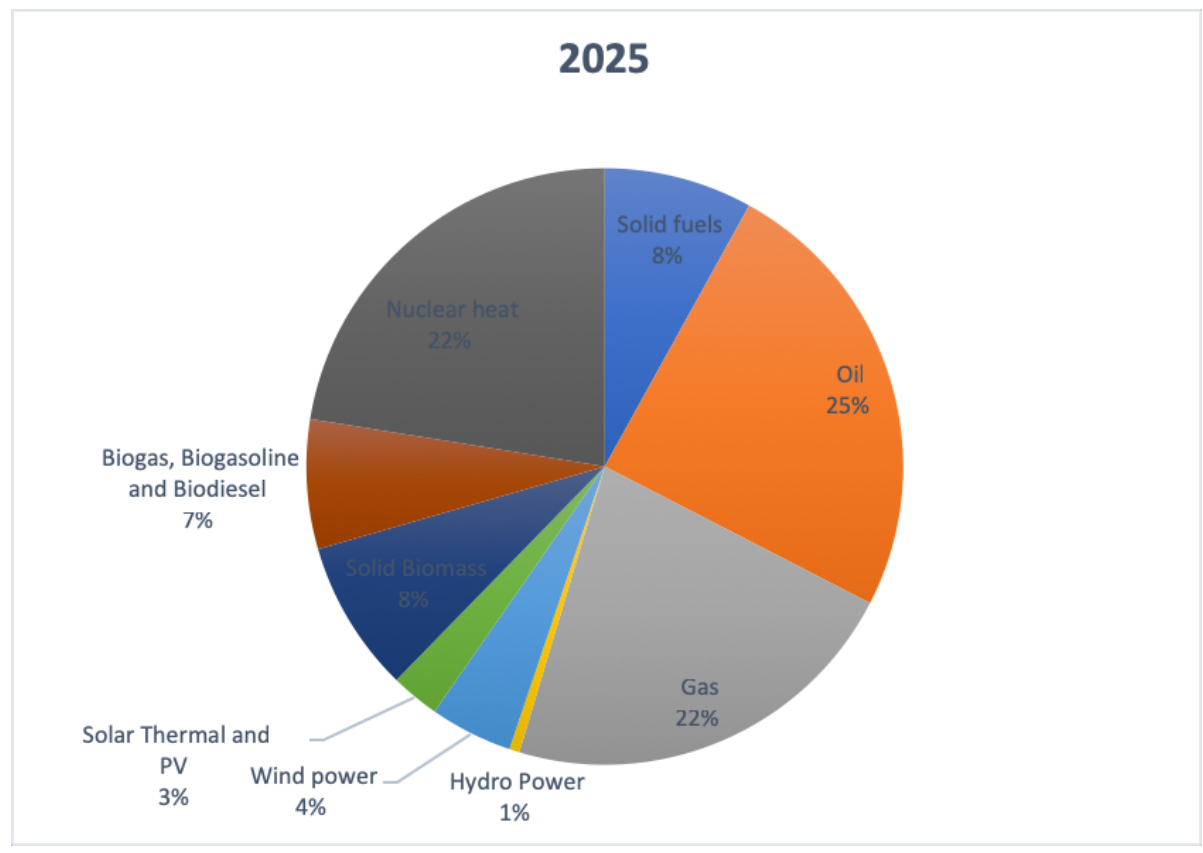

Figure 21: Energy Consumption Mix for Germany in 2030

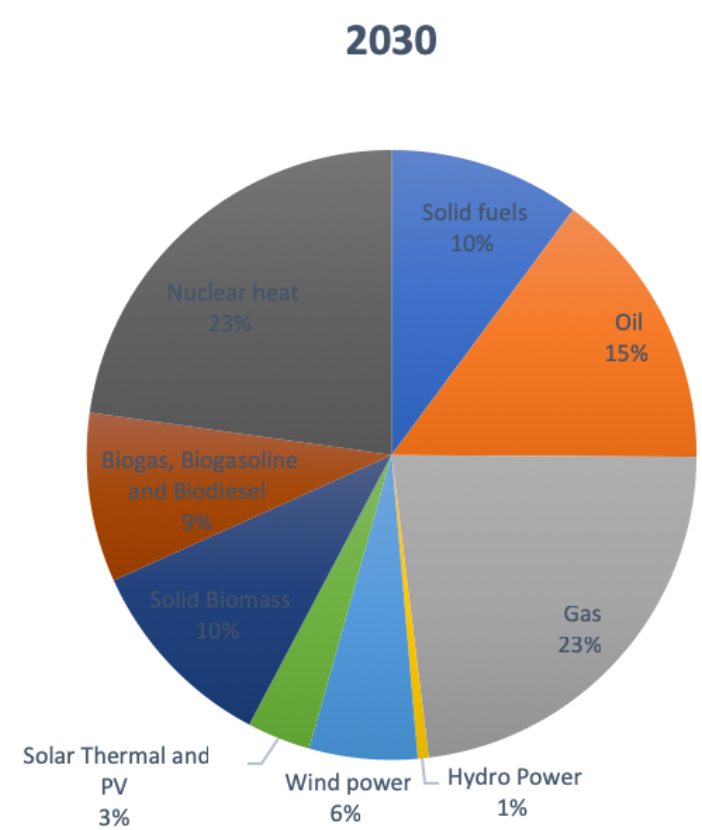


As it can be observed throughout these graphs, the share of fossil fuels decreases highly throughout the model years. The only fossil fuel that does not decrease as mentioned earlier, is gas. Nuclear increases in proportion, and ends up representing $23 \%$ of the consumption mix by 2030. Additionally, all renewables increases and start representing a more important share of the energy mix.

e) Total Cost and Total GHG emissions

The following Table 19 lists the total costs as well as the total emissions resulting from the policy stimulation scenario.

Table 19: Germany Total Cost and GHG Emissions in Million Dollars and tonnes $\mathrm{CO}_{2} \mathrm{e}$

\begin{tabular}{ccccc}
\hline & 2015 & 2020 & 2025 & 2030 \\
\hline $\begin{array}{c}\text { Total Cost in } \\
\text { Millions }\end{array}$ & 803,864 & 743,359 & 916,305 & 721,505 \\
Total GHG in & & & \\
Millions & 2,196 & 1,867 & 1,487 & 1,275 \\
\hline
\end{tabular}


Figure 22: Germany Total Cost and GHG Emissions in Million Dollars and tonnes $\mathrm{CO}_{2} \mathrm{e}$

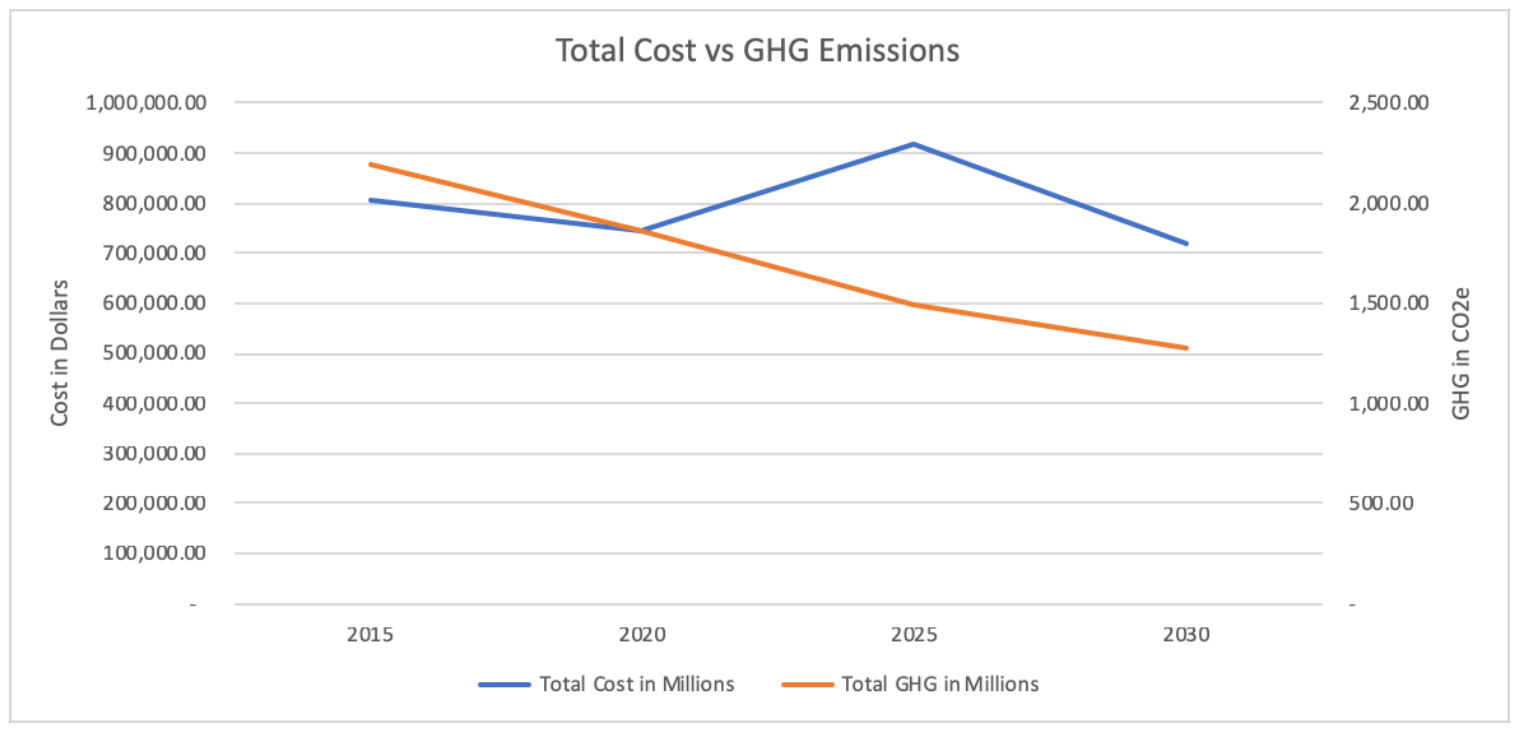

As we can observe from this Figure 22, GHG emissions were set to decrease in the model time period based on the GHG targets. However, the $40 \%$ decrease from the 1990 level target for 2020 was not feasible for this model, therefore an $85 \%$ of the 2015 level value was used. Similarly to France, the cost first decreases because of the decrease in demand and the smaller target that we put in place in terms of GHG emissions. However, for 2025, the cost increases by a lot because the model has to deal with a bigger jump in GHG emissions drop and has to buy renewable energy while still meeting a minimum fossil fuel domestic production and importation, which can be costly. By 2030, the country has prioritized renewables for its smaller demand, which results in smaller costs.

f) Total Demand and Total Cost

Table 20 shows the total demand and the total cost for Germany until 2030. 
Table 20: Germany Total Demand and Total Cost in Millions GWh and Dollars

\begin{tabular}{ccccc}
\hline & 2015 & 2020 & 2025 & 2030 \\
\hline Total Cost & 816,505 & 743,359 & 916,305 & 721,505 \\
Total Demand & 3.59 & 3.44 & 3.30 & 3.17 \\
\hline
\end{tabular}

Figure 23: Germany Total Demand and Total Cost in Millions GWh and Dollars

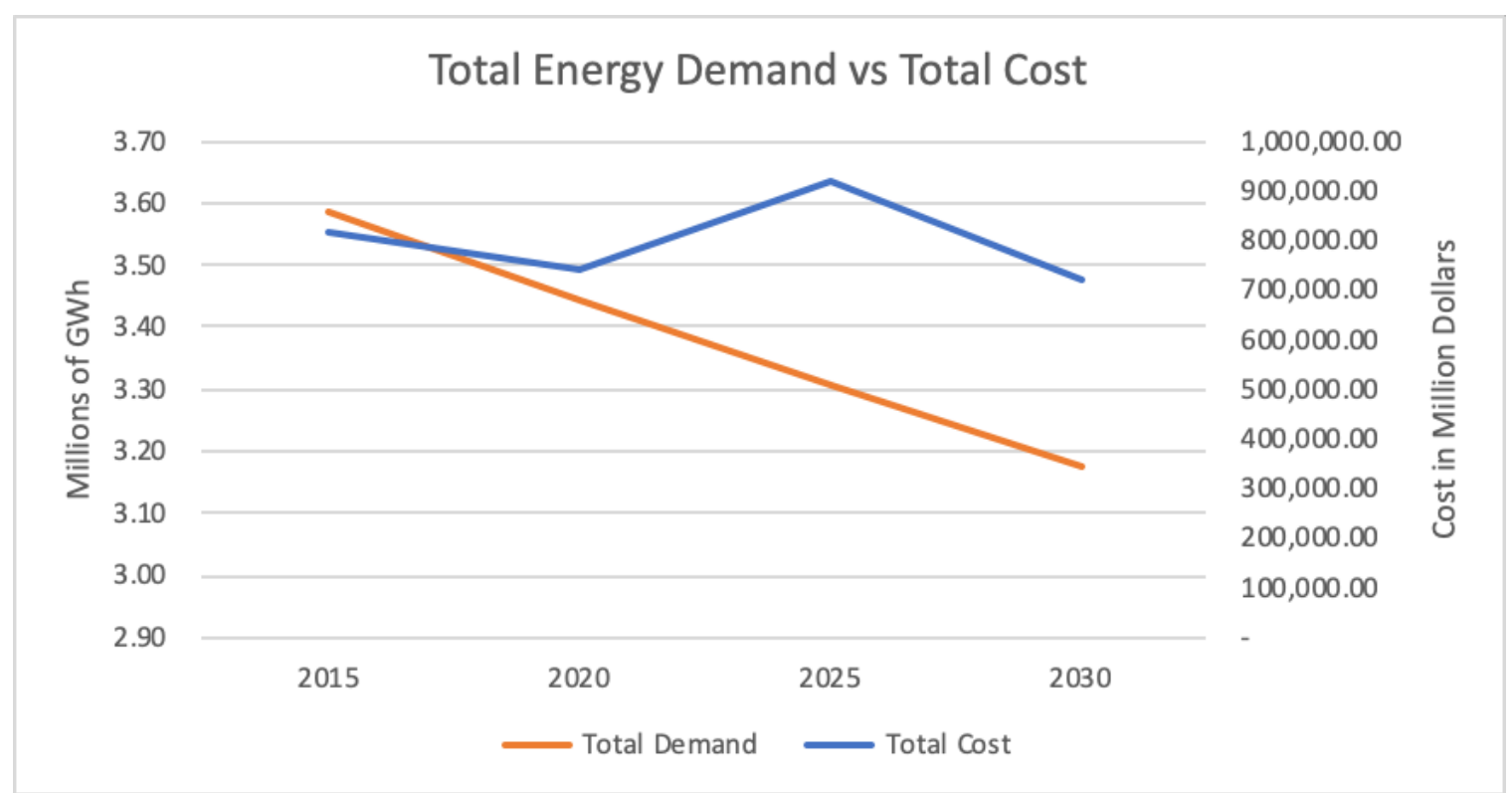

As discussed previously, demand was set to be lowered throughout the years, and explains the first decrease in price in 2020 , where the country was facing a slight increase in price for certain energies but had a lower demand. However, with stricter GHG emission targets and higher costs of fossil fuels, nuclear and hydro, the country had to deal with an increase in price in 2025 in order to meet a more drastic GHG target. By 2030, since the target was not as drastic anymore and the demand was a lot smaller, the total cost decreased and ended up being lower than the initial 2015 value. 


\section{B. Business as Usual (BAU) scenario}

The second set of scenarios that were performed did not include any demand nor any GHG emission constraints in order to compare how cost and GHG emissions would evolve. We have kept the demand and the GHG emissions at the 2015 level, while increasing the capacity in the same way as we did in the policy stimulation scenario. Following are the results obtained when performing this scenario:

\section{1) Results for France for BAU Scenario}

a) Domestic Production by Energy Type

Table 21 depicts France's domestic production under the BAU scenario.

Table 21: France Domestic Production by Energy Types in GWh

\begin{tabular}{ccccc}
\hline & 2015 & 2020 & 2025 & 2030 \\
\hline Solid fuels & - & - & - & - \\
Oil & 12,576 & 12,576 & 12,576 & 12,576 \\
Gas & 223 & 193 & 193 & 193 \\
Hydro Power & 56,154 & 45,546 & 45,546 & 45,546 \\
Wind power & 22,158 & & & 75,073 \\
Solar Thermal and & 8,817 & 59,163 & 67,556 & 29,873 \\
PV & & 23,542 & 26,882 & \\
\hline
\end{tabular}




\begin{tabular}{ccccc}
\hline Solid Biomass & 121,123 & 323,405 & 369,280 & 403,121 \\
Biogas, & 39,115 & 104,439 & 119,254 & 132,523 \\
Biogasoline and & & & \\
Biodiesel & & & & \\
Nuclear heat & $1,312,284$ & $1,312,284$ & $1,312,284$ & $1,312,284$ \\
\hline
\end{tabular}

Figure 24: France Domestic Production in GWh

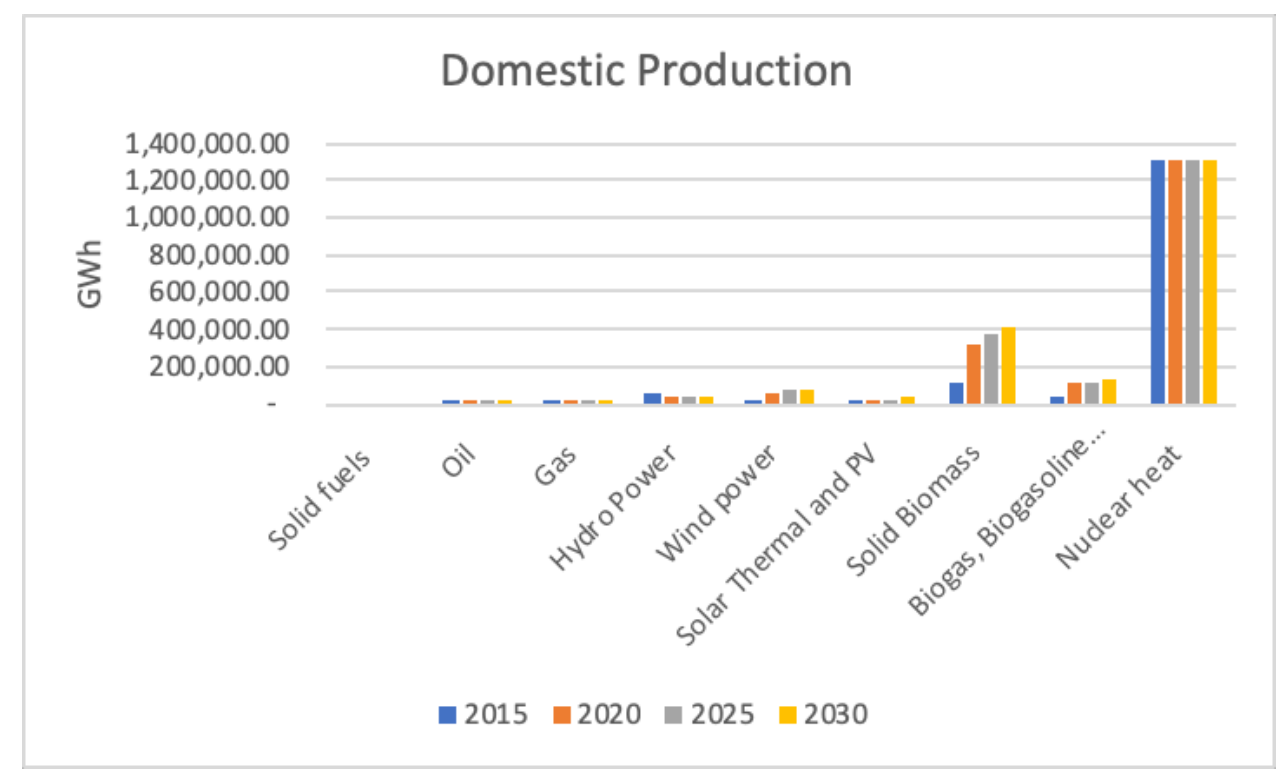

For Table 21 and Figure 24, it is quickly understandable than even in the BAU scenario, renewables will take over and start increasing in proportion. Indeed, the total production stays the same, so does oil and nuclear heat production. For gas, domestic production goes down by 13 percent, and by almost 19\% for hydropower. Other renewables, on their side, increase to be over $300 \%$ of the 2015 value in that time period due to the fact that their costs are expected to decrease throughout time. 
b) Comparison of Cost in Million Dollars under Scenario 1 and 2

The table number 22 compares the results in terms of cost between the two scenarios performed

Table 22: Costs under Scenario 1 and 2 in Million Dollars

\begin{tabular}{lcccc}
\hline & 2015 & 2020 & 2025 & 2030 \\
\hline $\begin{array}{c}\text { Scenario 1 (Policy } \\
\text { Stimulation) }\end{array}$ & 561,451 & 554,175 & 569,851 & 585,249 \\
Scenario 2 (BAU) & 561,451 & 575,104 & 615,114 & 657,512 \\
\hline
\end{tabular}

Figure 25: Costs under Scenario 1 and 2 in Million Dollars

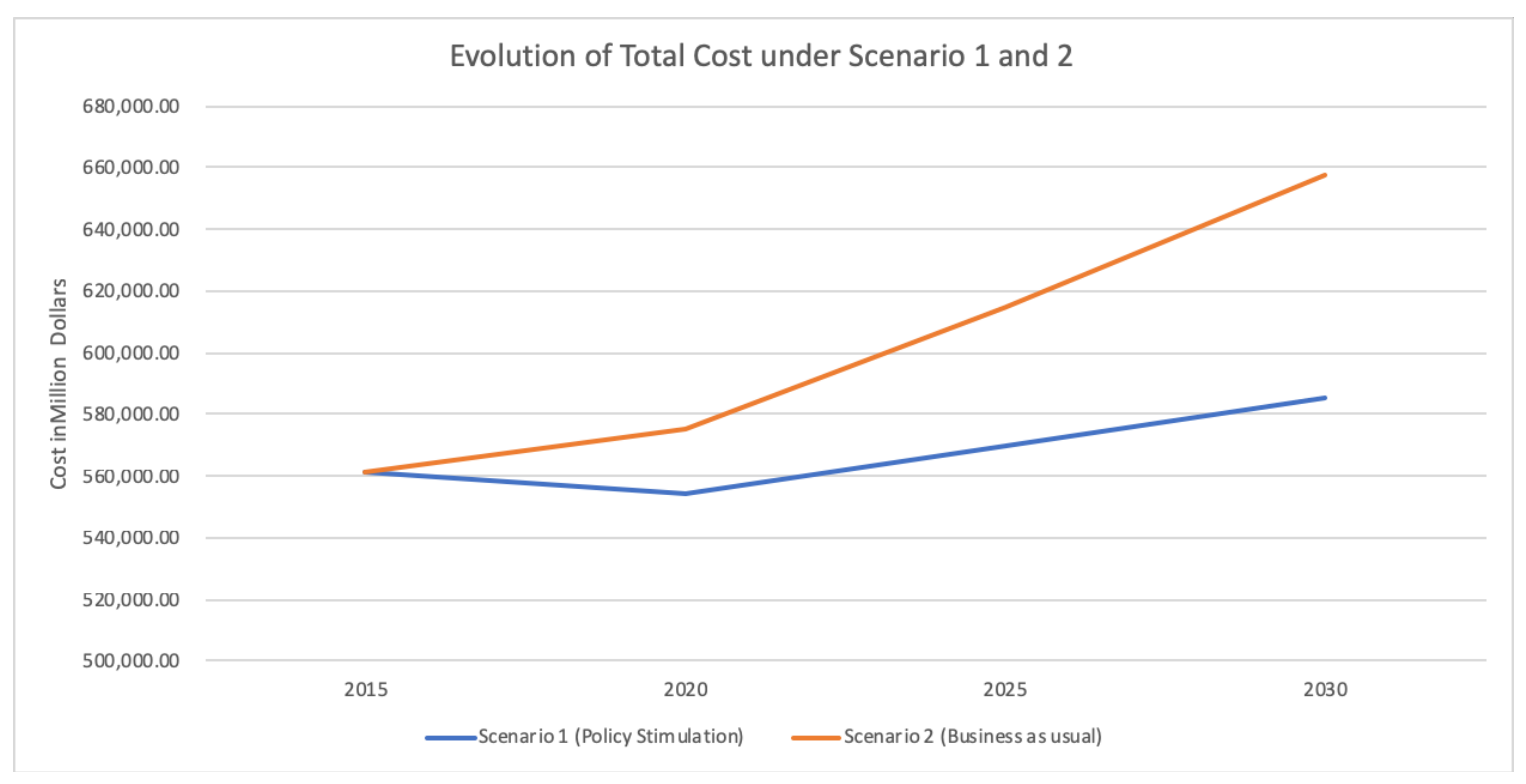

Both scenarios have the same shape in terms of trend, but the overall cost with a policy stimulation, or the application of the Paris Accord scenario) is a lot less than with the baseline scenario. This is due to the fact that energy demand will decrease over time 
as a result of complying with the GHG reduction target under the Paris Accord. Therefore it is important to note that setting up GHG targets will not only mitigate climate change, but will also decrease spending on energy

c) Comparison of GHG emissions in Million Tonnes of $\mathrm{CO}_{2} \mathrm{e}$ under Scenario 1 and 2

The table 23 below compares the results in terms of GHG emissions between the two scenarios performed

Table 23: GHG emissions under Scenario 1 and 2 in Million Tonnes CO2e

\begin{tabular}{lcccc}
\hline & 2015 & 2020 & 2025 & 2030 \\
\hline $\begin{array}{c}\text { Scenario 1 (Policy } \\
\text { Stimulation) } \\
\begin{array}{c}\text { Scenario 2 } \\
\text { (Business as usual) }\end{array}\end{array}$ & 964.95 & 700.08 & 537.66 & 481.81 \\
\hline
\end{tabular}


Figure 26: GHG Emissions under Scenario 1 and 2 in Million Tonnes CO2e

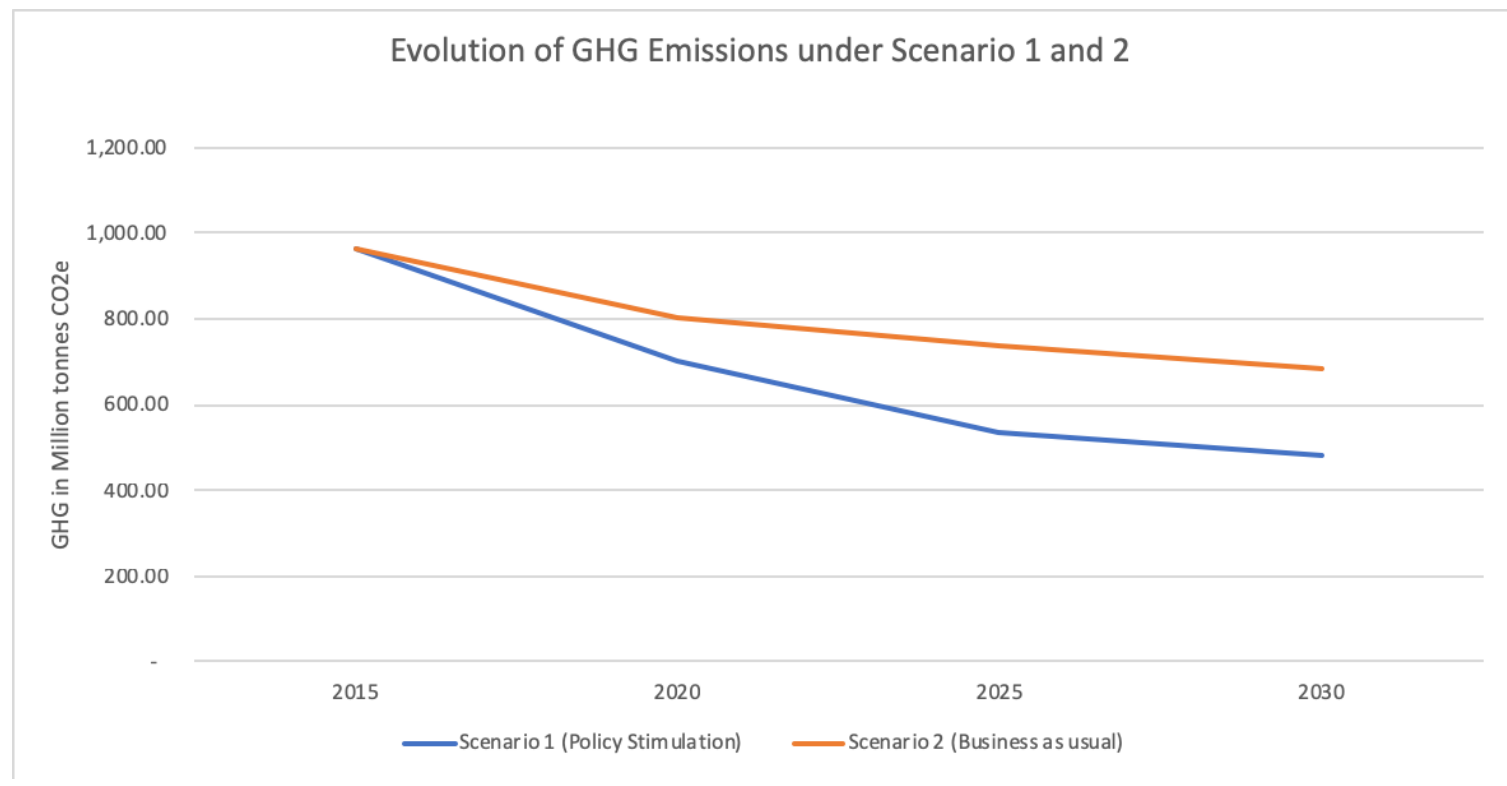

It can be determined that for both scenarios, the total emissions do go down. Both of the results have similar trends, and as expected the Paris Accord targets implementing scenario was more successful at reducing GHG emissions by 2030 (482 million of tonnes of $\mathrm{CO}_{2} \mathrm{e}$ ) than the business as usual one (681 million of tonnes of $\left.\mathrm{CO}_{2} \mathrm{e}\right)$. However, it is noteworthy to remark that GHG emissions will go down even for the BAU scenario, which can be explained by the fact that fossil fuels will increase in price and the model will prioritize less costly energies, which end up being the renewable ones.

\section{2) Results for Germany for Business as Usual Scenario}

a) Domestic Production by Energy Type

Below is table 24 that summarizes the results obtained for Germany until 2030 for the BAU scenario. 
Table 24: Germany Domestic Production by Energy Types in GWh

\begin{tabular}{|c|c|c|c|c|}
\hline & 2015 & 2020 & 2025 & 2030 \\
\hline Solid fuels & $500,135.28$ & $500,135.28$ & $500,135.28$ & $500,135.28$ \\
\hline Oil & $42,055.28$ & $42,055.28$ & $42,055.28$ & $42,055.28$ \\
\hline Gas & $73,677.22$ & $73,677.22$ & $68,367.12$ & $68,367.12$ \\
\hline Hydro Power & $20,874.64$ & $18,976.94$ & $16,072.52$ & $16,072.52$ \\
\hline Wind power & $83,625.55$ & $123,700.43$ & $164,568.72$ & $202,102.78$ \\
\hline Solar Thermal and & $49,228.23$ & $72,671.43$ & $96,680.70$ & $118,731.18$ \\
\hline \multicolumn{5}{|l|}{ PV } \\
\hline Solid Biomass & $153,582.78$ & $219,076.29$ & $291,454.96$ & $357,928.64$ \\
\hline Biogas, & $130,976.55$ & $200,806.81$ & $267,149.59$ & $328,079.81$ \\
\hline \multicolumn{5}{|l|}{ Biogasoline and } \\
\hline \multicolumn{5}{|l|}{ Biodiesel } \\
\hline Nuclear heat & $275,358.06$ & $275,358.06$ & $275,358.06$ & $275,358.06$ \\
\hline
\end{tabular}


Figure 27: Germany Domestic Production in GWh

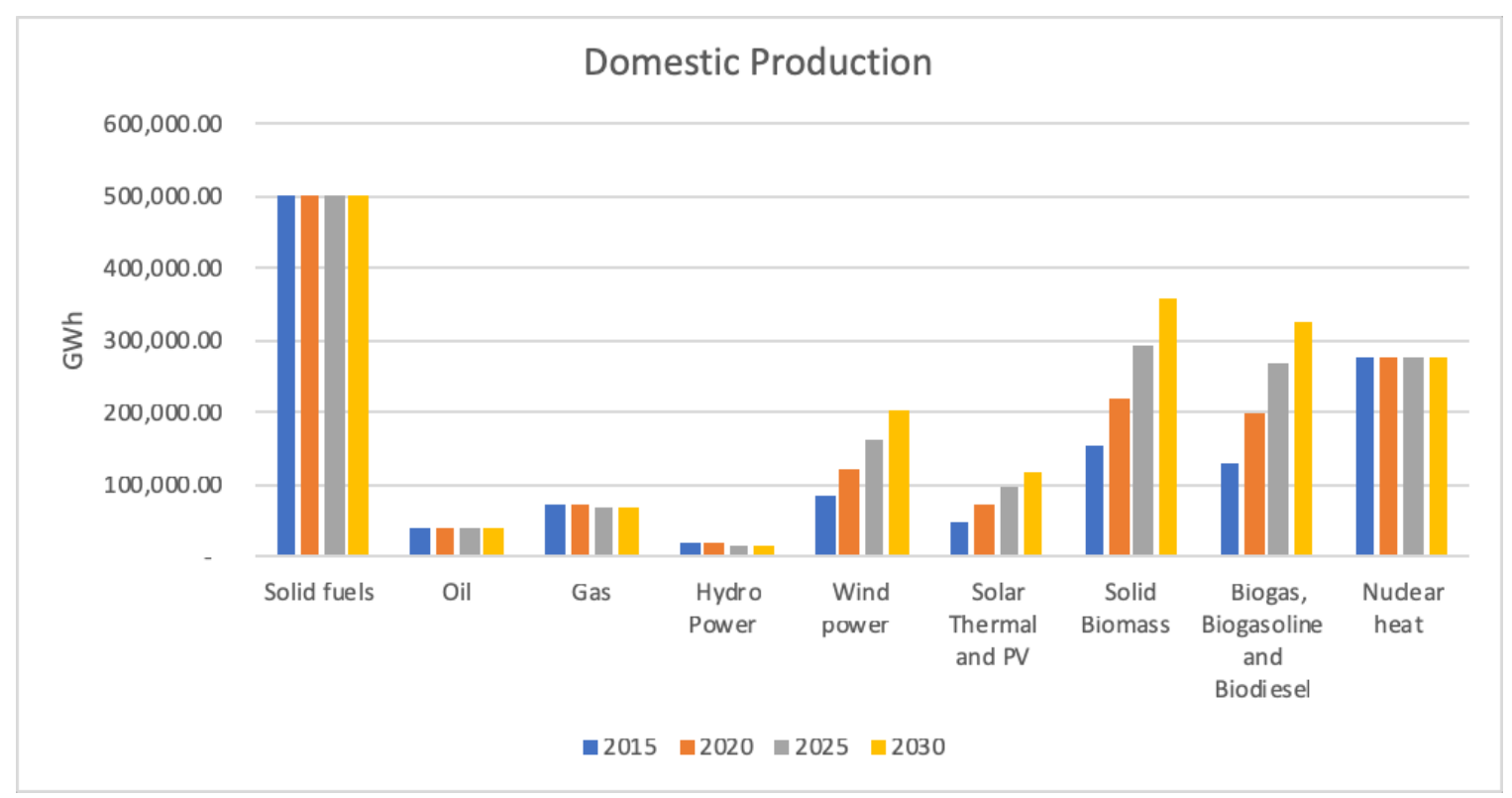

As observed from Table 24 and Figure 27, Germany's domestic production is still very different from France's one. Indeed, Germany has a more diversified portfolio, and will continue to produce fossil fuels and nuclear heat in the future under the BAU scenario. However, it is important to notice that just as in France's case, the domestic production increases for almost all renewable (except hydropower, which decreases the most) by over $200 \%$ of their initial value). Oil, gas and nuclear stay at the same level, while gas decreases by $7 \%$.

b) Comparison of Cost in Million Dollars under Scenario 1 and 2

Table 25 depicts the comparison of costs between the two scenarios: policy stimulation and BAU. 
Table 25: Costs under Scenario 1 and 2 in Million Dollars

\begin{tabular}{ccccc}
\hline & 2015 & 2020 & 2025 & 2030 \\
\hline $\begin{array}{c}\text { Scenario 1 (Policy } \\
\text { Stimulation) }\end{array}$ & $803,864.05$ & $743,359.42$ & $916,304.88$ & $721,505.39$ \\
$\begin{array}{c}\text { Scenario 2 } \\
\text { (Business as usual) }\end{array}$ & $803,864.05$ & $827,822.84$ & $848,146.80$ & $874,402.08$ \\
\hline
\end{tabular}

Figure 28: Costs under Scenario 1 and 2 in Million Dollars

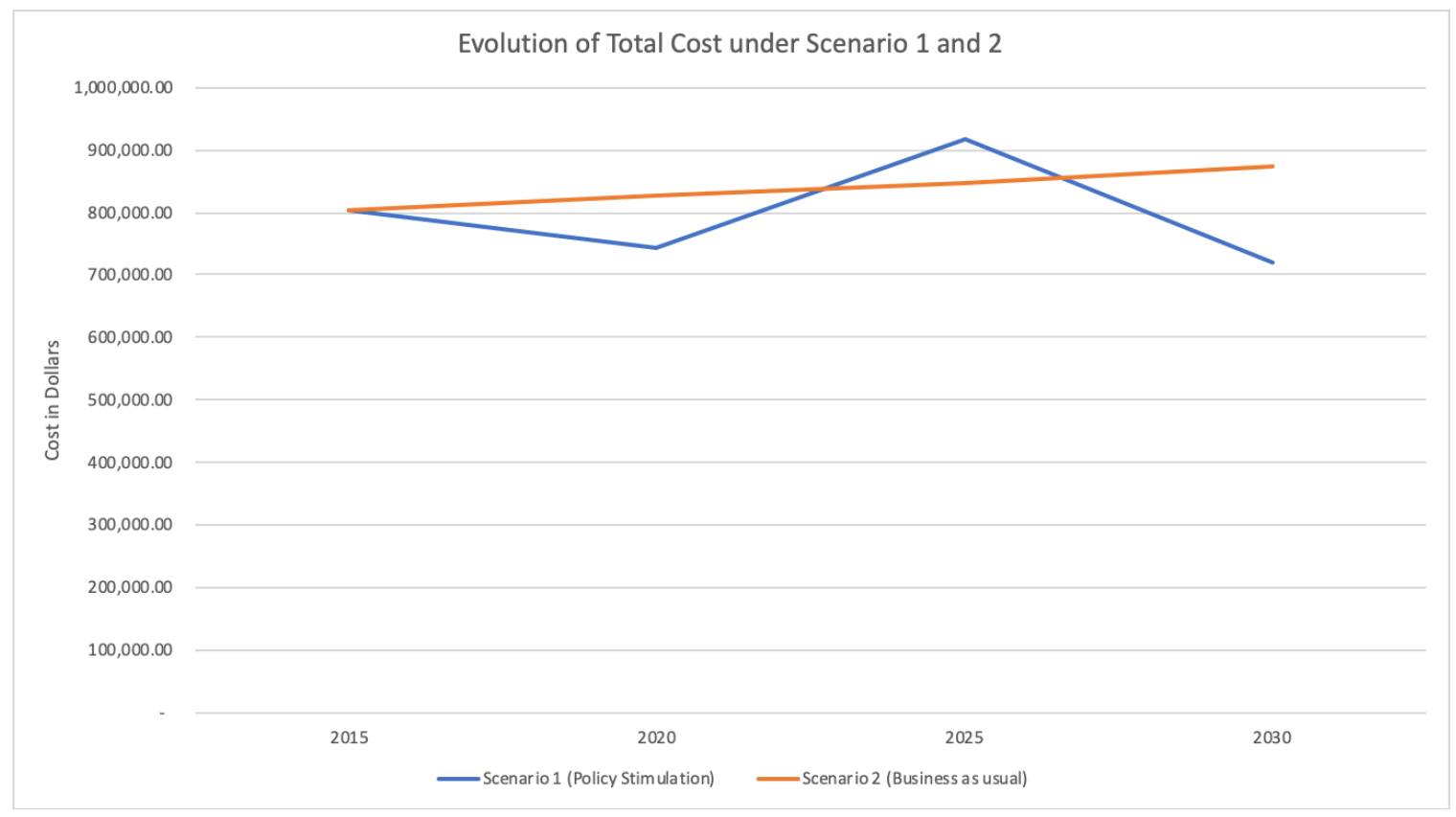

The trendline in costs is quite different in Germany compared to France. Indeed, as someone can observe on Figure 28, for the BAU, the cost increases steadily throughout time, which can be explained by a heavy reliance on fossil fuels, and a difficulty to switch from them. For the policy stimulation scenario, the cost first decreases, which can be explained by a drop-in demand, but then increases highly. This is due to the fact that Germany had a goal for 2020 that was too ambitious, and had to be reduced, meaning that 
for the year 2025, Germany had to pick up its pace towards GHG targets for 2030, leading to a higher cost. After that, by 2030, the lower demand, especially in fossil fuel energies and the availability of renewables leads to lower costs.

c) Comparison of GHG emissions in Million Tonnes of $\mathrm{CO}_{2}$ e under Scenario 1 and 2

Table 26 presents the results obtained for GHG emissions under scenario 1 and 2.

Table 26: GHG Emissions under Scenario 1 and 2 in Millions

\begin{tabular}{lcccc}
\hline & 2015 & 2020 & 2025 & 2030 \\
\hline $\begin{array}{c}\text { Scenario 1 (Policy } \\
\text { Stimulation) } \\
\begin{array}{c}\text { Scenario 2 } \\
\text { (Business as usual) }\end{array}\end{array}$ & $2,196.12$ & $1,866.70$ & $1,486.93$ & $1,274.51$ \\
\hline
\end{tabular}

Figure 29: GHG Emissions under Scenario 1 and 2

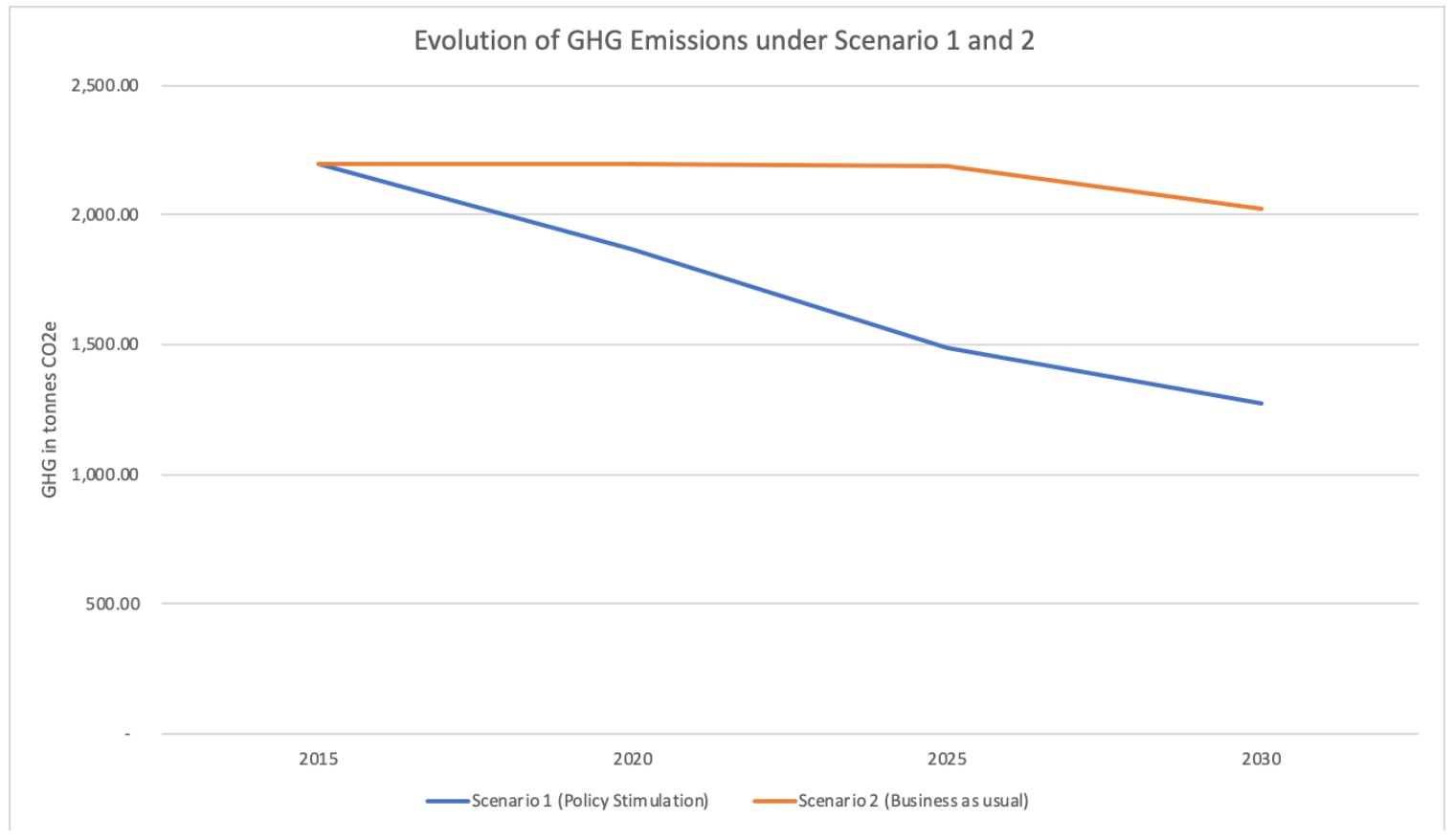


In terms of GHG emissions, similarly to France, the overall trend for Germany was also a decreasing one. Indeed, as observable on Figure 29, both scenarios' emissions go down between 2015 and 2030. However, for BAU scenario, the GHG emissions are first more or less stable until 2025, where we can assume that prices for fossil fuels are too high and the model has no choice but to rely on renewables. For the policy stimulation case, the GHG emission go down as expected thanks to the constraints, and it can be seen that the target was too ambitious for 2020, but doable for 2030 .

\section{2) Cost of Carbon}

Assume that the GHG is reduced from $k$ percent of the 2015 baseline level to $l$ percent of the 2015 baseline level. The marginal cost of carbon was calculated using the formula below:

$$
\text { Marginal cost of carbon: } \frac{(\text { Total cost })_{t=1}-(\text { Total Cost })_{t=0}}{(\text { Total GHG Emissions })_{t=1}-(\text { Total GHG Emissions })_{t=0}}
$$

1) Results for Cost of Carbon for France

Below are the results for the cost of carbon scenarios for France.

Table 27: 2015 Cost of Carbon Scenarios France

\begin{tabular}{|c|c|c|c|}
\hline \multirow{4}{*}{ Slack \% } & & & Maroinal Cost \\
\hline & GHG in (Thousand & Cost of Energy & of $\mathrm{GHG}$ \\
\hline & Tonnes) & Production (Million US\$) & Reductions \\
\hline & & & (US \$/tonne) \\
\hline
\end{tabular}




\begin{tabular}{llll}
\hline 100 & 964,951 & 497,782 & \\
95 & 916,703 & 499,694 & 39.62 \\
90 & 868,456 & 522,030 & 462.94 \\
86 & 829,858 & 592,504 & $1,825.86$ \\
\hline
\end{tabular}

Figure 30: 2015 Scenarios for France

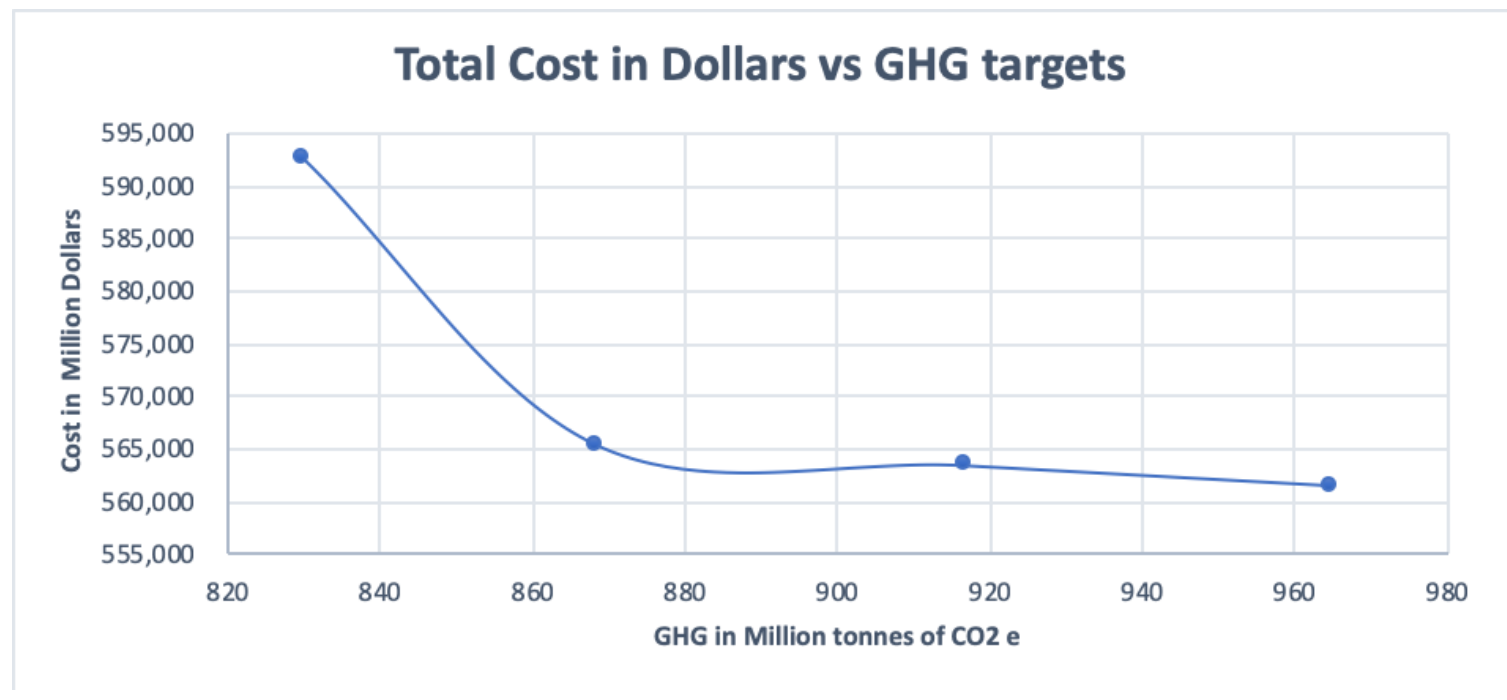

As we can observe, in scenarios where the GHG targets are reduced, the total cost increases exponentially due to the fact that the model forces the choice of renewable energies over regular fossil fuels. The marginal cost of carbon reduction for the $95 \%$ scenario is $\$ 39.62$ per ton of $\mathrm{CO}_{2} \mathrm{e}$ for France, however these costs increase exponentially for the $90 \%$ scenario to $\$ 462.94$ per ton of $\mathrm{CO}_{2} \mathrm{e}$, followed by $\$ 1,825.86$ per ton of $\mathrm{CO}_{2} \mathrm{e}$ for the $86 \%$ scenario, making it too costly to be realistically feasible. Additionally, by reducing GHG emissions, the model will prioritize renewables even if the country 
doesn't have the infrastructure needed, forcing imports that are $10 \%$ more expensive than domestic production.

\section{2) Results for Cost of Carbon for Germany}

Similar scenarios were applied to Germany's case for 2015 baseline, however the model was ran for slacks of $100 \%, 97.5 \%, 95 \%$ and $94.5 \%$, and was not feasible after that. Following are the results obtained:

Table 28: 2015 Scenarios for Germany

\begin{tabular}{|c|c|c|c|}
\hline Slack \% & $\begin{array}{c}\text { GHG in (Thousand } \\
\text { Tonnes) }\end{array}$ & $\begin{array}{c}\text { Cost of Energy Production } \\
\text { (Million US\$) }\end{array}$ & $\begin{array}{c}\text { Marginal Cost } \\
\text { of GHG } \\
\text { Reductions } \\
\text { (US \$/tonne) }\end{array}$ \\
\hline 100.00 & $2,196,117$ & 741,273 & \\
\hline 97.50 & $2,141,214$ & 851,148 & $2,001.26$ \\
\hline 95.00 & $2,086,311$ & 961,023 & $2,001.26$ \\
\hline 94.50 & $2,075,331$ & 982,998 & $2,001.26$ \\
\hline
\end{tabular}


Figure 31: 2015 Scenarios for Germany

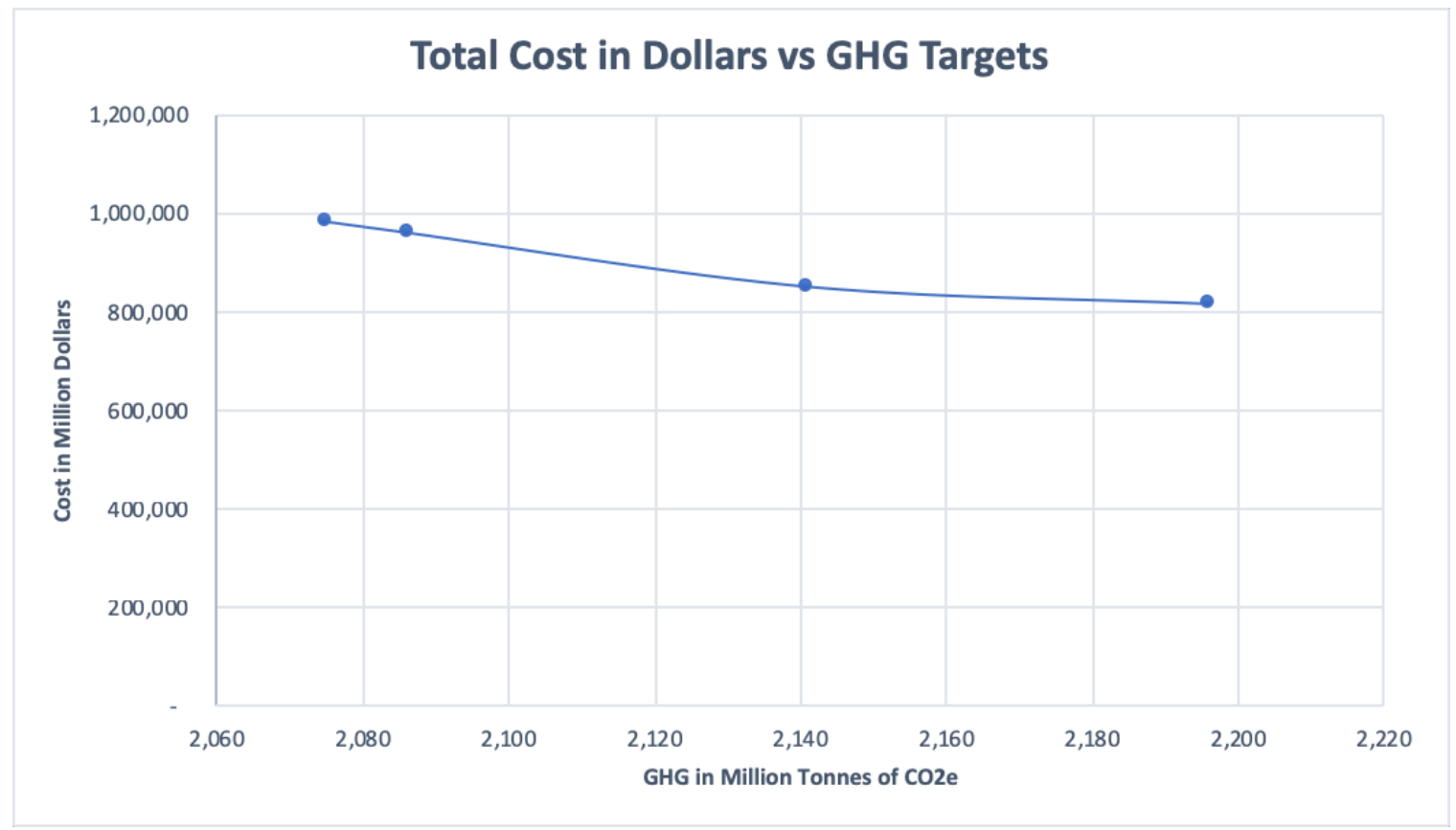

As mentioned, prior, Germany's scenario doesn't have as much room for slacks as France's, and only runs up to $94.5 \%$ of the GHG targets. Unlike France, who set a target for 2020 and 2030, Germany only set their target for 2050, meaning that GHG emissions levels were linear, explaining the linear trend in the graph as well as the cost of lowering emissions by a ton. By comparing France and Germany, it becomes evident that Germany will incur more expenses when it comes to additional GHG mitigation. It is also evident that Germany has already attained the least cost level for GHG mitigation, while France can still lower its GHG target before incurring the exponential cost seen on Figure 30. 


\section{CHAPTER 5}

\subsection{Discussion of the model}

As discussed before, advance planning is key to a successful energy transition. Germany has been one of Europe's pioneers in the area of energy transition, but its Energiewiende program was said to be flawed, even with the investments in renewables and called by some evolutionary rather than revolutionary (Fischer, Hake, Kuckshinrichs, Schroder and Venghaus, 2016). Additionally, many argue that the true cost of such transitions is very high due to the number of investments in the renewable sector needed, while others in favor of the Energiewiende deem that the country would actually make money when taking in account the environmental factor. Nonetheless, it is important to note that there is an overall decreasing trend when it comes to GHG emissions for Germany, even after they pledged to reduce nuclear power. Coal is an important portion of these emissions, however this resource's consumption has been decreasing since 1991. Similarly, France has been working towards reducing its GHG emissions through oil use. However, these first steps towards an energy transition have proved to be good lessons for future energy planning, especially in areas of investments for renewable infrastructure, which can be costly. Both countries have been trying to work hand in hand in order to coordinate their energy transitions in a more efficient way, towards more investments in renewables and a decrease of the use of nuclear.

This research first began by analyzing the current 2015 energy portfolio for both France and Germany, including their domestic production, imports, and sectorial demands. As mentioned before, these two countries have very different portfolios, when it comes to both production and consumption. The 2015 data needed in order to be able to 
construct the model, by deriving different supply capacities as well as consumption patterns. Based on these capacities, the model's constraints were put in place to modelize the next years. The model was then run for a policy stimulation scenario, where GHG targets from the Paris Accord were implemented, followed by a business as usual scenario, where demand and GHG emissions were kept constant, and lastly a cost of carbon scenario, where different levels of GHG emissions were applied to the 2015 initial GHG value.

\subsection{Implications for energy transition in France and Germany}

When observing the outcomes of the model, it becomes evident that, overall, the domestic production portfolio of Germany gave it an advantage over France, because of its diversity. For instance, upon comparing Figures 7 and 16, it is clear that France only produces certain types of energies, mostly nuclear heat, while Germany manages to have a minimum level of production in all resources. Nuclear heat, even though a relatively clean energy, and not very expensive, still raises the issue of safety in many countries, such as Germany. A debate between the outcome of climate change compared to the outcome of a possible nuclear accident ensures: is it worth to take the risk of a nuclear catastrophe such as Chernobyl or Fukushima to mitigate global warming? The nuclear intense lifestyle leads to two main issues for France. First, not all energy sources used go towards electricity generation; some are used as a "primary source", such as oil towards transportation, or solid fuels for the non-energy sector. However, France mainly produces nuclear heat, of which the energy can only be harvested through electricity generation, which leads to the second issue, the question of imports. France currently has to heavily rely on foreign energy sources for most of its non-electricity, non-nuclear energy needs. 
The need for a shift towards domestically produced renewables is much more crucial and immediate for France than it is for Germany. For France, it is not only a carbon saving strategy but also an energy independence strategy. However, it is key to remember that fossil fuels are still representing a large portion of consumption for both countries, even by 2030 , and despite Germany producing a small portion of them, both countries will be forced to rely on imports. Rojey, (2009) insists that fossil fuels will still be present, and actually will play a key role for an energy transition. Furthermore, he insists that the supply of fossil fuels needs to be diversified in order to avoid geopolitical risks.

We had set supply and demand constraints such that the model generates results that are consistent with a smooth transition. We kept a minimum level of demand of each energy type, meaning that even though we try to promote an energy transition, we cannot expect all demand sectors to avoid fossil fuels and nuclear energy in the short term. Additionally, it is known that some sectors are more flexible to an energy transition, while others will take longer to transition. The transportation sector for example, is expected to take a longer time because there is no economically viable alternative to replace oil totally, and biofuels, even though are developing, cannot yet cover the total transportation sector demand. This result was consistent with Price and Keppo (2017), who determined that the transport sector is reliant on oil even when applying different greenhouse gas emission targets to follow a decarbonization pathway until 2050 and letting the model increase in cost. In terms of nuclear power, many debates have been going on throughout the last years, and both countries do have plans to close down their power plants, as soon as 2022 for Germany (Dromta, 2017). Because of recent nuclear accidents, as mentioned earlier, many nations have decided to exit from nuclear, but this energy resource provides a key advantage: it is very low in GHG emissions, as can be 
observed in Table 2. Its cost is also one of the lowest ones, which is another advantage especially for France and Germany who already have power plants on their territory and do not have to build them in order to produce energy. Therefore, for this study, it was decided to keep the nuclear power production capacity at the 2015 levels. However, slowly, more government bodies could become warmer to the idea of nuclear energy on their territory as safer and smaller reactors are being made. As Ropeik (2017) mentions, some policies, such as the Massachusett's policy, are giving economic incentives towards nuclear plants in order to meet environmental targets. Although, by design the model did have too many constraints to operate within, it did have the ability to make finer and smoother adjustments or shifts between energy sources in each period subject to changes in energy costs and increasing GHG restrictions.

\section{$\underline{5.3 \text { Alternative energy scenarios and their cost implications }}$}

In terms of cost, it was important to have a comparison in order to evaluate how an energy transition would impact not only the environment, but also the economic costs of achieving such a transition. However, putting a price on energy and its impact on the environment is quite difficult. Indeed, within this research, price was set in terms of cost per GWh generated. Despite that, no tax of carbon was put in place, but such a set-up is possible if wanted within the model in order to estimate new total cost. Carbon taxes are useful tools in order to control the use of high carbon emission technologies and could cost effectively reduce GHG emissions. Both France and Germany have implemented such laws, but their effects are different. For Germany, the ecological tax reform could be considered as a success, since it reduced GHG emissions and also created jobs. For France, on the other hand, government tried to implement a carbon tax that would 
increase in amount every year on oil, gas and coal. This tax affects both the business and residential sectors, therefore creating a lot of opposition, and after a long time of protest by the yellow jackets, the idea of increasing carbon taxes was put aside. However, even without the application of any carbon taxes, this model is a useful one in order to estimate overall total costs incurred by the two countries while transitioning to greener energies.

As Trutnevyte ( 2016) points out, cost optimization models are usually adapted in order to present energy scenarios for policy makers. These models end up being simplified versions with varied constraints of the real-world situation. Different constraints dictate the outcomes of these energy scenarios, hence why we decided to conduct two different scenarios in this research: one where we implement the targeted GHG levels and future demand called policy stimulation, and one where these GHG levels and demands were kept at the 2015 level (BAU scenario). It is evident that the policy stimulation scenario not only mitigates GHG emissions, but also is more economically beneficial for both countries, as can be observed in Figure 25 for France and Figure 28 for Germany. This is due to the fact that overall demand decreases for the policy stimulation case, while it does not for the baseline scenario, and also the fact that in the baseline scenario, fossil fuels are still at the same level in terms of demand, while cost increases. This forces the model to pick a minimum amount of fossil fuels, increasing therefore the overall cost as these fossil fuels increase in price at a $2 \%$ yearly rate. For both countries, since demand is higher than supply for fossil fuels, the model calls for importing these resources, which adds another $10 \%$ to the cost. Similarly, GHG emissions are much higher in the BAU scenario, wherein we do not force the model to constraint these emissions. However, we do see a downward trend for GHG emissions for the BAU scenario as for the policy scenario. This is due to the fact that fossil fuels 
become expensive over the years due to the expected cost inflation, and while renewables do experience improving cost advantages due to the expected technological improvements, the model is forced to pick renewables to minimize the total costs. Price and Keppo (2017) have also implemented two similar scenarios, one being a business as usual, and the other one a climate policy run. For these scenarios, different slacks were applied to account for cost, and what is found is that coal and gas are easily substituted while oil is present even at higher costs, and non-biomass renewables' present an asymmetric behavior. The research also mentions energy distribution: what is used in order to produce electricity or what goes to other demand sectors such as transportation, and how this distribution affects the overall system. Some energies, such as coal, are used only for power generation, while others, like gas, can be used by other demand sectors.

One of the important policy relevant question is if both countries are already at the lowest cost GHG target possible, or could they still reduce their targets without facing high expenses? As observed from Figures 30 and 31, which show the cost at different levels of percent reductions from the 2015 total GHG emissions, the trends for France and Germany are very different. Indeed, Germany shows a steady and linear increase in cost, while France first deals with a linear and then an exponential increase. Similarly, when observing Tables 24 and 25, the cost of removing one tonne of $\mathrm{CO}_{2}$ for France first starts low at \$39.62 and then increases drastically, while it stays constant for Germany. This can be explained by the fact that Germany is already at its lowest cost optimal GHG emission target, while France has still some room to decrease this target by five to eight percent, without having to experience drastic increase in costs. Beyond this five to eight percent reduction levels, France's energy production cost would go up substantially. This 
is also confirmed by the fact that the model was running up to the $86 \%$ level for France, while it could only run to a $94.5 \%$ level for Germany. 


\section{CHAPTER 6}

$6 \underline{\text { Conclusion }}$

This research demonstrates that an energy transition is economically viable for both France and Germany. These two countries are not only leaders of the European Union, but also have two of the highest GDPs in the region, and therefore could be perfect examples to promote stable and planned energy transitions. The Paris Accord allows each nation to determine its own pace for energy transition and GHG reductions. Germany has set very ambitious goals for its GHG emissions, while France followed a more general European path. In this study, we find that given the current national energy demands of various sectors and its available domestic supply capacities, Germany may not be able to meet its $2020 \mathrm{GHG}$ emission target and will need to revisit its goals to be more realistic. We were able to run the model for feasible results only after we lowered the emission reduction targets. This shows more drastic energy transition planning would be necessary for Germany if it were to accomplish its nationally determined energy transition goal under the Paris Accord.

The decision taken by Germany following the Fukushima accident to leave the nuclear industry is one that arises many debated. This initiative raises the question of the future of nuclear power and spreads the idea of a phase out to multiple other countries including France. Such a decision has consequences not only at the national level, but also at the European one. When speaking about energy transition, at least in terms of electricity production, it is a common mistake to believe that the development of solar and wind power would act as a substitute to the production of nuclear power. These two renewable energies are considered to be intermittent, meaning that they produce power at 
random periods of time, in other words only when sun and wind are present. However, there is not yet technology that would allow to store the produced electricity in an efficient and inexpensive manner, meaning that the grid is unable to provide power to demand in any weather condition, season or even time of the day. Therefore, there is a need to possess also controllable production capacities that are not affected by the problem of intermittence, such as coal, gas, nuclear or even hydroelectric in order to provide a constant supply of electricity. It is known that nuclear possesses low GHG coefficients, however still took the decision to phase out that technology. The question is if such a path is realistic. Germany is a good example to illustrate the option of phasing out nuclear. Two options are possible in order to deal with the issue. In order to still meet its energy demand while closing down nuclear plants, Germany invested in more solar energy, wind poser, but also more gas plants, which are, not so ecologically friendly, but also dependent on gas that is a non-renewable and limited energy. Therefore, Germany is only taking steps back instead of promoting their so-called transition. The second option to eventually close down power plants is to reduce demand through efficiency and conservation practices. However, even if these practices are implemented, is it really a smart move to close down technologies that can produce large amounts of electricity at low GHG levels? France has been pushing the use of renewables, but however is still undecisive when it comes to the question of phasing out nuclear. The government put forward the idea of closing nuclear reactors by 2035 in order to reduce the share of nuclear to $50 \%$ of the electricity mix by 2035 , but once again, this means having to compensate with fossil fuels since renewables are not expanded enough to cover the demand. 
The topic of energy transition has become an important political issue for many reasons, including climatic problems, public health issues, higher energy costs and economic growth. The low-carbon energy transition debate has brought a number of issues and challenges to attention. First, promoting this energy transition needs to promote building wind turbines and solar panels, the technology of which still needs improvements. These energy types are expected to grow in the future years, but are still not fully competitive with other energy resources. Additionally, for many citizens, seeing PV panels or wind turbines is not pleasant, therefore having to build offshore wind turbines might be a good solution for France, but not so much for Germany. On top of that, these renewable resources still hold the issue of intermittence: no large-scale storage technology is yet developed in order to store energy produced by renewables for future use. Second, the energy transition needs to address challenges such as access to energy, widening gap between production and consumption, and the price and cost of domestic energy production. The two countries explored in this study are part of the developed world, and share a border meaning that access to electricity is more common than other places in the world. Therefore, when living in these two leading European countries, it can be quickly forgotten that not all humans have an equal access to energy. The development of renewable energy, as well as a decrease in the cost of infrastructure could lead to more access to electricity. Further, the development of these renewable energies as well as their storage would help to breach the gap between production levels and consumption levels. Third, politics also plays an incredible role in energy transitions. Even though local responses can be different from country to country, energy policy developments usually orbit around certain common goals: energy security, social equity, access to energy and cost efficiency. Both countries have been trying to implement 
different policies when it comes to the environment and an energy transition. But were these as successful as we would expect? The debate is one that provokes a lot of heat, and at the end of the day the decision is not always about the environment or how to slow down climate change, but more about who will have to pay the price for such a transition. The model developed in this study, even though only theoretical, provides a broad framework to evaluate some of these issues at the national level while setting energy and carbon targets and considering technological advances in energy production. However, an important portion that was left out was the impact of trade on these different mixes, in particular the effect of exports. This study only took in account imports, since no information about export destination was found, and therefore no relation between France and Germany in terms of energy supply was performed. This information would have been interesting to include within the research, as both countries share a border, and are known to trade electricity as well as other energy supplies. In this study, it is confirmed that reaching the Paris Accord targets is realistic, and that a smooth transition can be put in place in order to guarantee a durable result. 


\section{$\underline{\text { References }}$}

Aubertin, C. et al. (2015) "Introduction. Les enjeux de la conférence de Paris. Penser autrement la question climatique." Natures Sciences Sociétés 23 : S3-S5.

Berghmans, N. (2017). " La demande d'électricité en France: quels enjeux pour la transition énergétique." IDDRI Studies.

Brundtland, G. H. (1985). "World commission on environment and development." Environmental policy and law, 14(1), 26-30.

DeCarolis, J.F. (2011) "Using Modeling to Generate Alternatives (MGA) to Expand Our Thinking on Energy Futures." Energy Economics, vol. 33, pages 145-152. EBSCOhost, doi:10.1016/j.eneco.2010.05.002.

Dorian, J. P., Franssen, H. T., \& Simbeck, D. R. (2006). “Global challenges in energy." Energy Policy, 34(15), 1984-1991.

Drmota, V. (2017) “A Tale of Stances: Two Germany’s Development and Fear or Nuclear Energy". Harvard International Review.

European Commission. "The 2020 national renewable energy action plans" https://ec.europa.eu/energy/en/topics/renewable-energy/national-renewableenergy-action-plans-2020

Eurostat. (2017) “Energy Balances” European Commission, (nrg_100a) $<$ https://ec.europa.eu/eurostat/web/energy/data/energy-balances $>$

Falkner, R. (2016): "The Paris Agreement and the new logic of international climate politics." International Affairs 92.5: 1107-1125.

Fischer, C. (2010) "Renewable portfolio standards: when do they lower energy prices?" The Energy Journal: 101-119. 
Fischer, W., Hake, J. F., Kuckshinrichs, W., Schröder, T., \& Venghaus, S. (2016). "German energy policy and the way to sustainability: Five controversial issues in the debate on the "Energiewende"." Energy, 115, 1580-1591.

Global Nuclear Energy Report. (2014) “Uranium reserves and production”, pages 49-57

Hafner, M. (2017) "Determining Future Energy Efficiency Potential Across Sectors - A Case study for Germany". Enerdata.

Heinrichs, H. U., Markewitz, H. (2017) "Long-term impacts of a coal phase-out in Germany as part of a greenhouse gas mitigation strategy." Applied energy 192: 234-246.

Kim, J., \& Park, S. (2018). “A contingent approach to energy mix policy.” Energy Policy, 123, 749-758.

Kern, F., Rogge K.S. (2016) "The pace of governed energy transitions: Agency, international dynamics and the global Paris agreement accelerating decarbonisation processes?" Energy Research \& Social Science 22 : 13-17.

Lee, S., Kim, M., \& Lee, J. (2017). “Analyzing the impact of nuclear power on CO2 emissions." Sustainability, 9(8), 1428.

Lenk, S., \& Wisotzky, F. (2011). "Chemical modelling of the groundwater composition in aquifers affected by lignite mine dumps discharge (surface mine Inden, Germany)." Environmental Earth Sciences, 62(3), 581-591.

McMichael, A. J. (2013). "Globalization, climate change, and human health.” New England Journal of Medicine, 368(14), 1335-1343.

Price, J., \& Keppo, I. (2017). "Modelling to generate alternatives: A technique to explore uncertainty in energy-environment-economy models." Applied energy, 195, 356369

O'Connor, D. (2011). "Biodiesel GHG emissions, past, present, and future." A report to IEA Bioenergy Task, 39. 
Rojey, A. (2009). "Energy and Climate: How to achieve a successful energy transition." John Wiley \& Sons.

Rogelj, J., D. Shindell, K. Jiang, S. Fifita, P. Forster, V. Ginzburg, C. Handa, H. Kheshgi, S. Kobayashi, E. Kriegler, L. Mundaca, R. Séférian, and M.V. Vilariño, (2018): "Mitigation Pathways Compatible with $1.5^{\circ} \mathrm{C}$ in the Context of Sustainable Development." Global Warming of $1.5^{\circ} \mathrm{C}$. An IPCC Special Report on the impacts of global warming of $1.5^{\circ} \mathrm{C}$ above pre-industrial levels and related global greenhouse gas emission pathways, in the context of strengthening the global response to the threat of climate change, sustainable development, and efforts to eradicate poverty. In Press.

Ropeik, D. (2017) "Clean energy mind games: if policy makers want to accelerate the transition to a low carbon economy, they should heed the lessons of the decision sciences and take another look at nuclear energy." Issues in Science and Technology. Vol.33 Issue 4, p59.

Ross, K., Kern, K. (2013). "The Energiewende in Germany: background, developments and future challenges." Renewable Energy L. \& Pol'y Rev.

Salvatore, J. (2013). "World energy perspective: cost of energy technologies". World Energy Council.

Smil, V. (2016) "Examining energy transitions: A dozen insights based on performance." Energy Research \& Social Science22 : 194-197.

Smith, P, et al. (2007) "Greenhouse gas mitigation in agriculture." Philosophical transactions of the royal Society B: Biological Sciences 363.1492 : 789-813.

Steinbacher, K., \& Röhrkasten, S. (2019). “An outlook on Germany's international energy transition policy in the years to come: Solid foundations and new challenges.” Energy Research \& Social Science, 49, 204-208.

Tahvonen, O., \& Salo, S. (2001). "Economic growth and transitions between renewable and nonrenewable energy resources." European Economic Review, 45(8), 13791398. 
Taylor, T. G., \& Tainter, J. A. (2016). "The nexus of population, energy, innovation, and complexity." American Journal of Economics and Sociology, 75(4), 1005-1043.

Trutnevyte, E. (2016). "Does cost optimization approximate the real-world energy transition?" Energy, 106:182-193

Vasser, C. P. (2009) “The Kyoto Protocol: Economic Assessments, Implementation”. Nova Science Publishers, Incorporated.

Vidalenc, E., Meunier, L., Topper, B. (2013) “ADEME ENERGY TRANSITION SCENARIOS 2030-2050” ADEME, French Environment and Energy Management Agency.

Warringa, G., Schep, E., Afman, M., Bruyn, S.d. (2016). " Cost Effective Share Bioenergy 2030: How do Other Options Compare to Bioenergy".CE Delft, pages $39-42$.

Welsch, M. (2017) “Europe’s Energy Transition: Insights for Policy Making.” Academic Press.

World Nuclear Association. (2011) "Comparison of Lifecycle Greenhouse Gas Emissions of Various Electricity Generation Sources."

Горюнова, Н. Н., \& Олударе, О. А. (2017). “Возобновляемые источники энергии как основа реализации Парижского соглашения по снижению выбросов парниковых газов в России.” Общество: политика, экономика, право, (2). 